B O N N E V I L L E P O W E R A D M I N I S T R A T I O Washington Phase II Fish Diversion Screen Evaluations in the Yakima and Touchet River Basins

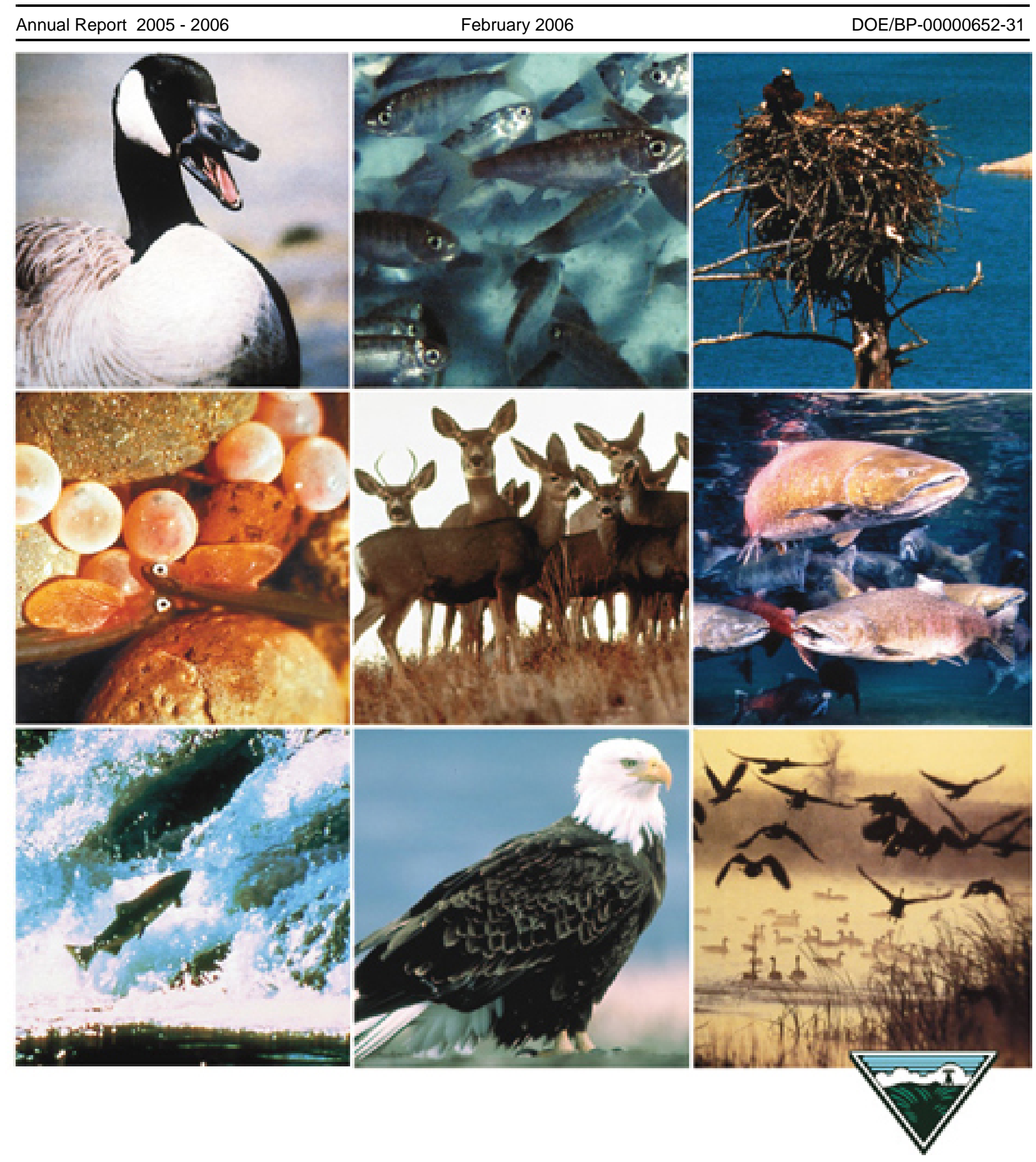


This Document should be cited as follows:

Chamness, Mickie, C. Abernethy, Cherylyn Tunnicliffe, "Washington Phase II Fish Diversion

Screen Evaluations in the Yakima and Touchet River Basins ", 2005-2006 Annual Report, Project No. 198506200, 81 electronic pages, (BPA Report DOE/BP-00000652-31)

\author{
Bonneville Power Administration \\ P.O. Box 3621 \\ Portland, OR 97208
}

This report was funded by the Bonneville Power Administration (BPA), U.S. Department of Energy, as part of BPA's program to protect, mitigate, and enhance fish and wildlife affected by the development and operation of hydroelectric facilities on the Columbia River and its tributaries. The views in this report are the author's and do not necessarily represent the views of BPA. 


\title{
Washington Phase II Fish Diversion Screen Evaluations in the Yakima and Touchet River Basins
}

\author{
Annual Report \\ April 2005 - April 2006 \\ Prepared by: \\ Mickie A. Chamness, C. Scott Abernethy, and Cherylyn Tunnicliffe \\ Pacific Northwest National Laboratory \\ P.O. Box 999 \\ Richland, Washington 99352 \\ Prepared for: \\ U.S. Department of Energy \\ Bonneville Power Administration \\ Division of Fish and Wildlife \\ P.O. Box 3621 \\ Portland, Oregon 97208-3621 \\ Project number: 1985-062-00 \\ Contract number: 00000652-0028
}

January 2006 


\section{Summary}

In 2005, Pacific Northwest National Laboratory (PNNL) researchers evaluated 25 Phase II fish screen sites in the Yakima and Touchet river basins. Pacific Northwest National Laboratory performs these evaluations for Bonneville Power Administration (BPA) to determine whether the fish screening devices meet National Marine Fisheries Service (NMFS) criteria to promote safe and timely fish passage. Evaluations consist of measuring velocities in front of the screens, using an underwater camera to look at the condition and environment in front of the screens, and noting the general condition and operation of the sites.

Results of the evaluations in 2005 include the following:

- Most approach velocities met the NMFS criterion of less than or equal to $0.4 \mathrm{fps}$. Less than $13 \%$ of all approach measurements exceeded the criterion, and these occurred at 10 of the sites. Flat-plate screens had more problems than drum screens with high approach velocities.

- Bypass velocities generally were greater than sweep velocities, but sweep velocities often did not increase toward the bypass. The latter condition could slow migration of fish through the facility.

- Screen and seal materials generally were in good condition.

- Automated cleaning brushes generally functioned properly; chains and other moving parts were typically well-greased and operative.

- Washington Department of Fish and Wildlife (WDFW) and U.S. Bureau of Reclamation (USBR) generally operate and maintain fish screen facilities in a way that provides safe passage for juvenile fish.

- In some instances, irrigators responsible for specific maintenance at their sites (e.g., debris removal) are not performing their tasks in a way that provides optimum operation of the fish screen facility. New ways need to be found to encourage them to maintain their facilities properly.

- We recommend placing datasheets providing up-to-date operating criteria and design flows in each sites logbox. The datasheet should include bypass design flows and a table showing depths of water over the weir and corresponding bypass flow. This information is available at some of the sites but may be outdated. These data are used to determine if the site is running within design criteria.

- Modifying use of debris control plates at Gleed helped minimize the extreme fluctuations in flow, but approach velocities are still too high. Other ways to reduce the approach velocities need to be tried, possibly including redesign of the site.

- Alternatives to a screen site at Taylor should be considered. A lot of effort was spent trying to increase water to the site, but it still was unable to operate within NMFS criteria for most of the year and may be a hazard to juvenile salmonids.

We conclude that the conditions at most of the Phase II fish screen facilities we evaluated in 2005 would be expected to provide safe passage for juvenile fish. For those sites where conditions are not always optimum for safe fish passage, PNNL researchers will try to coordinate with the WDFW and USBR in 2006 to find solutions to the problems. Some of those problems are consistently high approach velocities at specific sites, including Congdon, Naches-Selah, Union Gap, and Yakima-Tieton. We would 
like to be able to monitor changes in velocities as soon as operations and maintenance personnel adjust the louvers or porosity boards at these sites. This will give them immediate feedback on the results of their modifications and allow additional adjustments as necessary until the conditions meet NMFS criteria.

Pacific Northwest National Laboratory has performed evaluations at many of these sites over the past 8 years, providing information WDFW and USBR personnel can use to perform their operations and maintenance more effectively. Consequently, overall effectiveness of the screens facilities has improved over time. 


\section{Acknowledgments}

The authors thank the following people for their help and cooperation. Jonathan McCloud, Bonneville Power Administration, directed the project. Ray Gilmour and Pat Schille of the Washington Department of Fish and Wildlife and Tom Leonard of the U.S. Bureau of Reclamation provided valuable information on the operation and maintenance of individual sites. Brian Miller assisted with the field work, while Craig Allwardt provided the much-needed macro to generate the plots provided in this report. 


\section{Abbreviations and Acronyms}

ADV

BPA

cfs

fps

NMFS

NOAA

NPCC

NPPC

O\&M

PNNL

RMS

USBR

WDFW

WIP

acoustic Doppler velocimeter

Bonneville Power Administration

cubic feet per second

feet per second

National Marine Fisheries Service

National Oceanic and Atmospheric Administration

Northwest Power and Conservation Council

Northwest Power Planning Council

operations and maintenance

Pacific Northwest National Laboratory

root mean square

U.S. Bureau of Reclamation

Washington Department of Fish and Wildlife

Wapato Irrigation Project 


\section{Contents}

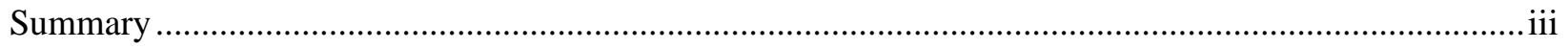

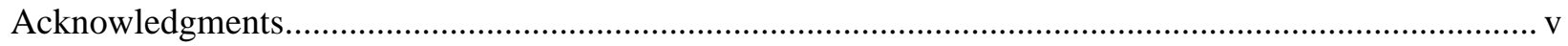

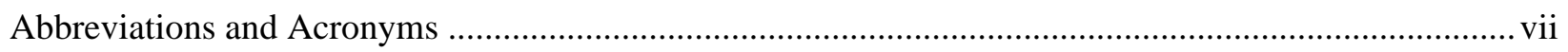

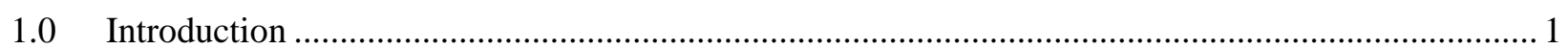

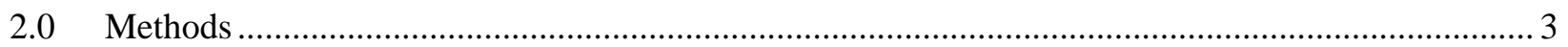

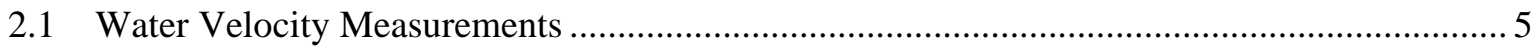

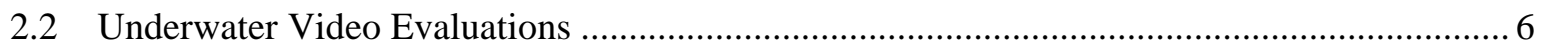

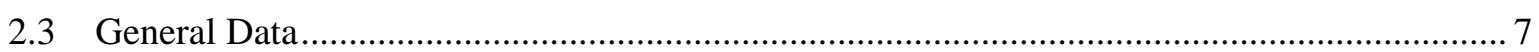

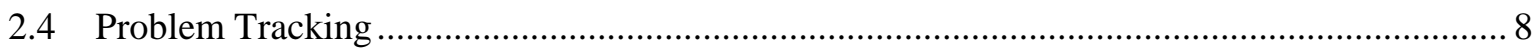

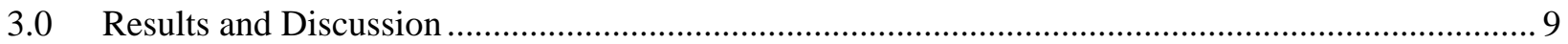

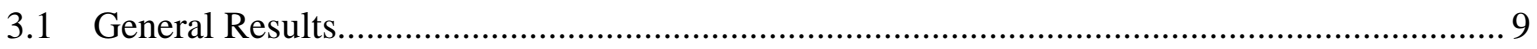

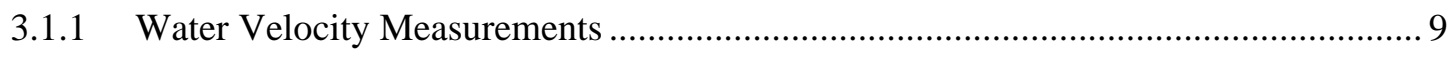

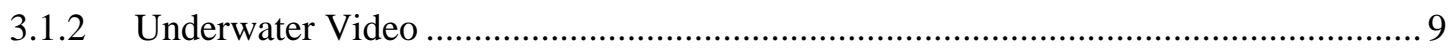

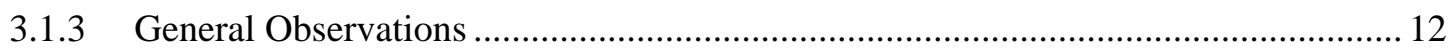

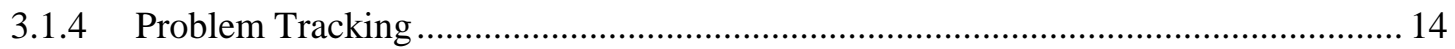

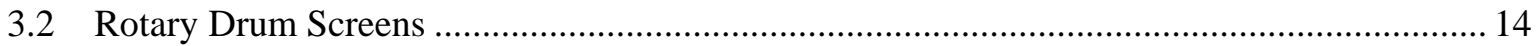

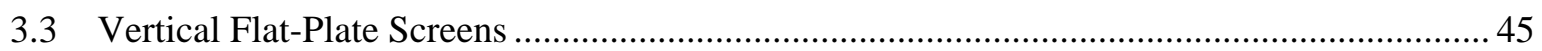

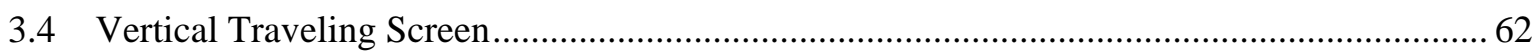

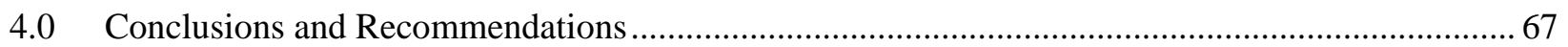

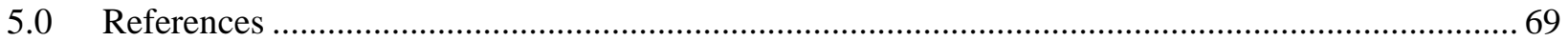




\section{Figures}

1. Yakima River Basin Phase II fish screen facilities ........................................................................ 3

2. Huntsville Mill fish screen location in the Touchet River basin...................................................... 4

3. Acoustic Doppler velocimeter probe equipment and the Marsh-McBirney $511^{\circledR}$ velocity meter ......... 5

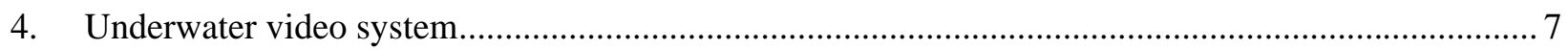

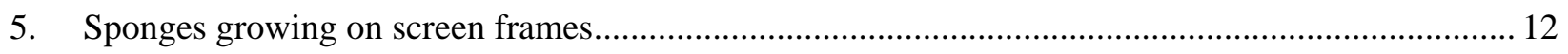

6. Water velocities and sediment accumulation, Bachelor-Hatton, May 2005 ..................................... 15

7. Bachelor-Hatton water velocities and sediment accumulation, June 2005 ..................................... 16

8. Clark water velocities and sediment accumulation, May 2005 .................................................... 17

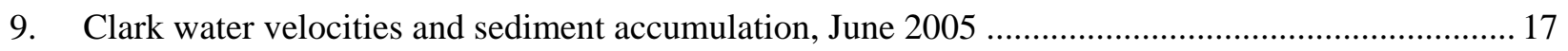

10. Clark water velocities and sediment accumulation, September 2005........................................... 18

11. Congdon water velocities and sediment accumulation, May 2005.............................................. 19

12. Congdon water velocities and sediment accumulation, June 2005............................................... 19

13. Congdon water velocities and sediment accumulation, September 2005 ........................................ 20

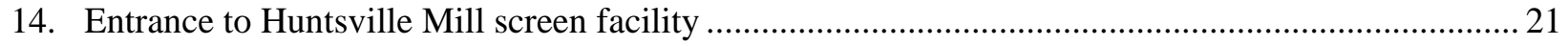

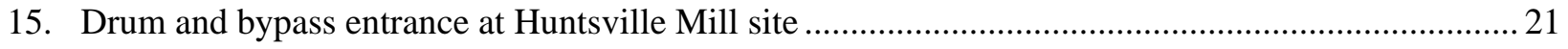

16. Huntsville Mill water velocities and sediment accumulation, May 2005........................................ 22

17. Huntsville Mill water velocities and sediment accumulation, June 2005 ....................................... 22

18. Huntsville Mill water velocities and sediment accumulation, July 2005......................................... 23

19. Huntsville Mill water velocities and sediment accumulation, September 2005 …............................ 23

20. John Cox water velocities and sediment accumulation, May 2005 ................................................. 24

21. John Cox trash rack, laden with debris .......................................................................................... 25

22. Kelley-Lowry water velocities and sediment accumulation, May 2005 .......................................... 26

23. Kelley-Lowry water velocities and sediment accumulation, June 2005....................................... 26

24. Kelley-Lowry water velocities and sediment accumulation, September 2005 ................................. 27

25. Lindsey water velocities and sediment accumulation, May 2005 ................................................... 28

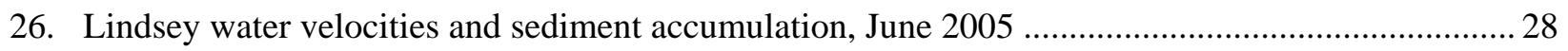

27. Lindsey water velocities and sediment accumulation, September 2005......................................... 29

28. Naches-Cowiche water velocities and sediment accumulation, May 2005 ..................................... 30

29. Naches-Cowiche water velocities and sediment accumulation, June 2005 .................................... 30

30. Naches-Cowiche water velocities and sediment accumulation, September 2005 ............................ 31

31. New Cascade water velocities and sediment accumulation, May 2005............................................ 32

32. New Cascade water velocities and sediment accumulation, June 2005.......................................... 32

33. New Cascade water velocities and sediment accumulation, September 2005 ................................... 33

34. Powell-LaFortune water velocities and sediment accumulation, May 2005 ................................... 34

35. Powell-LaFortune water velocities and sediment accumulation, June 2005 .................................. 34

36. Powell-LaFortune water velocities and sediment accumulation, September 2005............................ 35

37. Upper trash rack at Powell-LaFortune partly blocked with debris ................................................... 35 
38. Snipes-Allen water velocities and sediment accumulation, May 2005............................................ 36

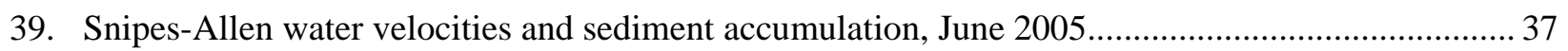

40. Snipes-Allen water velocities and sediment accumulation, September 2005 ................................... 37

41. Taylor outfall channel and the river beyond it in June .................................................................. 38

42. Taylor water velocities and sediment accumulation, June 2005 ..................................................... 39

43. Taylor water velocities and sediment accumulation, September 2005 ............................................. 39

44. Toppenish Pump water velocities and sediment accumulation, May 2005 ..................................... 40

45. Toppenish Pump water velocities and sediment accumulation, June 2005 .................................... 41

46. Toppenish Pump water velocities and sediment accumulation, September 2005.............................. 41

47. Upper WIP water velocities and sediment accumulation, May 2005 ............................................. 42

48. Upper WIP water velocities and sediment accumulation, June 2005 .............................................. 43

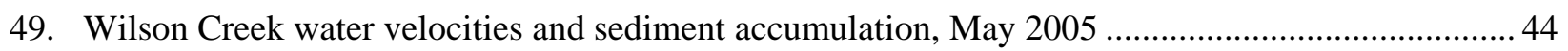

50. Wilson Creek water velocities and sediment accumulation, June 2005 ........................................ 44

51. Wilson Creek water velocities and sediment accumulation, September 2005................................. 45

52. Ellensburg Mill water velocities and sediment accumulation, May 2005 ........................................ 46

53. Ellensburg Mill water velocities and sediment accumulation, June 2005 ...................................... 46

54. Ellensburg Mill water velocities and sediment accumulation, September 2005 .............................. 47

55. Fruitvale water velocities and sediment accumulation, May 2005 ................................................. 48

56. Fruitvale water velocities and sediment accumulation, June 2005 ................................................ 48

57. Fruitvale water velocities and sediment accumulation, September 2005 ...................................... 49

58. Water being piped in from the Old Union screen site into the Fruitvale forebay.............................. 49

59. Naches-Selah water velocities and sediment accumulation, May 2005 ......................................... 50

60. Naches-Selah water velocities and sediment accumulation, June 2005 ............................................ 51

61. Naches-Selah water velocities and sediment accumulation, September 2005................................. 51

62. Packwood water velocities and sediment accumulation, May 2005.............................................. 52

63. Packwood water velocities and sediment accumulation, June 2005 .................................................. 53

64. Packwood water velocities and sediment accumulation, September 2005 ..................................... 53

65. Selah-Moxee water velocities and sediment accumulation, May 2005 ........................................... 54

66. Selah-Moxee water velocities and sediment accumulation, June 2005 ............................................. 55

67. Selah-Moxee water velocities and sediment accumulation, September 2005 .................................. 55

68. Union Gap water velocities and sediment accumulation, May 2005 ............................................... 56

69. Union Gap water velocities and sediment accumulation, June 2005 ........................................... 57

70. Union Gap water velocities and sediment accumulation, September 2005 .....................................5 57

71. Yakima-Tieton water velocities and sediment accumulation, May 2005 ....................................... 58

72. Yakima-Tieton water velocities and sediment accumulation, June 2005 ....................................... 59

73. Yakima-Tieton water velocities and sediment accumulation, September 2005 ............................... 59

74. Younger water velocities and sediment accumulation, May 2005 ............................................... 60

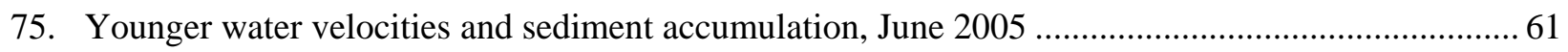

76. Younger water velocities and sediment accumulation, July 2005 ................................................. 61 


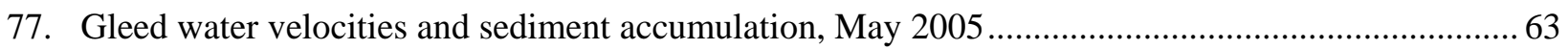

78. Gleed water velocities and sediment accumulation, June 2005 _..................................................... 63

79. Gleed water velocities and sediment accumulation, July 2005 ..................................................... 64

80. Gleed water velocities and sediment accumulation, September 2005 ............................................64

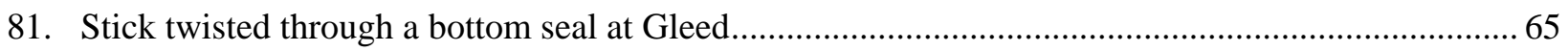

\section{Tables}

1. Agency responsible for the operation and maintenance of each fish screen facility........................... 8

2. Percentage of approach velocity measurements exceeding NMFS criterion, by year ....................... 10

3. Summary of problems at fish screens evaluated from 1999 through 2005 .................................... 11 


\subsection{Introduction}

Irrigation has played an important role in the development of the middle Columbia River Basin. Water has been diverted from western rivers since the mid-1850s to irrigate crops. During the 1920s, some of these diversions were equipped with fish-protection devices, but it was not until the Mitchell Act of 1938 provided funding to protect fish that screening irrigation diversions and evaluating their effectiveness truly got under way (Bryant and Parkhurst 1950; McMichael et al. 2004).

In more recent history, the Bonneville Power Administration (BPA), under guidance from the Northwest Power and Conservation Council (NPCC, formerly the Northwest Power Planning Council) expanded screening efforts to protect and enhance fish populations. The NPCC Columbia River Fish and Wildlife Program lists effective screening of irrigation diversions as an essential element in its plan to restore declining steelhead and salmon runs (NPPC 1984, 1987, 1994, 2000).

Research on the effectiveness of fish-screening devices initiated changes in design and operating procedures of screening facilities over the years. For example, maximum allowable screen size openings decreased as protecting fish at their earliest developmental stages became a concern. These and other new requirements for fish protection are developed by the National Marine Fisheries Service (NMFS 1995) ${ }^{(a)}$ and adopted by individual state agencies. In addition, the BPA has established a monitoring and evaluation program to ensure that new and updated screening facilities meet current fish protection standards.

As a part of the BPA monitoring and evaluation program, Pacific Northwest National Laboratory (PNNL) researchers have conducted fish screen evaluations in the Yakima Basin since 1985. Initially, PNNL monitored Phase I screening facilities to determine whether fish that entered irrigation canals were guided back to the river safely (Neitzel et al. 1985, 1987, 1988, 1990a, 1990b). Additional studies examined water velocities in front of the screens to determine whether NMFS criteria were being met (Abernethy et al. 1989, 1990). Two studies conducted at the PNNL Aquatics Laboratory in Richland, Washington, used modular drum screens constructed by the Washington Department of Fish and Wildlife (WDFW) to determine fish survival through submerged orifices and the relative effectiveness of two screen configurations at bypassing fish (Abernethy et al. 1996; Neitzel et al. 1997). The methods currently used for evaluating screening facilities were developed while these earlier studies were conducted, then refined over the next several years (Blanton et al. 1998, 1999, 2000; McMichael et al. 2004). Results of previous evaluations can be found in the documents by Blanton as well as in Chamness et al. (2001), Carter et al. (2002, 2003), and Vucelick et al. (2004, 2005).

As the Phase II screening program continued, PNNL evaluated more sites for the BPA. In 2000, 21 Phase II sites were evaluated. The Powell-LaFortune and Wilson Creek sites were added in 2001, and Packwood and Selah-Moxee were added in 2004, for a total of 25 sites. For 2005, the new Huntsville Mill site on the Touchet River was added while the Bull Ditch site, which was removed in September 2004, was taken off our list.

(a) Although the NMFS now is known as the National Oceanic and Atmospheric Administration (NOAA) Fisheries, criteria were issued under the NMFS and are referred to as such in this report. 
The evaluations of these sites addressed two main questions:

1. Are screens designed, operated, and maintained to meet NMFS criteria over a wide range of conditions?

2. Are screen sites effective at protecting fish from injury and from unnecessary migration delay?

This report documents the fish screen evaluations conducted during 2005. Methods used to collect data are described in Section 2. In Section 3, results common to many of the sites are provided. This is followed by the results of evaluations at each site, with comparisons to previous years and to NMFS criteria, as well as each site's overall conditions and general observations. 


\subsection{Methods}

Twenty-four operating screen sites in the Yakima (Figure 1) and one site in the Touchet (Figure 2) river basins were evaluated three times between May 9 and September 30, 2005. Pacific Northwest National Laboratory researchers collected three types of data at each site, based on criteria set by the NMFS for Phase II fish screen facilities. The types of data collected include water velocity measurements, underwater video, and general operational data (e.g., screen submergence, bypass conditions, fish presence).

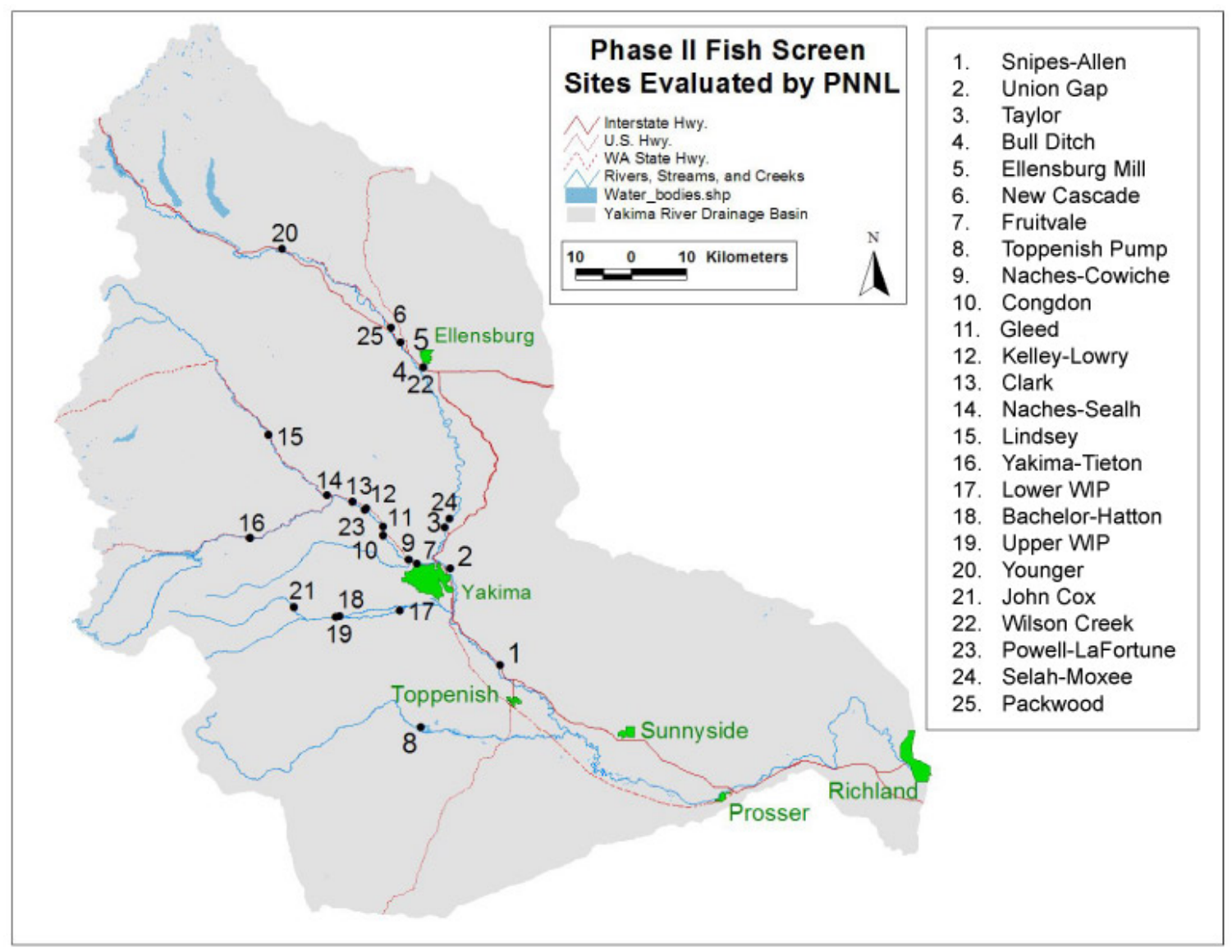

Figure 1. Yakima River Basin Phase II fish screen facilities 


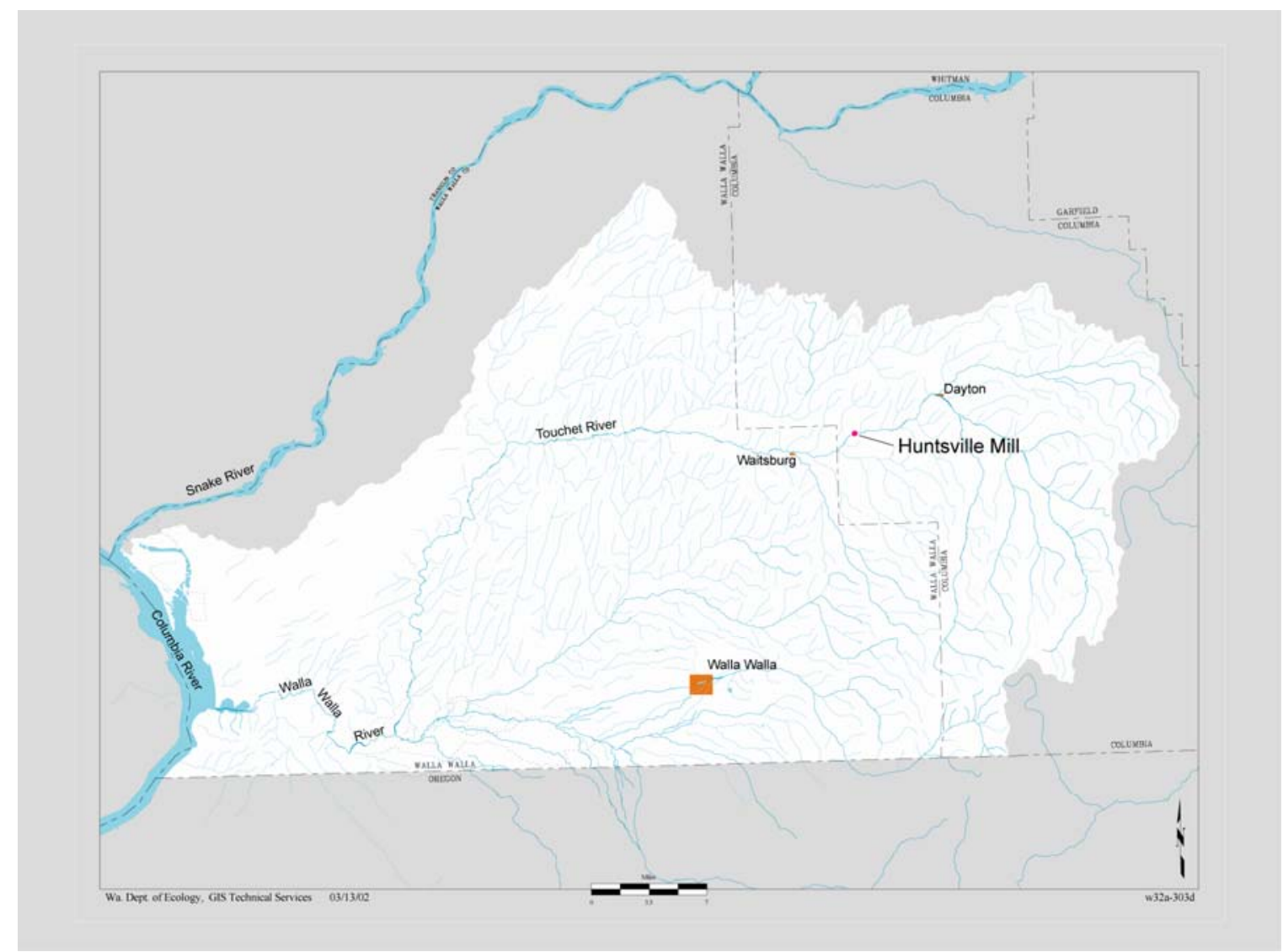

Figure 2. Huntsville Mill fish screen location in the Touchet River basin

The NMFS criteria for juvenile fish screen sites define velocity and general operational conditions that would be expected to promote safe fish passage through Phase II screen sites (NMFS 1995). These include the following:

- a uniform flow distribution over the screen surface to minimize approach velocity

- approach velocities less than or equal to $0.4 \mathrm{fps}$

- sweep velocities that are greater than approach velocities

- a bypass flow greater than or equal to the maximum flow velocity vector resultant upstream of the screens (generally the sweep velocity)

- a gradual and efficient acceleration of flow from the upstream end of the site into the bypass entrance to minimize delay of emigrating salmonids

- screen submergence between 65 and 85\% for drum screen sites.

In addition, the NMFS criteria call for silt and debris accumulation to be kept to a minimum. For our evaluations, the accumulation of silt and/or debris is considered excessive if the intersection of the seal and the screen is buried or if the debris impacts the ability of the site to pass fish safely. Screen operators should try to achieve these criteria at all sites throughout the year. In this report, PNNL compares the field measurements of water velocity, underwater video, and general data collection results for each screen site to the NMFS criteria and to previous screening facility performance evaluations. 


\subsection{Water Velocity Measurements}

With the exception of one site, water velocities in front of the screens and in the bypass are measured using a SonTek acoustic Doppler velocimeter (ADV). The ADV emits sound at $10 \mathrm{kHz}$. The frequency of the returning sound waves increases or decreases depending on whether the water is flowing toward or away from the ADV receiver. The difference between the emitted frequency and the received frequency is used to calculate the velocity of the water. The probe uses three receivers extending out at an angle from the transmitter to calculate the three-dimensional water velocity at a point $10 \mathrm{~cm}$ below the probe.

As shown in (Figure 3), the ADV probe is mounted securely to a horizontal metal arm extending approximately $12 \mathrm{in}$. from a vertical pole. The probe sits upstream or to the side of the vertical pole to minimize interference when velocity readings are taken. The length of the horizontal arm and its position on the vertical pole are adjustable. Velocities typically are recorded at each sampling point along the screen for $30 \mathrm{~s}$ at a rate of $2 \mathrm{~Hz}$ (this provides 60 data points in 30 seconds at each sampling point) and stored in a computer file. Turbulence, as measured by the root mean square (RMS) of velocity fluctuations about the mean measured velocity, is calculated by the software and stored with the data. Velocity and associated turbulence data are plotted and presented by site in Section 3 of this report.

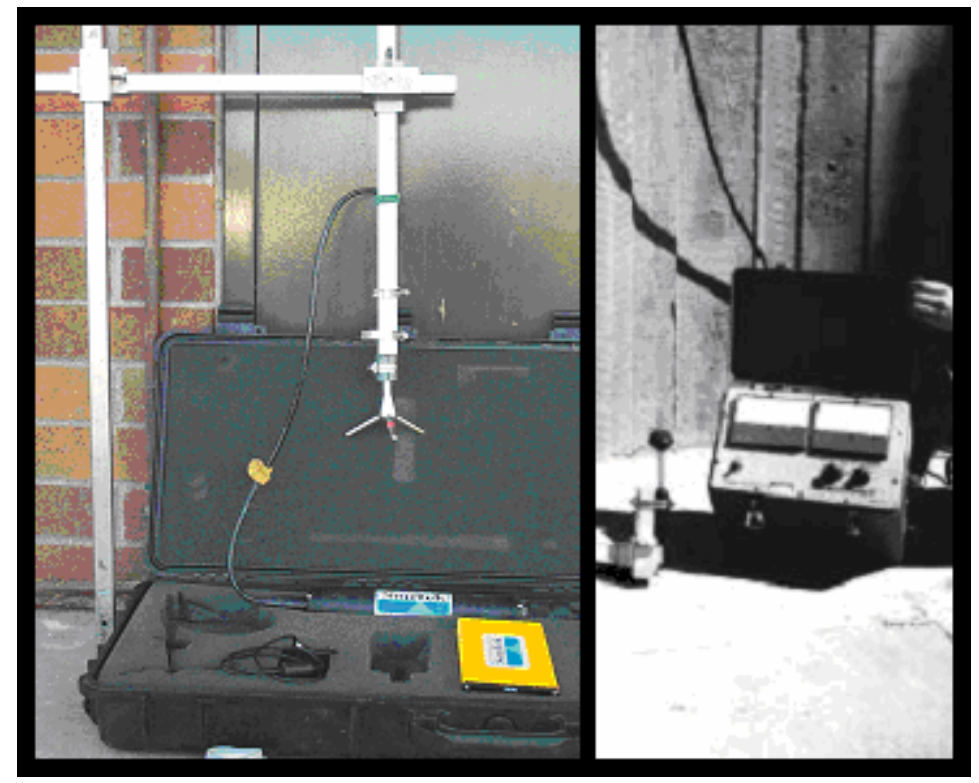

Figure 3. Acoustic Doppler velocimeter probe equipment (left) and the Marsh-McBirney $511^{\circledR}$ velocity meter (right)

When the water is too shallow or there is too much vegetation or debris in the forebay for the ADV to function properly, water velocities are measured using a Marsh-McBirney Model $511^{\circledR}$ electromagnetic water current meter. The meter uses a bidirectional probe that allows measurement of velocities in two directions (approach and sweep) simultaneously. Output is read visually from a panel gage and recorded. Figure 3 shows the Marsh-McBirney probe on the right. Turbulence cannot be recorded accurately using this technique and is not shown on the resulting data plots in Section 3.

All measurements using either probe are taken with the axes of the probe oriented to measure water flowing parallel (sweep) and perpendicular (approach) to the screen face. Measurements of water 
velocity are taken at two to five evenly spaced points along the front of each screen and in the entrance to the fish bypass. The vertical pole is placed close to but not touching the front surface of the screen. The probe is positioned as close to the screen surface as possible, usually about 3 in.; however, it is impossible to get that close at some sites. Probe height depends on depth of water in the forebay. If the distance between water surface and the sill next to the screen is less than $48 \mathrm{in}$., one measurement is made at 0.6 depth from the surface. If the distance is greater than or equal to 48 in., measurements are taken at 0.2 and 0.8 depths from the surface. Bypass velocities are measured with the probe at the same positions as the other measurements. The pole is set inside the bypass entrance with the probe pointing toward the forebay.

When the screen site is operating, flow measurements are taken in front of every screen during site visits. Automatic cleaning brushes are usually turned off during velocity measurements, while drum screens are allowed to operate normally during measurements. Average sweep and approach velocities are calculated for each visit to each site.

Graphical representations of velocity data include lines for mean sweep and approach velocity measurements, a reference line at $0.4 \mathrm{fps}$ (which represents the NMFS criterion for approach velocity), and a shaded area representing sediment accumulation in front of the screens as estimated with the support pole for the velocity probe, where the pole came to rest on the sill and in the bypass. The error bars on the velocity graphs represent the RMS, or turbulence, about the mean velocity.

\subsection{Underwater Video Evaluations}

Underwater video is used to inspect the conditions of the seals, to look for gaps between the seals and the screens that could allow small fish to pass through the site into the canal or be entrained or otherwise harmed, to record fish presence at the sites, and to monitor and document sediment and debris accumulation in front of the screens. The latter is important because debris can severely decrease seal life, cause drag on screen motors, and provide cover for fish predator species.

The video system consists of a digital deep-sea camera (DeepSea Power and Light, Inc., Model MULTI-SEACAM 1050) connected to a digital video recorder (Sony Video Walkman, Model GV-D800), which in turn is connected to a pair of video glasses (Olympus Eye-Trek, Model FMD-200, Figure 4). The advantage of this system is that it allows the person operating the camera to see underwater in real time, thus providing better video quality and a greater potential for problem identification. In addition, the end product of this system is digital video, which greatly improves the quality of still pictures captured from the video.

The camera is mounted securely on a vertical pole and adjusted as needed at each site. The camera is usually angled slightly downward to look for potential gaps between the screen and the bottom seal. The camera is usually moved from upstream to downstream, following the side and bottom seal/screen interfaces. The bypass also is inspected, looking both upstream and downstream for signs of excessive debris, the position of the flush gate (if present), and fish presence.

Written observations are made in the field when something of interest is seen with the camera (i.e., debris, gaps, and fish). All videos are later reviewed in detail, and images of interest are digitally captured using Optimas ${ }^{\mathrm{TM}}$ software. 


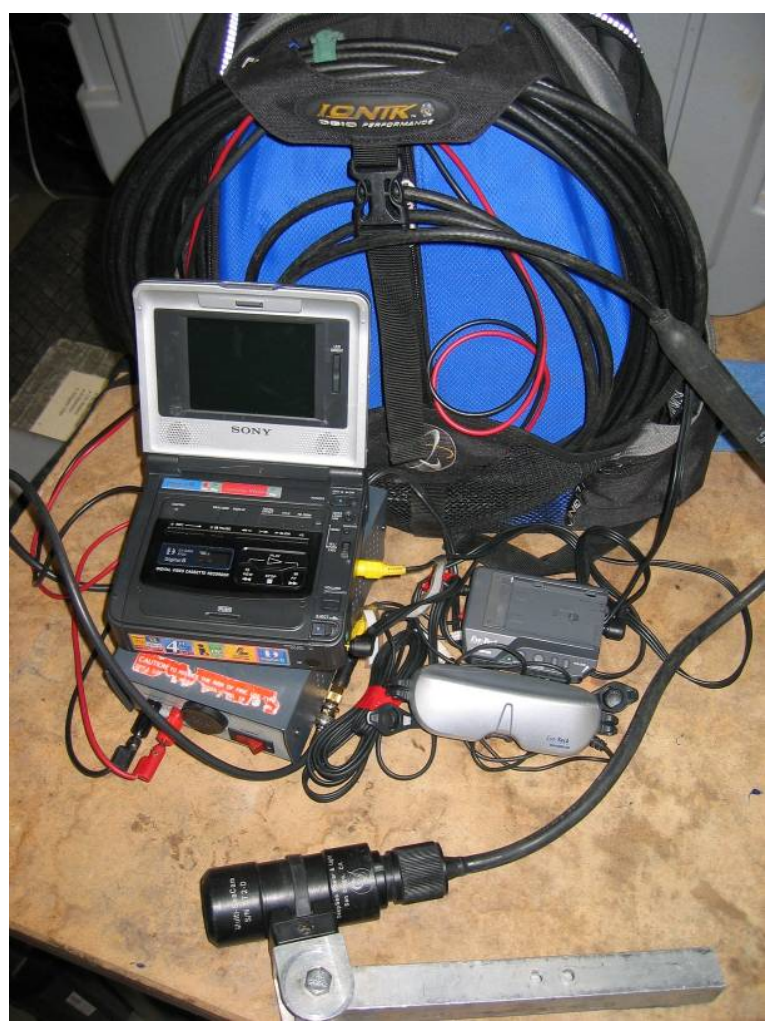

Figure 4. Underwater video system

\subsection{General Data}

In addition to the velocity data and videotapes, information is recorded on the general condition and environment at the sites. This information includes

- general site descriptions and photographs

- screen and seal conditions

- screen submergence levels

- cleaning system operation and occurrence of head loss across the screen face

- bypass conditions

- bypass outfall conditions

- caulking between drum screen frame and cement structure

- fish presence

- observations of debris in the forebay, bypass, or outfall

- presence or absence and condition of operator control aids such as water gages and drum submergence marks on screen frames.

- any interesting notes recorded in the onsite log book. 


\subsection{Problem Tracking}

A problem identification and tracking program was implemented in 2002 in response to comments from the Northwest Power Planning Council Independent Scientific Review Panel. The problem tracking program provides increased accountability of operations and maintenance in situations where problems could be fixed within the season. When a problem such as a blocked bypass or excessive submergence is identified at a screen site, field personnel immediately notify the responsible operations and maintenance (O\&M) agency (Table 1), which is asked to notify PNNL when the problem is rectified or when a repair schedule is implemented. When PNNL receives notice that a problem is fixed, a team is sent to the site to reevaluate whether operating conditions met NMFS criteria for safe fish passage.

Table 1. Agency responsible for the operation and maintenance of each fish screen facility. USBR = U.S. Bureau of Reclamation; WDFW = Washington Department of Fish and Wildlife.

\begin{tabular}{||l|l||}
\hline \multicolumn{1}{|c|}{$\begin{array}{c}\text { Fish screen } \\
\text { facility }\end{array}$} & \multicolumn{1}{|c||}{$\begin{array}{c}\text { Responsible } \\
\text { agency }\end{array}$} \\
\hline \hline Bachelor-Hatton & USBR \\
\hline Clark & WDFW \\
\hline Congdon & WDFW \\
\hline Ellensburg Mill & WDFW \\
\hline Fruitvale & WDFW \\
\hline Gleed & WDFW \\
\hline Huntsville Mill & WDFW \\
\hline John Cox & USBR \\
\hline Kelly-Lowry & WDFW \\
\hline Lindsey & WDFW \\
\hline Lower WIP & USBR \\
\hline Naches Cowiche & WDFW \\
\hline Naches Selah & WDFW \\
\hline
\end{tabular}

\begin{tabular}{||l|l||}
\hline \multicolumn{1}{|c|}{$\begin{array}{c}\text { Fish screen } \\
\text { facility }\end{array}$} & \multicolumn{1}{|c||}{$\begin{array}{c}\text { Responsible } \\
\text { agency }\end{array}$} \\
\hline \hline New Cascade & WDFW \\
\hline Packwood & WDFW \\
\hline Powell-LaFortune & WDFW \\
\hline Selah-Moxee & WDFW \\
\hline Snipes-Allen & WDFW \\
\hline Taylor & WDFW \\
\hline Toppenish Pump & USBR \\
\hline Union Gap & WDFW \\
\hline Upper WIP & USBR \\
\hline Wilson Creek & WDFW \\
\hline Yakima-Tieton & USBR \\
\hline Younger & WDFW \\
\hline & \\
\hline
\end{tabular}




\subsection{Results and Discussion}

The overall results we obtained in 2005 are presented first, followed by more detailed descriptions of findings at each site. The site-by-site findings are organized by screen type into three groups: rotary drum screens, flat-plate screens, and vertical traveling screens.

\subsection{General Results}

\subsubsection{Water Velocity Measurements}

2005 was a low-water year, and this is reflected in the velocities measured at many of the sites. Water velocities at each site were often highly variable, both spatially and temporally. In most cases, average sweep and approach values were lower near the bottom of the forebay, but specific patterns of flow varied across each screen site spatially and through the irrigation season. If more than $10 \%$ of approach velocities were greater than $0.4 \mathrm{fps}$ during an inspection, the site was considered to be in violation of the NMFS criterion for approach velocities. At 10 sites, $10 \%$ of the approach velocities exceeded $0.4 \mathrm{fps}$, the NMFS criterion for protection of juvenile salmonids, at least once in 2005 (Table 2). In 2004, 7 sites had similarly high approach velocities. Many of the sites with high approaches in 2005 were flat-plate screens. The reason for this increased incidence is not known.

Thirteen sites had bypass velocities slower than average sweep velocities at least once during 2005, the same number as in 2004 (Table 3). Sites with slow bypass velocities relative to sweep velocities could result in migration delay. Five drum screen sites had submergence outside of the NMFS criterion, compared to three in 2004.

\subsubsection{Underwater Video}

Underwater video surveys found four sites had excessive silt or debris at least once during 2005, three less than in 2004 (Table 3). Most screens were properly sealed to prevent fish entrainment and injury. In general, visible screen seals were in good condition, although small bulges had developed in side seals at a few sites. In a few cases, bottom frame seals were buried in debris or aquatic plants and could not be viewed with the underwater video camera. All drum screen seals that were classified as in "good condition" were tight against the screen and not cracked, warped, or punctured in any way. The USBR did some maintenance at dry sites in August, so that by the end of the season almost all of the drum screen sites had expanding foam caulk placed between the concrete sides of the facility and the metal "cheeks" of the drum frame. Caulk blocks off an area that could entrain small fish, although normally they cannot move into the aftbay (canal) through this route. Flat-plate screen seals were generally in good condition with the exception of some panels showing loose or missing caulking (e.g., Yakima-Tieton, Packwood). Those flat-plate sites with loose or missing caulking had the same problem in previous years and have never been repaired. These sites were not identified under the problem-tracking protocol unless there was a danger of entrainment or impingement through gaps in the caulking. 
Table 2. Percentage of approach velocity measurements exceeding NMFS criterion, by year. Shaded values are those with $10 \%$ or more exceeding the criterion

\begin{tabular}{|c|c|c|c|c|c|c|c|c|c|}
\hline \multirow{2}{*}{$\begin{array}{c}\text { Screen } \\
\text { Type }\end{array}$} & \multirow[b]{2}{*}{ Screen Site } & \multicolumn{8}{|c|}{ Percentage of Approach Velocity Measurements $\geq 0.4 \mathrm{ft} / \mathrm{s}$} \\
\hline & & 1998 & 1999 & 2000 & 2001(d) & 2002 & 2003 & 2004 & 2005 \\
\hline \multirow{16}{*}{$\begin{array}{l}\text { Drum } \\
\text { Screens }\end{array}$} & Bachelor-Hatton & 34.1 & 0.0 & 15.4 & (e) & 2.5 & 1.7 & 10.0 & 0.0 \\
\hline & Clark & 0.0 & (a) & 0.0 & 0.0 & 0.0 & 0.0 & 0.0 & 0.0 \\
\hline & Congdon & 4.4 & 8.3 & 7.1 & 13.3 & 11.1 & 6.7 & 22.2 & 53.3 \\
\hline & Huntsville Mill & (c) & (c) & (c) & (c) & (c) & (c) & (c) & 10.0 \\
\hline & John Cox & (c) & (c) & 39.3 & (e) & 27.5 & 34.8 & 38.9 & 20.0 \\
\hline & Kelly-Lowry & 0.0 & 0.0 & 0.0 & 20.0 & 0.0 & 0.0 & 3.7 & 0.1 \\
\hline & Lindsey & 0.0 & 0.0 & 0.0 & 0.0 & 0.0 & 0.0 & 0.0 & 0.0 \\
\hline & Lower WIP & (b) & 0.0 & 0.0 & (e) & 38.9 & 5.6 & 0.0 & (c) \\
\hline & Naches-Cowiche & 0.0 & 12.5 & 2.6 & 5.0 & 1.7 & 0.0 & 5.0 & 0.1 \\
\hline & New Cascade & (a) & 0.0 & 1.4 & (e) & 2.5 & 0.0 & 1.7 & 0.0 \\
\hline & Powell-LaFortune & (c) & (c) & (c) & 0.0 & 0.0 & 1.7 & 0.0 & 0.0 \\
\hline & Snipes-Allen & 0.0 & 0.0 & 0.0 & 0.0 & 0.0 & 0.0 & 0.0 & 0.0 \\
\hline & Taylor & 0.0 & 0.0 & 0.0 & 0.0 & 0.0 & 0.0 & 0.0 & 0.0 \\
\hline & Toppenish Pump & 60.0 & 25.4 & 9.4 & 3.3 & 31.1 & 5.8 & 9.2 & 10.7 \\
\hline & Upper WIP & 9.4 & 2.5 & 3.3 & (e) & 5.0 & 8.3 & 0.0 & 0.1 \\
\hline & Wilson Creek & (c) & (c) & (c) & 0.0 & 4.4 & 0.0 & 0.0 & 0.0 \\
\hline \multirow{8}{*}{$\begin{array}{l}\text { Vertical } \\
\text { plate } \\
\text { screens }\end{array}$} & Ellensburg Mill & 0.0 & 33.3 & 25.9 & 0.0 & 0.0 & 0.0 & 0.0 & 0.0 \\
\hline & Fruitvale & (a) & 0.0 & 17.5 & 0.0 & 5.6 & 0.0 & 0.0 & 0.0 \\
\hline & Naches-Selah & 2.8 & 27.8 & 28.7 & 8.3 & 29.6 & 20.4 & 46.3 & 23.2 \\
\hline & Packwood & (c) & (c) & (c) & (c) & (c) & (c) & 0.0 & 0.0 \\
\hline & Selah-Moxee & (c) & (c) & (c) & (c) & (c) & (c) & 5.6 & 12.5 \\
\hline & Union Gap & 5.0 & 22.9 & 12.5 & 4.2 & 2.8 & 9.7 & 43.1 & 18.1 \\
\hline & Yakima-Tieton & 5.2 & 2.1 & 1.4 & 2.1 & 14.4 & 2.8 & 18.1 & 27.8 \\
\hline & Younger & (c) & 0.0 & 8.3 & 0.0 & 33.3 & 0.0 & 5.6 & 27.8 \\
\hline $\begin{array}{l}\text { Vertical } \\
\text { travelling } \\
\text { screen }\end{array}$ & Gleed & (a) & 14.3 & 17.5 & 0.0 & 17.4 & 28.8 & 35.0 & 29.2 \\
\hline \multicolumn{10}{|c|}{$\begin{array}{l}\text { (a) No data; electrical interference prevented velocity measurements. } \\
\text { (b) No data; flooded in May and nearly dry by July } 1998 . \\
\text { (c) Not sampled. } \\
\text { (d) Based on September data only, except Snipes-Allen, Taylor, Toppenish Pump, Naches-Selah, and Union Gap. } \\
\text { (e) No data; equipment problems in May and June, and site was dry in September. }\end{array}$} \\
\hline
\end{tabular}


Table 3. Summary of problems at fish screens evaluated from 1999 through 2005

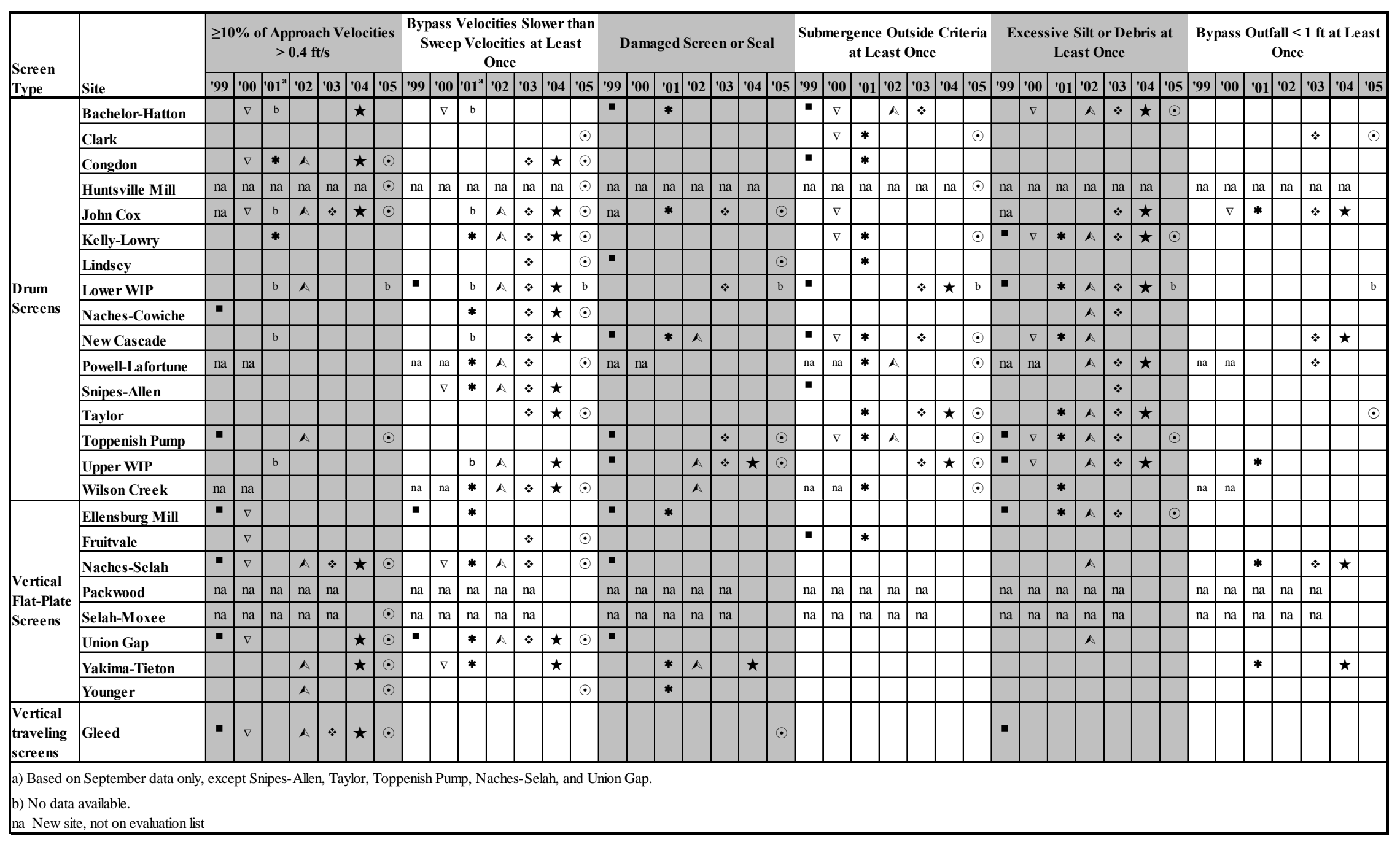


We observed freshwater sponges growing on the drum frames at Snipes-Allen and Toppenish Pump in 2004, but they have grown noticeably larger in 2005 (Figure 5).
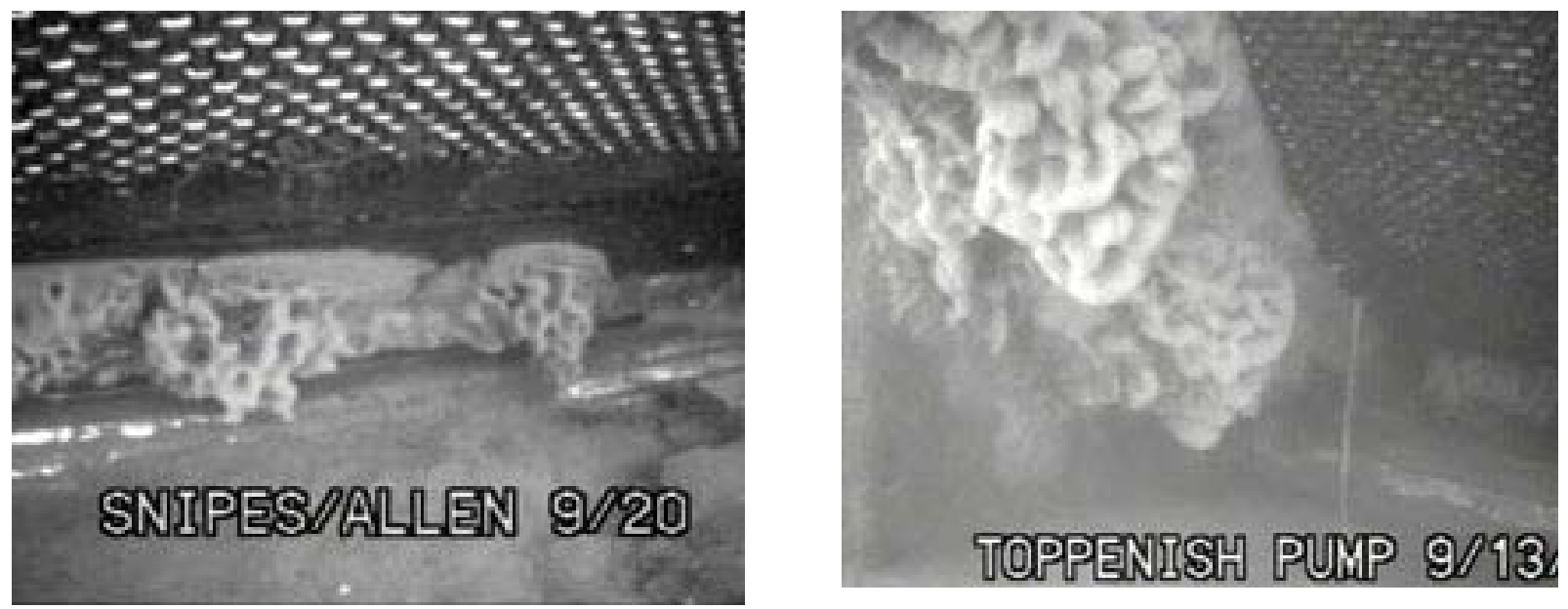

Figure 5. Sponges growing on screen frames

We do not believe the sponges pose any danger to the structure, but they will affect water flow and sediment/debris movement and probably should be removed. Some sponges contain minute silica spicules that are an irritant to skin, so care may be needed if they are removed.

\subsubsection{General Observations}

The following types of observations are made during each site visit:

- Are screens in good condition and do drums turn smoothly?

- Are seals in good condition?

- Are brushes effective and in good working order?

- Are cheeks caulked to prevent fish from becoming wedged in the gap between the drum screen frame and the cement structure (the cheek)?

- Are there gages?

- Are there sediment, vegetation, or other factors affecting the function of the site?

- Does the logbook indicate any problems since the last inspection?

In 2005, most sites were operating in a manner that would be expected to provide safe passage for juvenile salmonids. Some sites, such as Lindsey, are well-maintained, well-designed, and rarely exceed criteria, while others, such as Gleed, have a history of problems over the past several years.

Automated cleaning brushes functioned properly in most cases, and chains and other moving parts were well-greased and operated smoothly. Only $17 \%$ of the sites had problems with excessive debris in 2005 compared to 28\% in 2004 (Table 3). The buildup of sediment and debris is a concern because it can create habitat for predators and cause mechanical brushes or drums to become less effective or even cease 
functioning. The WDFW was generally proactive in removing silt and debris during the season. Both the WDFW and USBR typically visited sites every 1 to 2 weeks to perform routine maintenance.

Most drums screens turned smoothly. Phase II rotary drum screens are designed to be operated at submergence levels between 65 and 85\%. At higher submergence levels, fish may roll over the top of the screen and enter the canal. Lower submergence levels can prevent the screen from efficiently removing debris from the forebay area. In 2005, 20\% of drum screens were outside the submergence criterion at least once, the same as in 2004.

Flat-plate screen sites do not have the same rollover and debris removal issues to contend with as rotary drum screens. However, should a flat-plate screen become completely submerged, fish can freely enter the irrigation canals by swimming over the top of the screen. Therefore, beginning in 2001, flatplate screen sites were marked in Table 3 only if screens were completely submerged at any point during the irrigation season. None of the flat-plate screens was totally submerged in 2005, although the logbook indicated Fruitvale may have been close at one point.

The NMFS established a number of guidelines and criteria concerning bypass conduit design and outfall conditions (NMFS 1995). These criteria state

For diversions 25 cfs and greater, the required pipe diameter shall be greater than or equal to 24 inches and that the minimum depth of open-channel flow in the bypass conduit shall be greater than or equal to 9 inches, unless otherwise approved by the NMFS.

Pipe diameter criteria exist primarily to minimize debris clogging and sediment deposition and to facilitate cleaning. For screens with a diversion flow of less than $25 \mathrm{cfs}$, the requirements are a 10-in.diameter pipe and a minimum allowable water depth in the pipe of 1.8 in. All screens with bypasses that were evaluated (except for Clark, John Cox, Lindsey, Lower WIP, Packwood, Taylor, Wilson Creek, and Younger) are designed and built for diversion flows greater than 25 cfs. However, many sites had bypass pipes with diameters much smaller than the NMFS criterion. In 2005, bypass water levels in the bypass pipes was adequate in $85 \%$ of the site visits. Most of the site visits with lower water levels were close to the criterion 9-in. depth. More often, an area of concern is the depth of water just downstream of the outfall because it creates easy access for avian predators. Only two sites, Clark and Taylor, had less than $1 \mathrm{ft}$ of water at the outfall, and only Taylor has a chronic problem that will need to be fixed by cleaning out, deepening, and possibly extending the outfall channel to meet the main river channel.

Visual operator control aids, while not required, are extremely useful for the O\&M personnel who inspect the sites. Operator aids complement the operating criteria and help "flag” operational or procedural problems. Operator aids include marks indicating submergence level on drum screen frames; water depth or elevation gages in the forebay, aftbay, and irrigation canal and on-site reference lists on what gage readings equal the allocated water usage; and marks indicating the extent to which headgate, bypass weir, or canal headgates are open. Providing highly visible indicators of screen system operation as it relates to NMFS criteria or to proper water diversion to the canal can save time and reduce incidences of operator error that may result in fish impingement, entrainment, or stranding at a site. Another operator aid is information on design flows for the diversion and bypass, tables of bypass flow as it relates to depth of water over the weir. This type of information is often kept in the site logbox but is not always available or up-to-date. With this information, the O\&M personnel and the irrigator can easily check to see if they are operating the site to protect juvenile fish, as it was designed. 
Most sites are equipped with gages measuring elevation or water depth, although gages were not always present both in front of and behind the screens. Selah-Moxee, Packwood, and Huntsville Mill do not have gages yet. Drum screen submergence marks were present at most sites and had been repainted at many of the sites. Algae covers the marks at many sites later in the season but can be easily rubbed off. As a result of this study, PNNL recommends regular cleaning and repainting of these marks to facilitate operator adjustments and evaluation.

\subsubsection{Problem Tracking}

Three types of problems were identified this year. The first problem is high approach velocity that occurs every year at various sites. The most critical period is in the spring when juvenile salmonids are emigrating. Later in the season, most salmonids left in the river are larger and stronger swimmers. In several cases, the WDFW was able to modify the sites to lower approach values. But both the USBR and WDFW had some sites that seemed to be operating within design criteria for the site and felt they could do nothing to reduce approach velocities.

The second type of problem was problems with seals. Only Gleed and John Cox had severe enough problems that we notified the WDFW and USBR, respectively. Most of the other seal problems were related to relatively minor bulges in side seals at several sites later in the season. These were not processed through the problem-tracking protocol.

The third type of problem relates to issues with irrigators fulfilling their maintenance responsibilities. Kelley-Lowry, Powell-LaFortune, and John Cox have had problems for several years with sediment or debris accumulations that the irrigator is responsible for removing. In all three of these cases, the irrigator has been notified of the problem several times but has not responded quickly, if at all. Personnel from the WDFW and USBR have been trying to work with these groups and educate them as to the problems the debris causes. Enforcement will be a last resort.

Agency response by both the WDFW and USBR was good for specific problems with specific remedies, such as removing sticks from seals. When problems were felt to be harder to fix, such as high approach velocities at certain sites, there was often no specific response to correct the problem.

\subsection{Rotary Drum Screens}

Sixteen of the Phase II fish screen facilities in the Yakima River basin are rotary drum screens. A description of the evaluations results and plots of velocity data for each of these facilities is presented in the following paragraphs.

\section{Bachelor-Hatton}

The Bachelor-Hatton site was evaluated on May 9 and June 21 and visited when dry on September 22, 2005. High flows a year ago deposited a gravel bar in front of the outfall and shifted the main channel to the opposite side of the stream bed. The side channel dug last year did not allow adequate flow past the outfall when the stream was low. A new side channel was dug before May 9, 2005, that provides better flow and a deeper channel past the outfall, improving the conditions for small fish. 
All measured approach velocities were below the NMFS criterion (Figures 6 and 7). This site has always had problems with the angle of water flowing into the forebay causing reversed sweeps past the first two screens. Sweep velocities increased slightly toward the bypass across the last two screens that had flow toward the bypass. Bypass flows were always higher than the sweep velocities and ran smoothly into the outfall channel.

Submergence was good in May and June, at 75\% and 77\%, respectively. It is interesting to note how quickly water levels can change at this site. In May, a severe thunderstorm raised the water levels about 5 in. in less than 2 hours. In June, adjustments in water distribution at the Upper Wapato Irrigation Project site, less than 1 mile upstream, caused water levels to drop between 5 and 6 in. at Bachelor-Hatton in one morning.

Video surveys showed seals generally in good condition. By the time of our visit in September, the bottom seal of the third screen had been replaced. Sediment was accumulating in front of the downstream screens and in the bypass entrance in May, obscuring the bottom seal of the last screen in June. Gaps between the cement cheeks and the drum frame up to 3/4 in. wide have not been caulked in the past, but in September we found all cheeks had been caulked during fall maintenance. This caulking prevents small fish from becoming wedged in the gap.

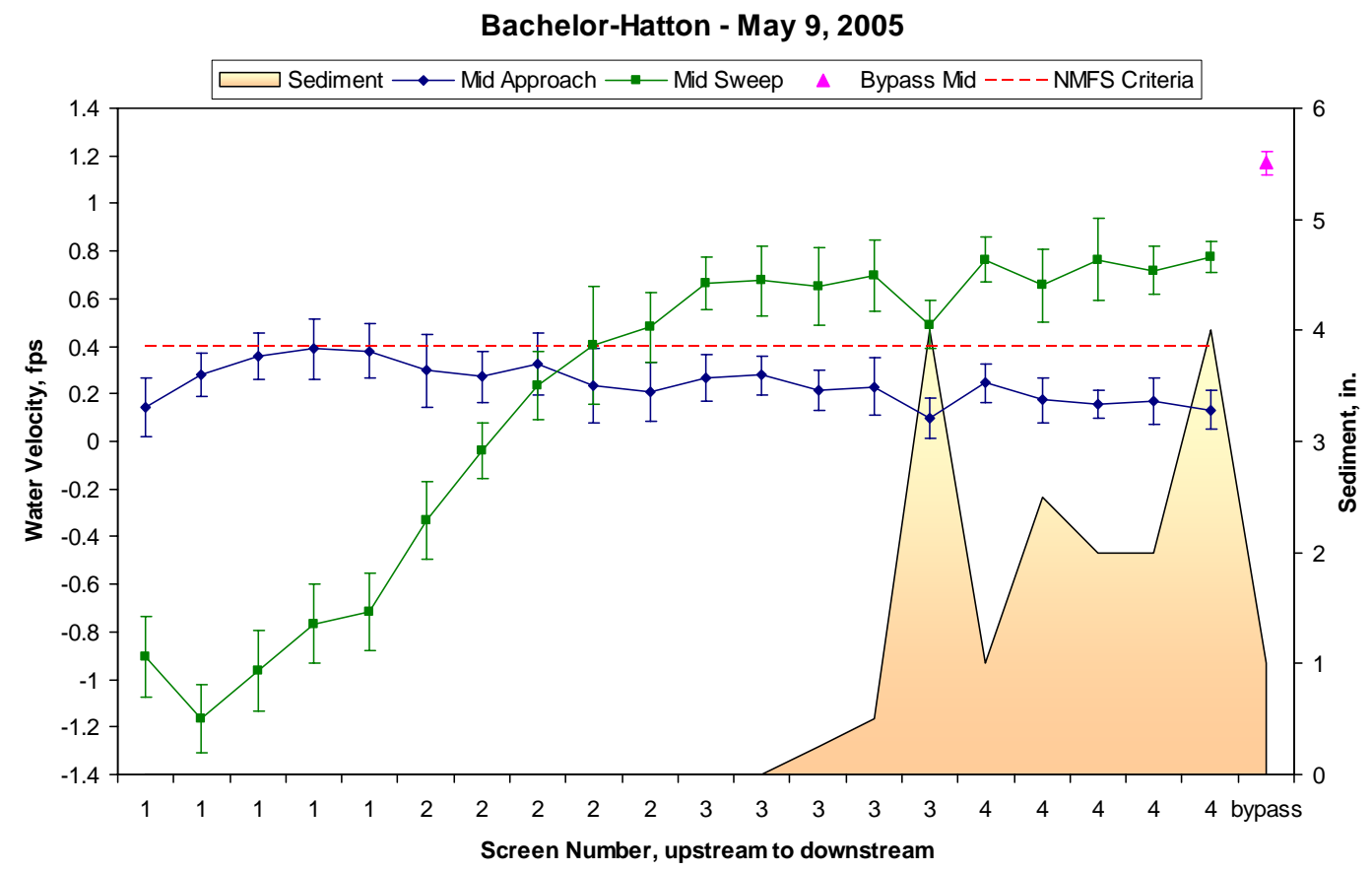

Figure 6. Water velocities and sediment accumulation, Bachelor-Hatton, May 2005. Error bars represent turbulence. 


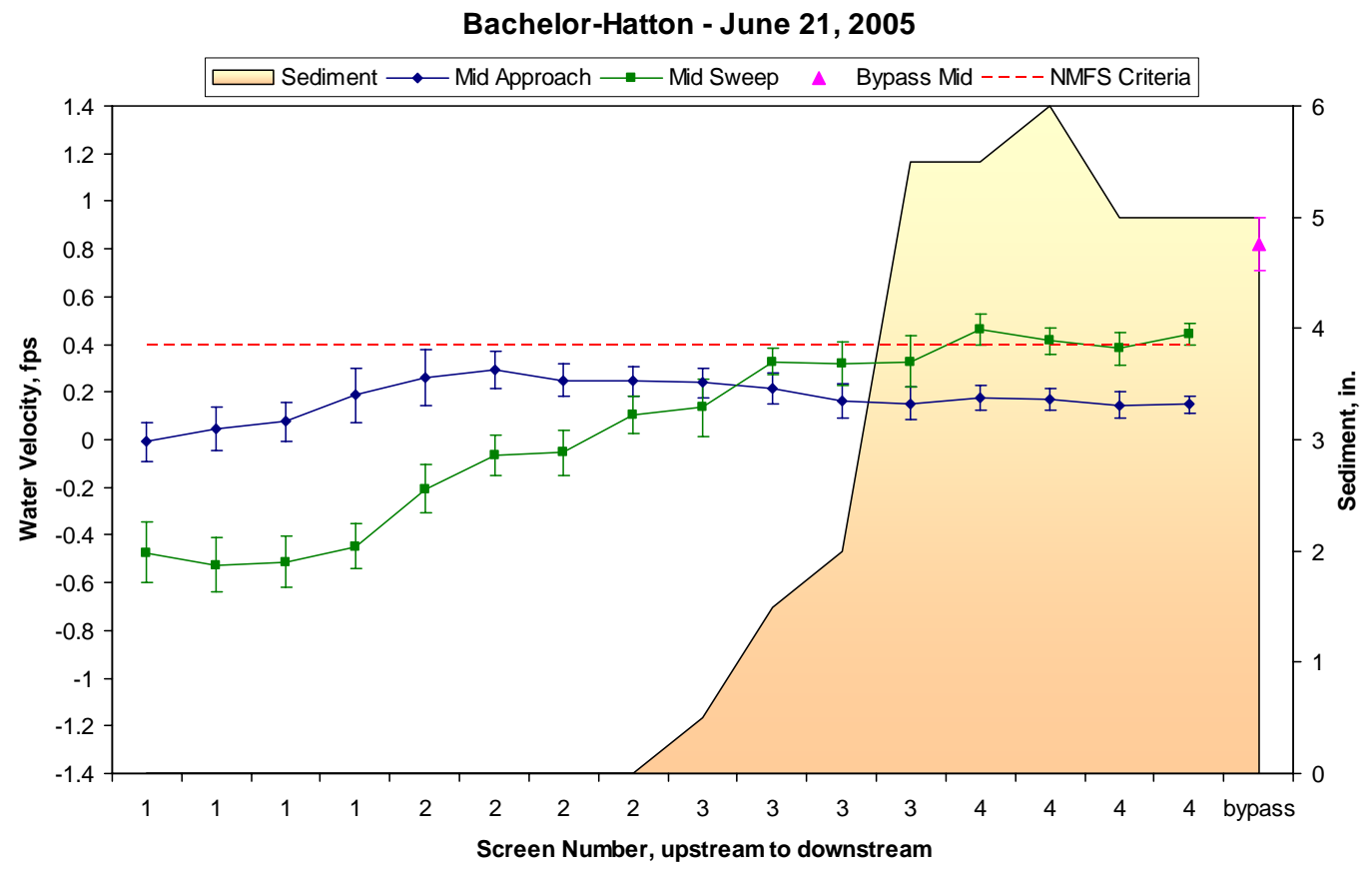

Figure 7. Bachelor-Hatton water velocities and sediment accumulation, June 2005. Error bars represent turbulence.

\section{Clark}

We evaluated the Clark site on May 25, June 28, and September 19, 2005. Submergence was at 74, 56, and 71\% from May through September, respectively. Approach velocities all were below 0.4 fps and were always less than the sweep velocities (Figures 8 through 10). Sweep velocities increased toward the bypass in May and September. Water levels were low in June, which caused the site to fall outside NMFS, with less than 2 in. of water spilling over the weir, only 5 in. of water in the bypass pipe, and less than $1 \mathrm{ft}$ of water at the point of discharge. Bypass velocity was slightly higher than the sweep, but sweep decreased toward the bypass. After flip-flop in September, sweep increased toward the bypass. Water flowed smoothly over the weir and through the bypass during all evaluations. There were no problems with water overflowing the headgates as in previous years.

The drum turned smoothly in May and June, but in September its movement was jerky. There was a lot of vegetation in the aftbay, but there was no obvious reason for the irregular turning. Juvenile salmonids were seen in the forebay in June, and some redside shiners were seen in September. Demand for water through this site is sporadic, as it provides water for the local fire department as needed. 


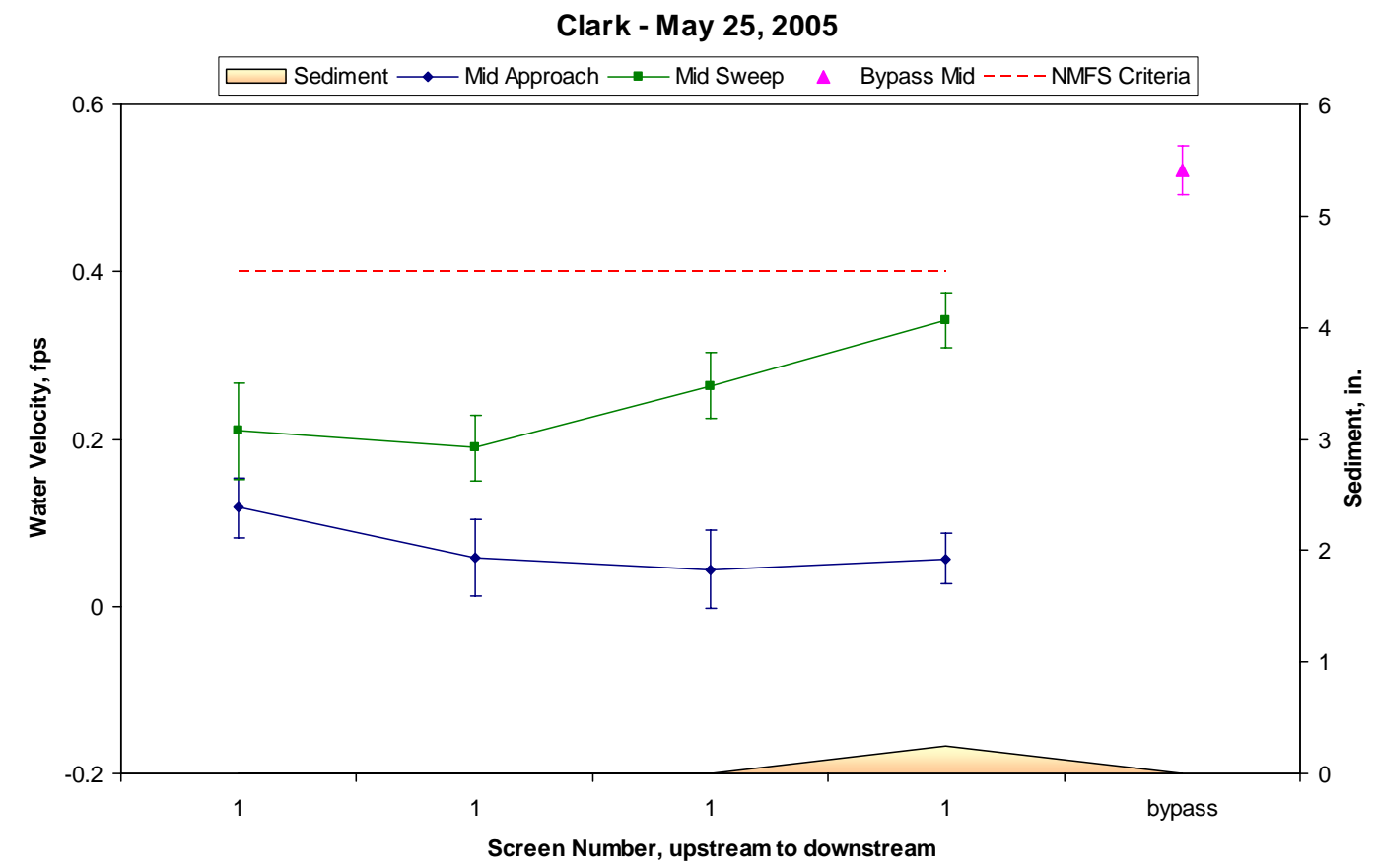

Figure 8. Clark water velocities and sediment accumulation, May 2005. Error bars represent turbulence.

Clark - June 28, 2005

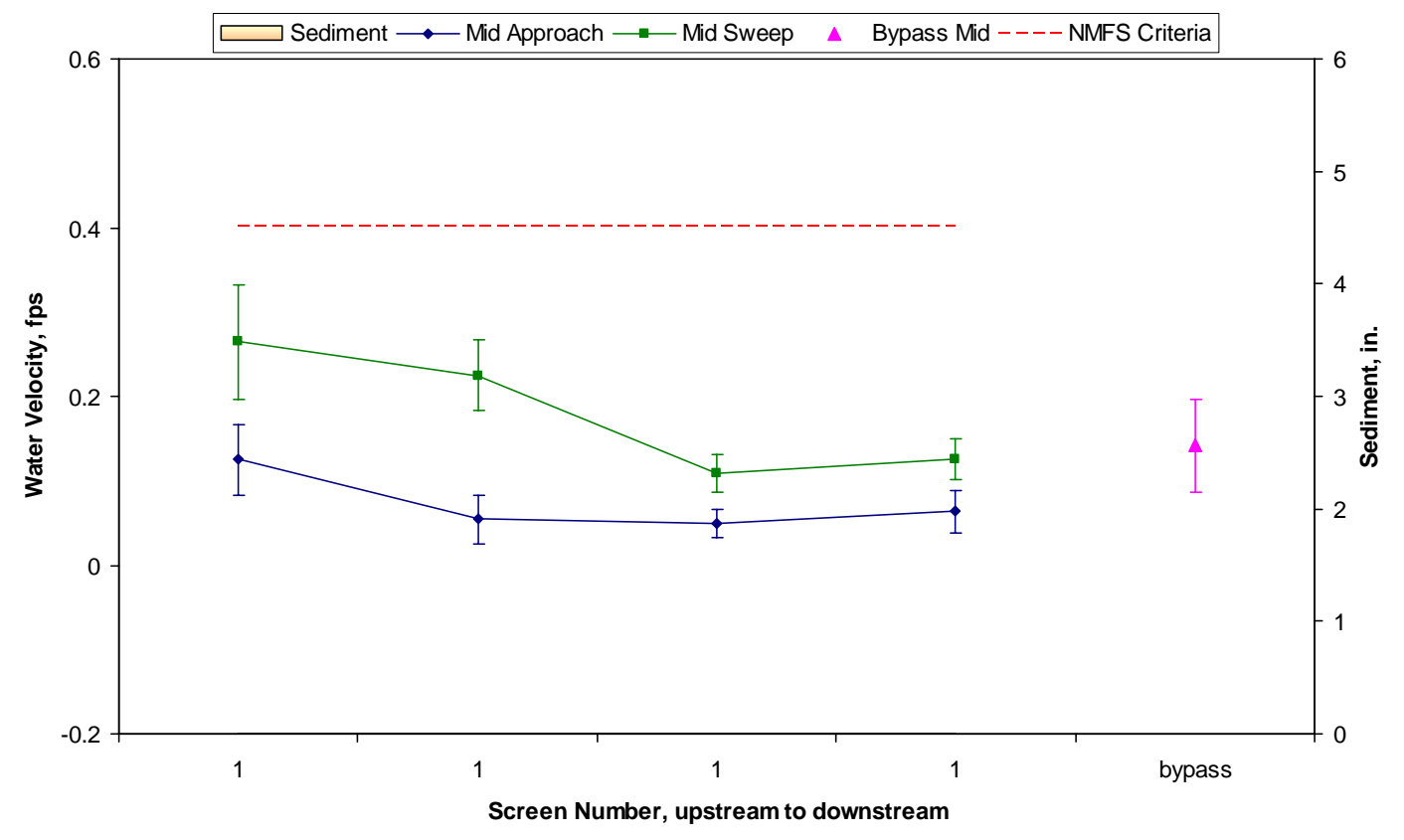

Figure 9. Clark water velocities and sediment accumulation, June 2005. Error bars represent turbulence. 
Clark - September 19, 2005

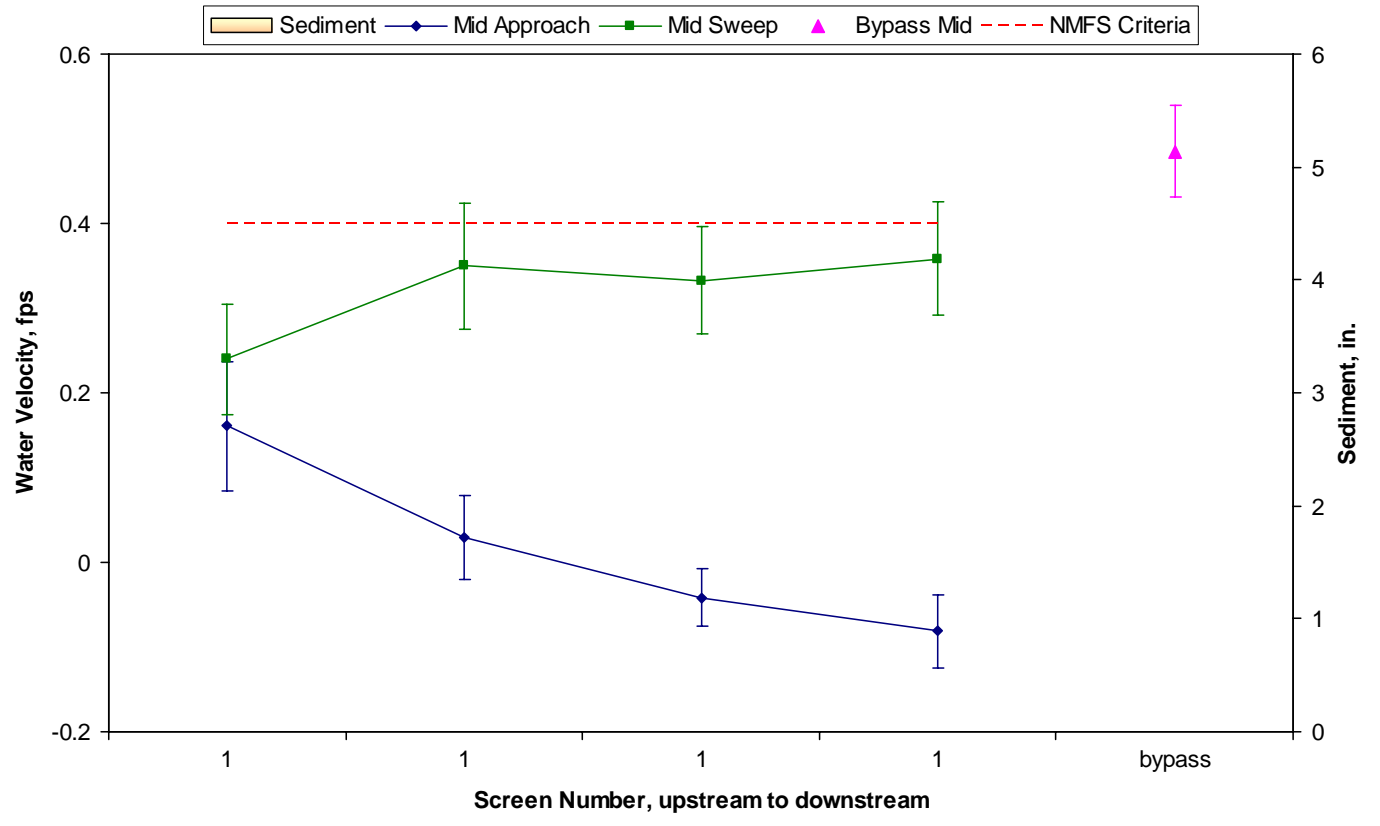

Figure 10. Clark water velocities and sediment accumulation, September 2005. Error bars represent turbulence.

\section{Congdon}

The Congdon facility was evaluated on May 10, June 30, and September 15, 2005. Approach velocities did not meet the NMFS criterion of 0.4 fps in May (Figure 11). June and September approach velocities met this criterion in 93\% and 47\% of the measurements, respectively (Figures 12 and 13). Ray Gilmour (WDFW) was notified on May 10 concerning the high approach velocities. He said there was probably nothing to be done because the site was operating within the specifications. In 2006, we would like to look at design flows for the diversion and bypass as well as the operating procedures for the screens at this site, and work together with WDFW personnel to see whether changes to stoplog position or other facility settings can be made to keep the site within criteria.

Sweep velocities always were higher than approach velocities, and bypass velocity was generally higher than the sweep velocity except in June, when the ditch rider raised the weir while we were there. This resulted in only $2.5 \mathrm{in}$. of water over the weir and decreased the amount of water moving through the bypass. Otherwise, flow over the weir and through the bypass was generally adequate. According to the logbook, there were at least a couple occasions in July and August when there was no bypass flow and the WDFW had to reset the weir to allow bypass flows again. Submergence met the criterion for drum screens at 85, 75, and 80\% in May, June, and September, respectively. Seals and screens were in good condition during all visits. Several predator-sized northern pikeminnow were waiting at the outfall for anything coming through the bypass. 
Congdon - May 10, 2005

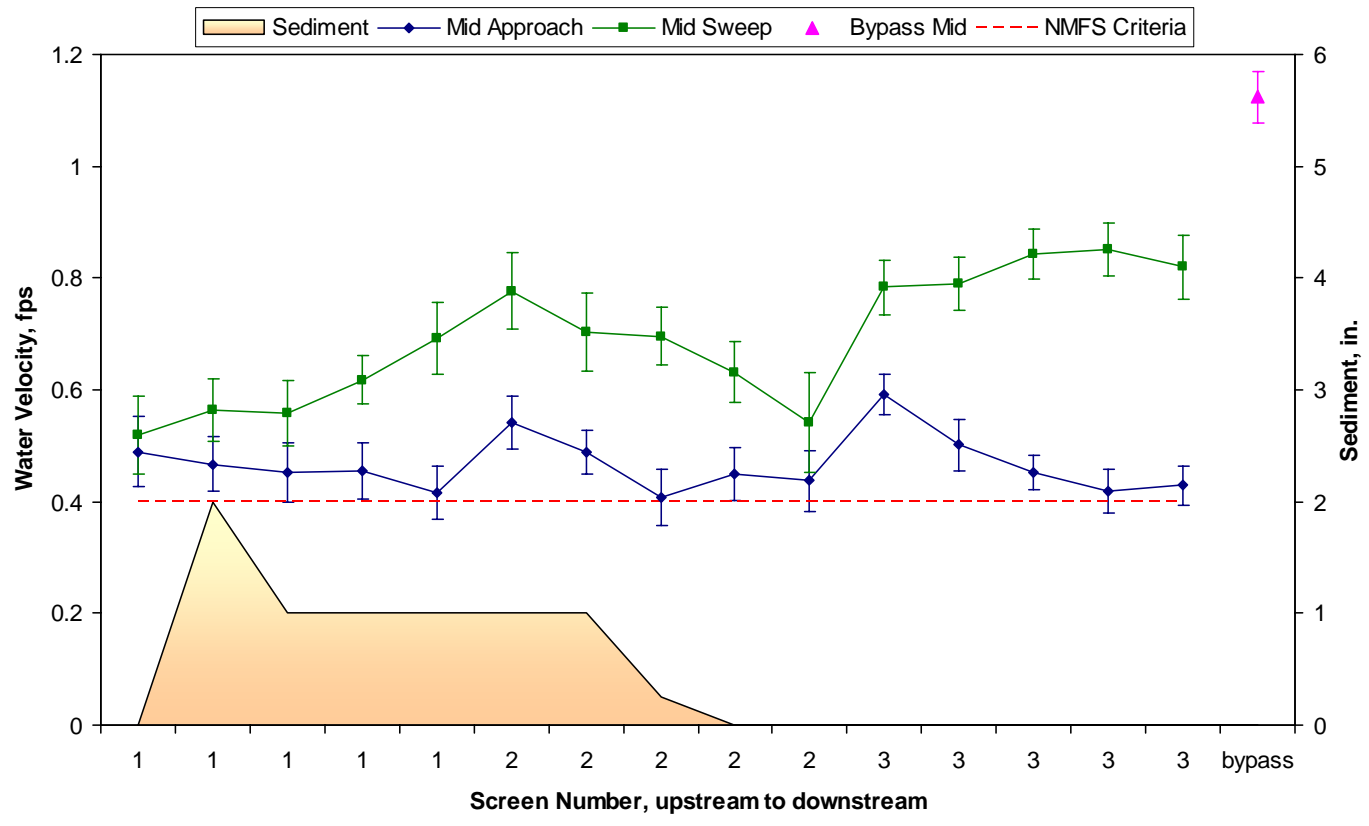

Figure 11. Congdon water velocities and sediment accumulation, May 2005. Error bars represent turbulence.

Congdon - June 30, 2005

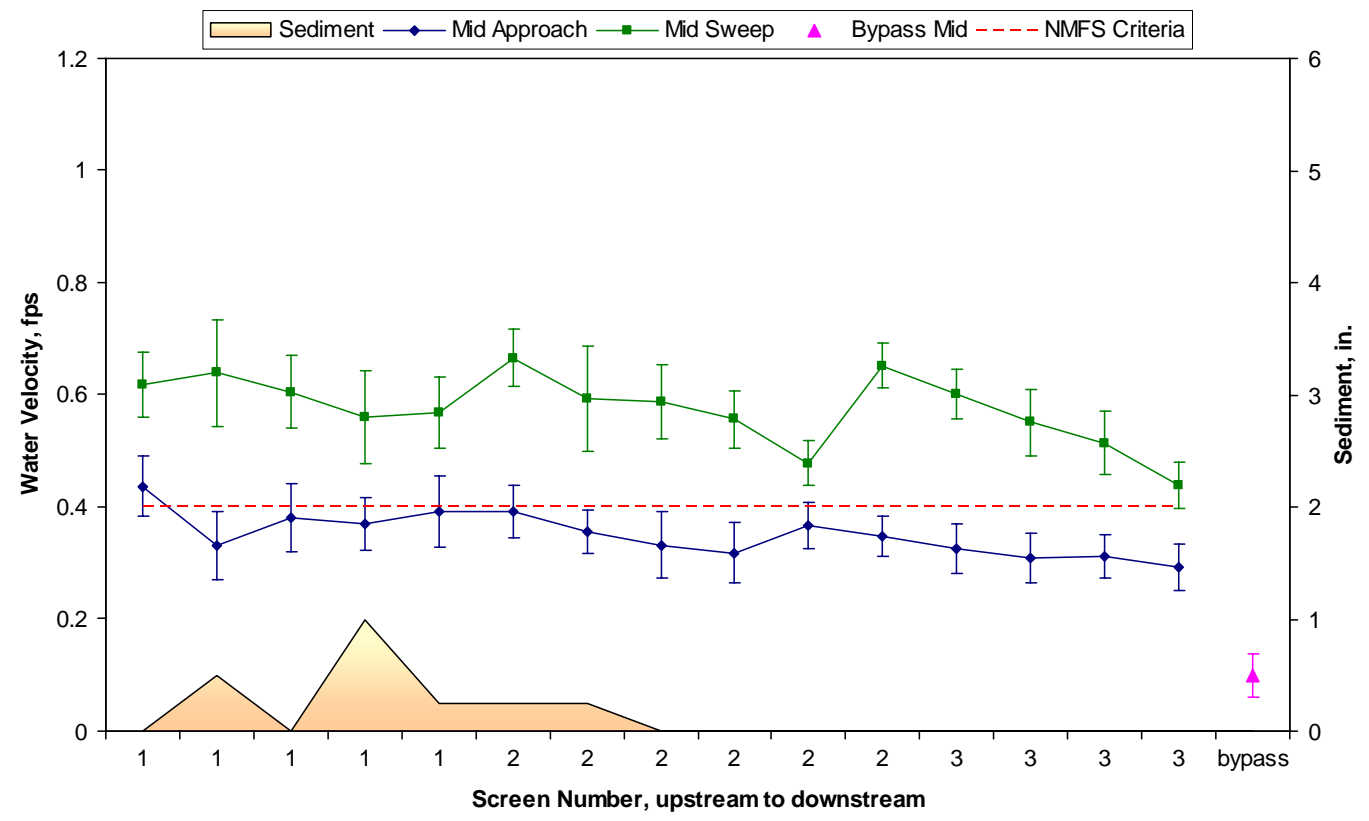

Figure 12. Congdon water velocities and sediment accumulation, June 2005. Error bars represent turbulence. 


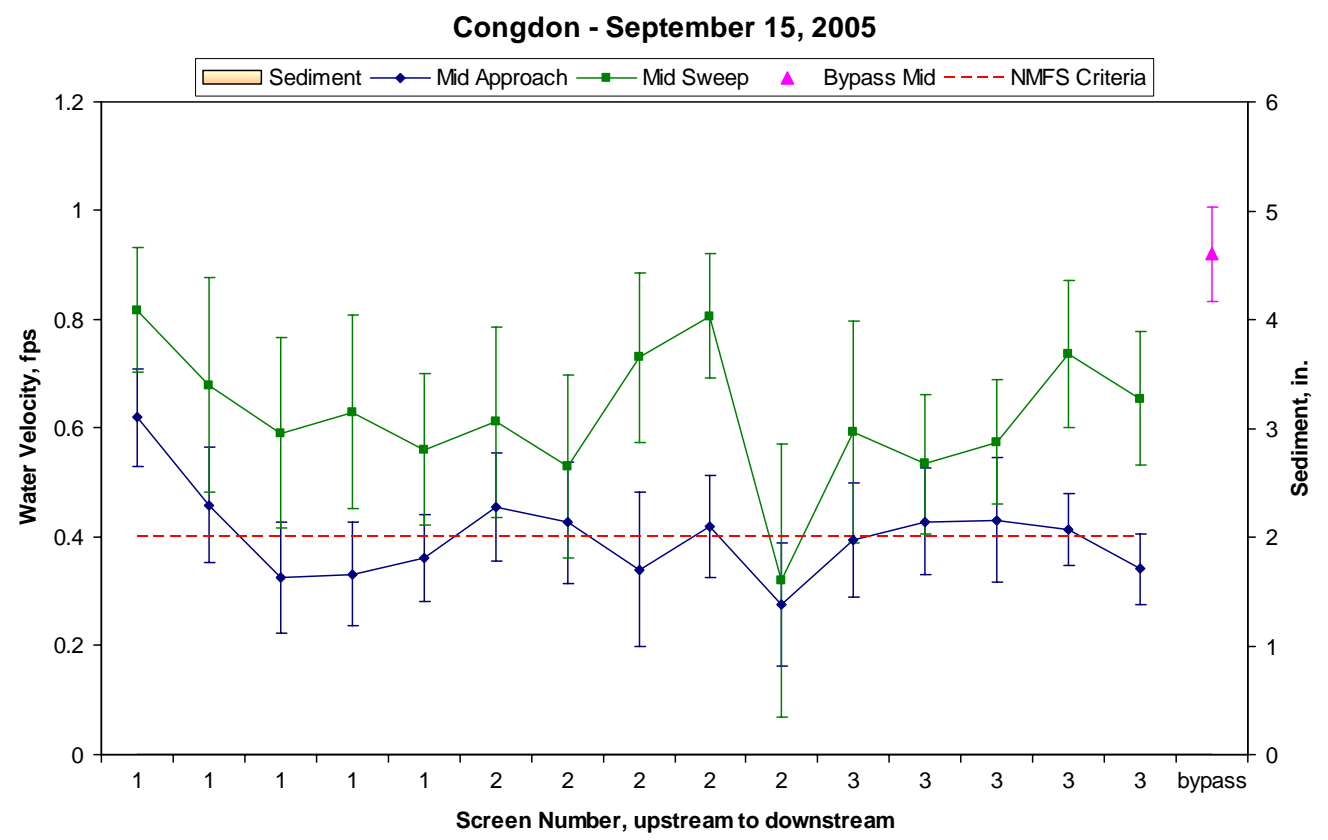

Figure 13. Congdon water velocities and sediment accumulation, September 2005. Error bars represent turbulence.

\section{Huntsville Mill}

Huntsville Mill is a new site built along the Touchet River (Figure 2), completed and operated in 2004 and first evaluated for this project this year. Flow to the site is through a long open channel with headgates just below the divergence from the main channel (Figure 14). It has a single drum screen made of perforated plate with 3/32-in. holes staggered on 5/32-in. centers. The drum is 36 in. in diameter by 8 $\mathrm{ft}$ long (Figure 15). Bypass flows through a pipe into a shaded pool and then flows through another long open channel to the river.

This site was visited for the first time on May 24, 2005. Subsequent evaluations were on June 27, July 13, September 8, and September 30, 2005. Submergence was 74, 86, 82, <20, and 82\% from May through September 30. The high submergence on June 27 also caused high approach values in two of the four measurements. The WDFW was notified on June 28, and stoplogs were added in the aftbay to decrease the approach velocities. We checked the site again on July 13 and found both the submergence and approach velocities improved. On September 8, essentially no water was moving through the site, and beaver activity had dammed the channel back to the river, probably blocking passage for fish. We notified WDFW personnel on September 12. They found the trash rack blocked with debris on September 14. The site had much better submergence when visited on September 30.

Sweep velocities were generally constant or decreased slightly toward the bypass during all visits (Figures 16 through 19) and were greater than approach velocities except at the upstream position in May and June. Bypass flows were greater than sweep in all cases. Approach velocities exceeded the NMFS criterion only in June. Seals and the drum were in good condition. Water moved smoothly through the bypass whenever water was running through the site. Checkboards are used in the downwell to create a plunge pool. Juvenile salmonids were noticed in the pool at the bypass outfall in July. This site does not yet have gages, a logbook, any site design or operating criteria, or contact information. 


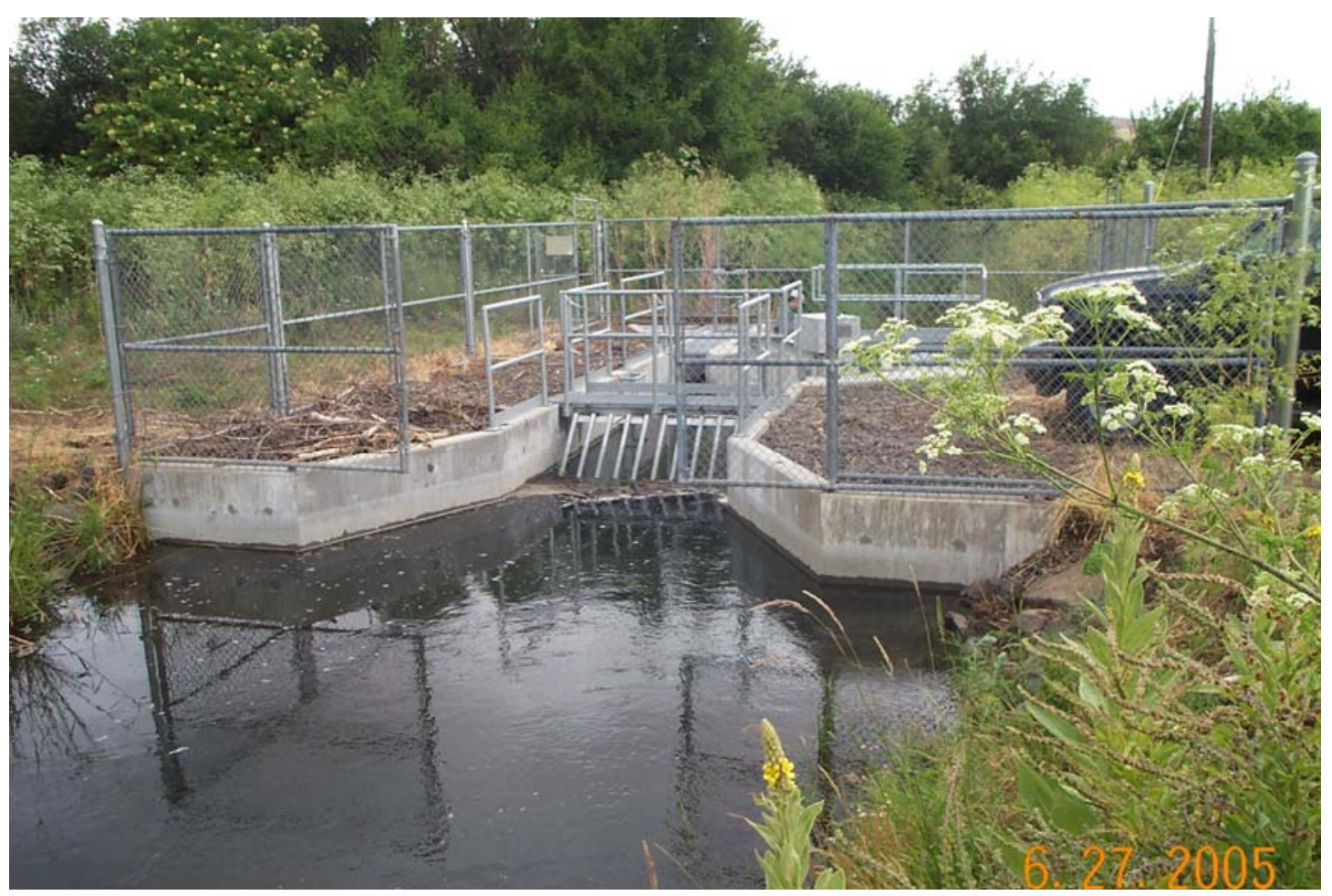

Figure 14. Entrance to Huntsville Mill screen facility

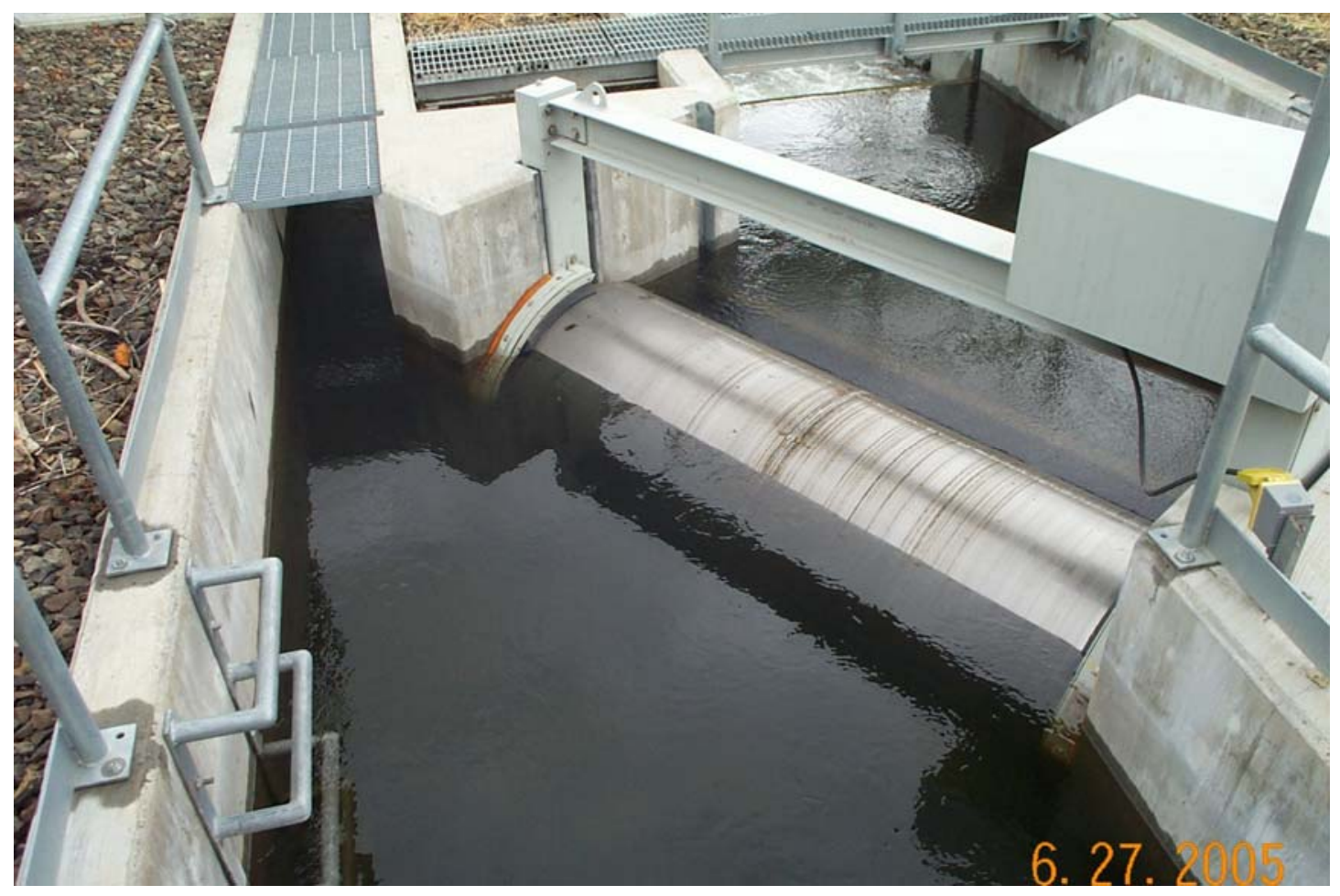

Figure 15. Drum and bypass entrance at Huntsville Mill site 
Huntsville Mill - May 24, 2005

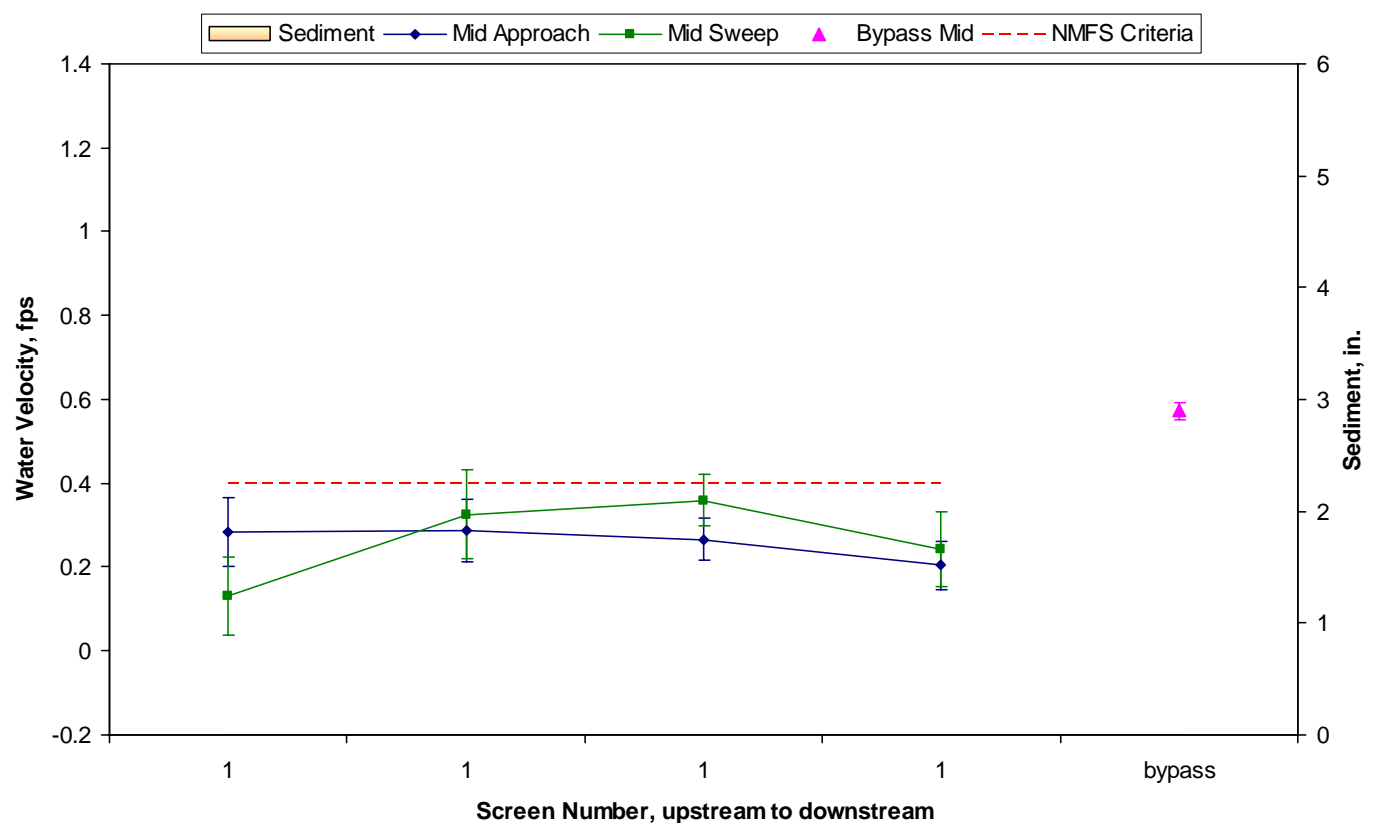

Figure 16. Huntsville Mill water velocities and sediment accumulation, May 2005. Error bars represent turbulence.

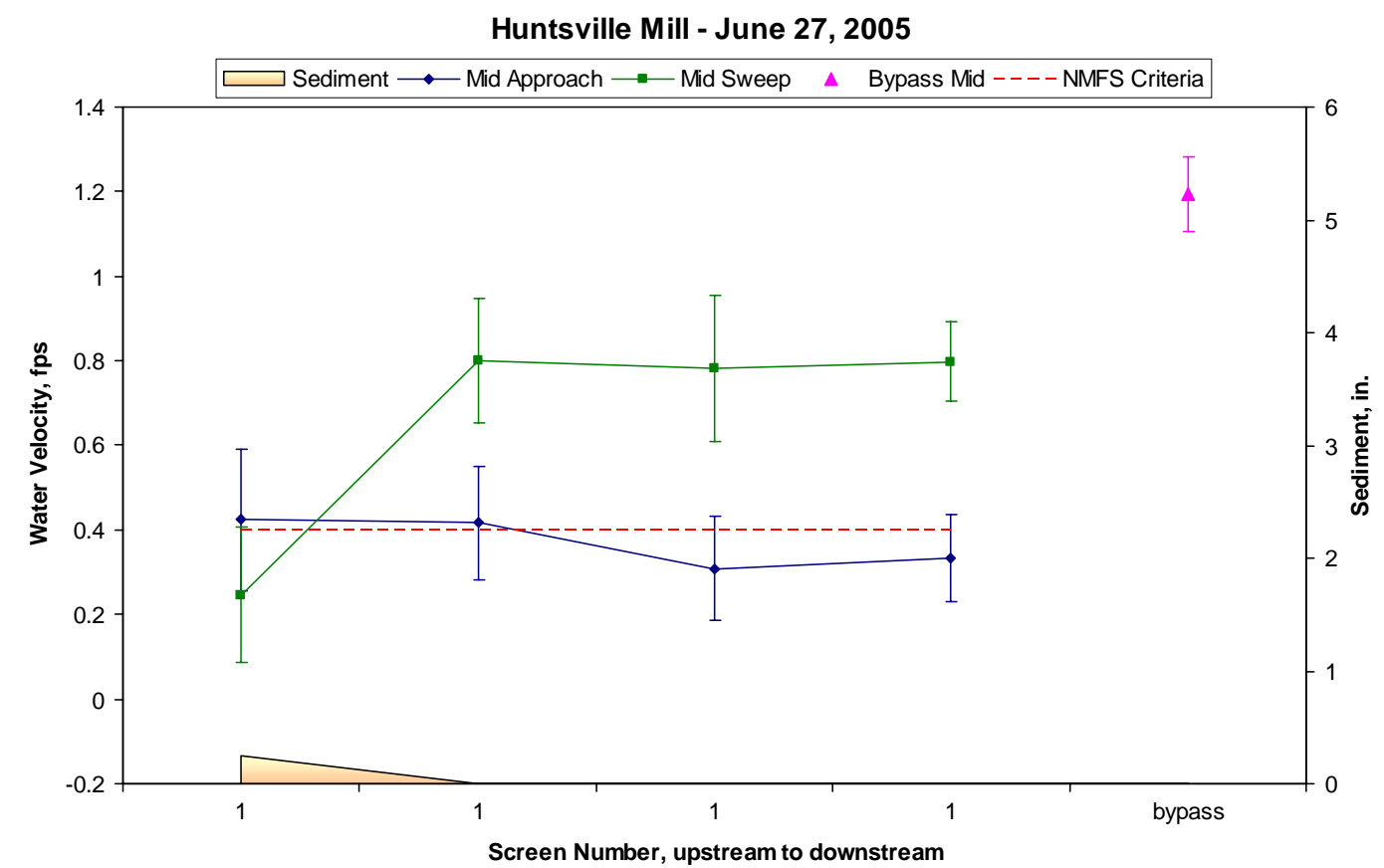

Figure 17. Huntsville Mill water velocities and sediment accumulation, June 2005. Error bars represent turbulence. 


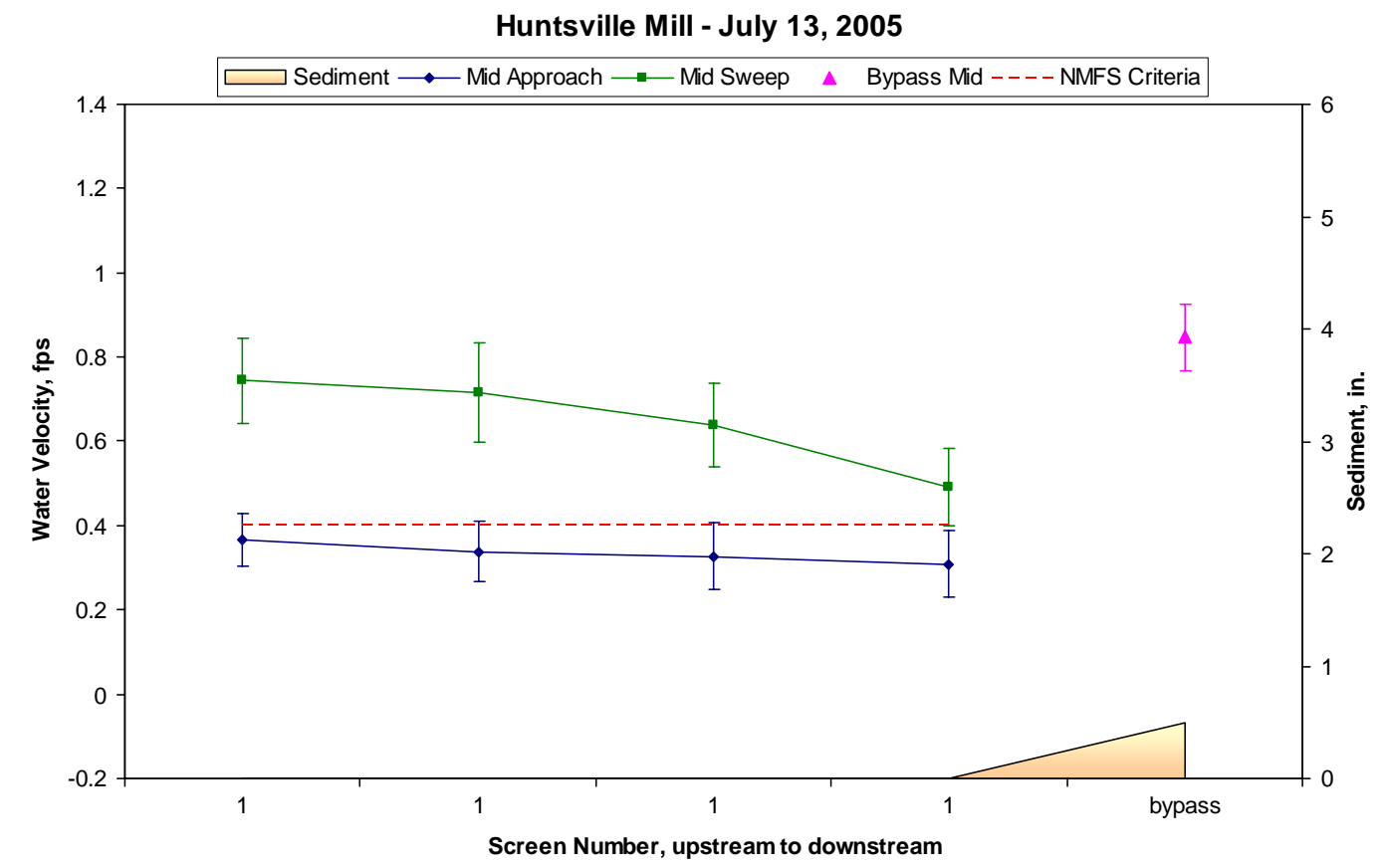

Figure 18. Huntsville Mill water velocities and sediment accumulation, July 2005. Error bars represent turbulence.

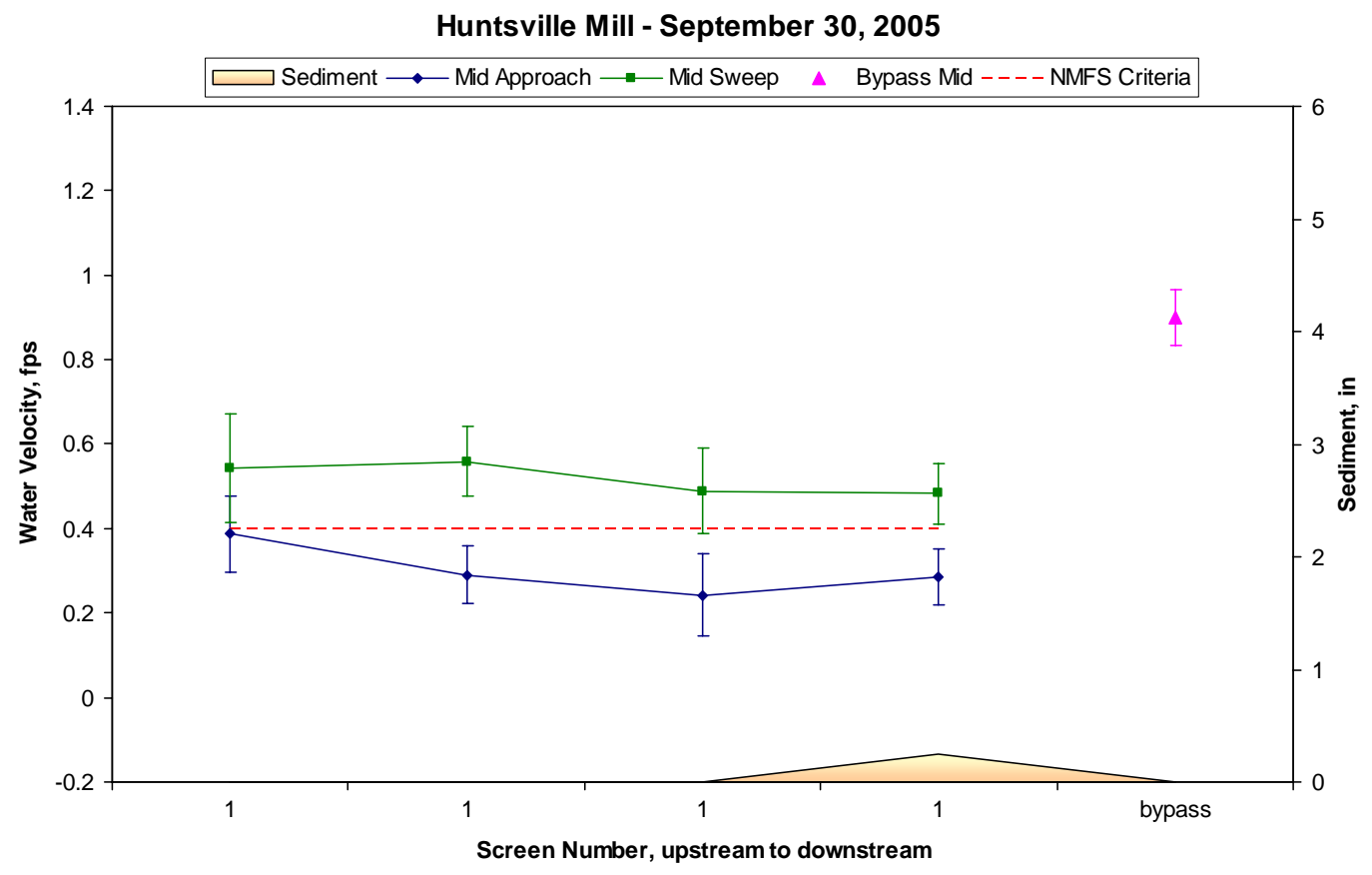

Figure 19. Huntsville Mill water velocities and sediment accumulation, September 2005. Error bars represent turbulence. 


\section{John Cox}

The John Cox site was operational during only one visit in 2005, on May 9. Submergence was at $75 \%$ on that date. Approach velocities exceeded the NMFS criterion in the first measuring point along each screen, probably due to eddies around the cement framework (Figure 20). Sweep was greater than approach velocities but did not increase toward the bypass and, in fact, was greater than the bypass flow.

In May, the bypass ramp was up several inches, and the area underneath was jammed full of sticks and debris. The bypass was still able to pass fish. The trash rack was also mostly blocked with sticks and debris, which had been there so long that grass was growing on the top of the pile (Figure 21). The pile covered much of the trash rack and may pose a problem for fish passage. Debris on the trash rack has been a problem here for several years. The irrigation district is supposed to maintain it but does not do so as often as needed. Underwater video showed a small stick wedged between the downstream screen and seal. The USBR personnel were notified on May 9 about the excessive approach values, the stick in the seal, and the debris underneath the open ramp. They were going to correct the problems within a few days. We were not notified of the corrections, but the problems had been fixed by the time of our visit on June 21, when the site had been shut down for the season. Cheeks between the frame and cement structure were caulked in September for the first time, so they will be ready for the 2006 season.

John Cox - May 9, 2005

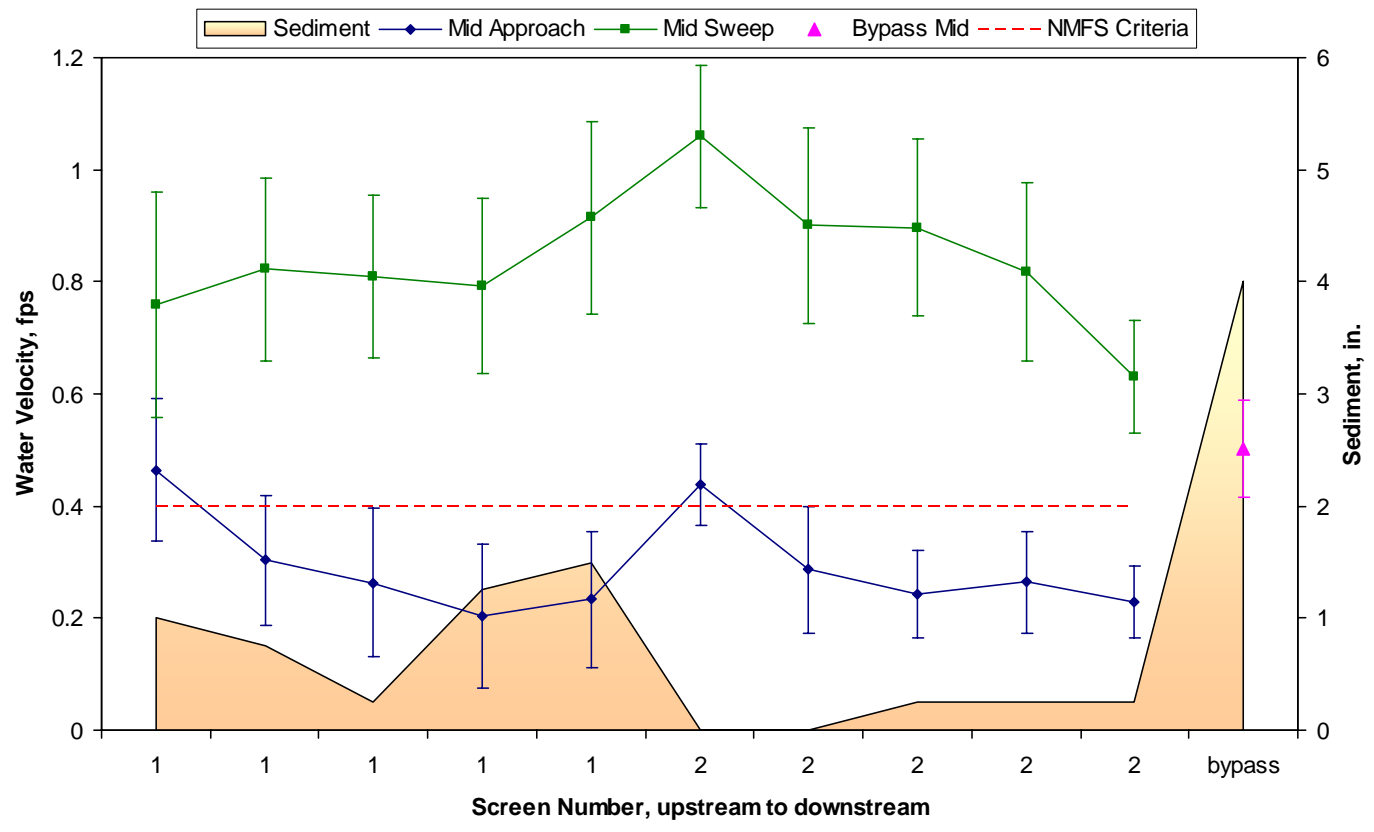

Figure 20. John Cox water velocities and sediment accumulation, May 2005. Error bars represent turbulence. 


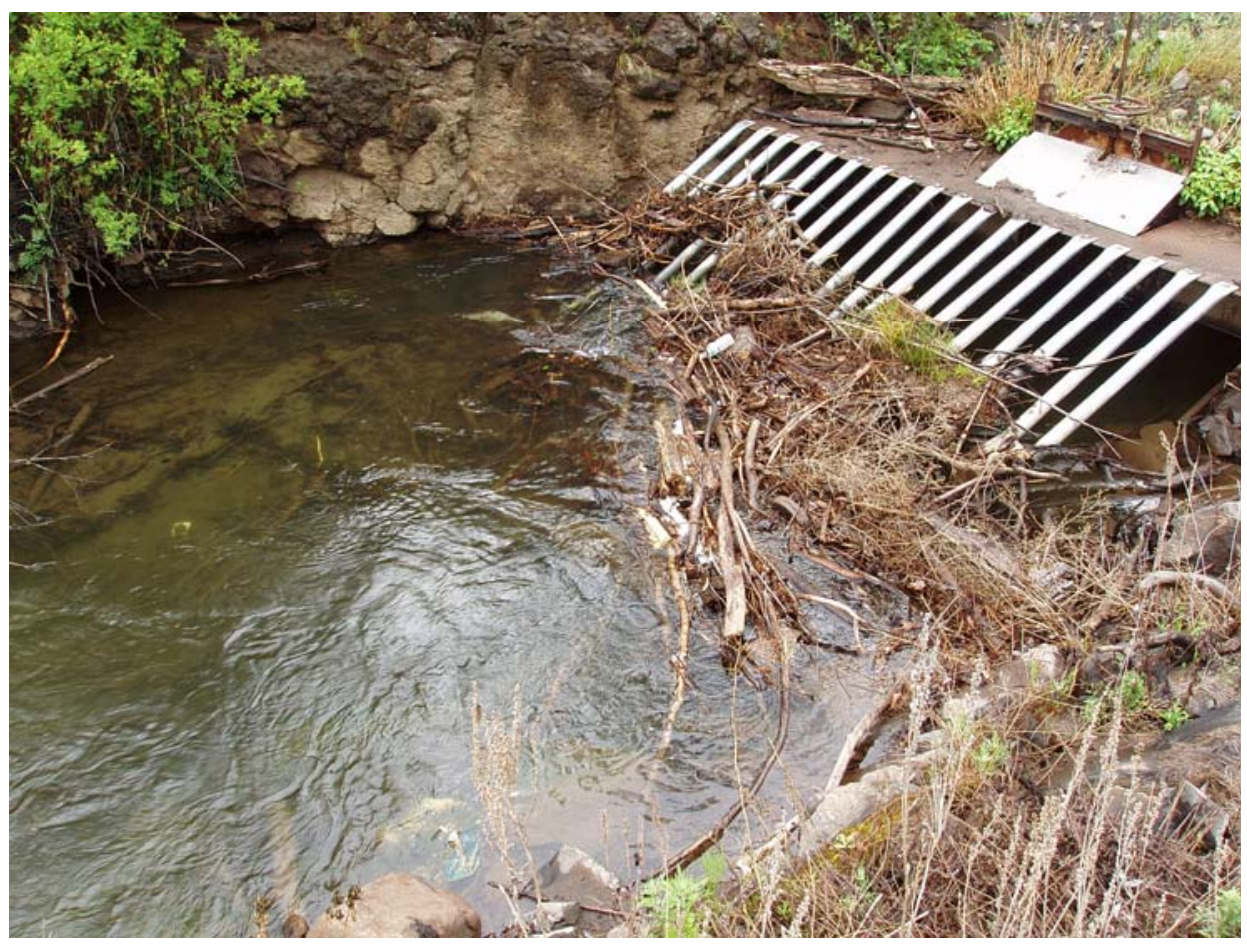

Figure 21. John Cox trash rack, laden with debris

\section{Kelley-Lowry}

The Kelley-Lowry site was visited on May 25, June 28, and September 15, 2005. Sediment buildup in the forebay continued to be a problem this year and was so thick that it prevented us from measuring velocities at $20 \%$ and $80 \%$ of the water depth, forcing us to measure at $60 \%$ of the depth instead (Figures 22 through 24). The top of the sediment was only $18 \mathrm{in.} \mathrm{below} \mathrm{water} \mathrm{level.} \mathrm{We} \mathrm{believe} \mathrm{the}$ sediment mound we observed in June caused a pocket of stagnant water in front of screen 1, shown in Figure 23. It also made it almost impossible to see the bottom seals, either because they were covered with sediment or because we could not get the camera down far enough to see the seals. The WDFW does not have an agreement with the irrigation district to remove sediment at this site; consequently, it is the irrigation district's responsibility. They have not fulfilled this responsibility to date. Because of the severity of the problem, WDFW personnel have agreed to clean out the sediment in the forebay before the beginning of the 2006 season, although they anticipate continued problems because of the amount of sediment in the channel leading to the site.

Sweep velocities always were greater than approach values (Figures 22 through 24) and also were greater than bypass velocities. Approach values were less than the NMFS criterion of $0.4 \mathrm{fps} 100,90$, and $90 \%$ of the time from May through September. Submergence was at 80, 85, and 87\% from May through September. Bypass flows ran freely through the downwell, which has checkboards to make a plunge pool. The outfall is difficult to see from within the facility, and dense vegetation kept us away when we tried to find it from the other side. 


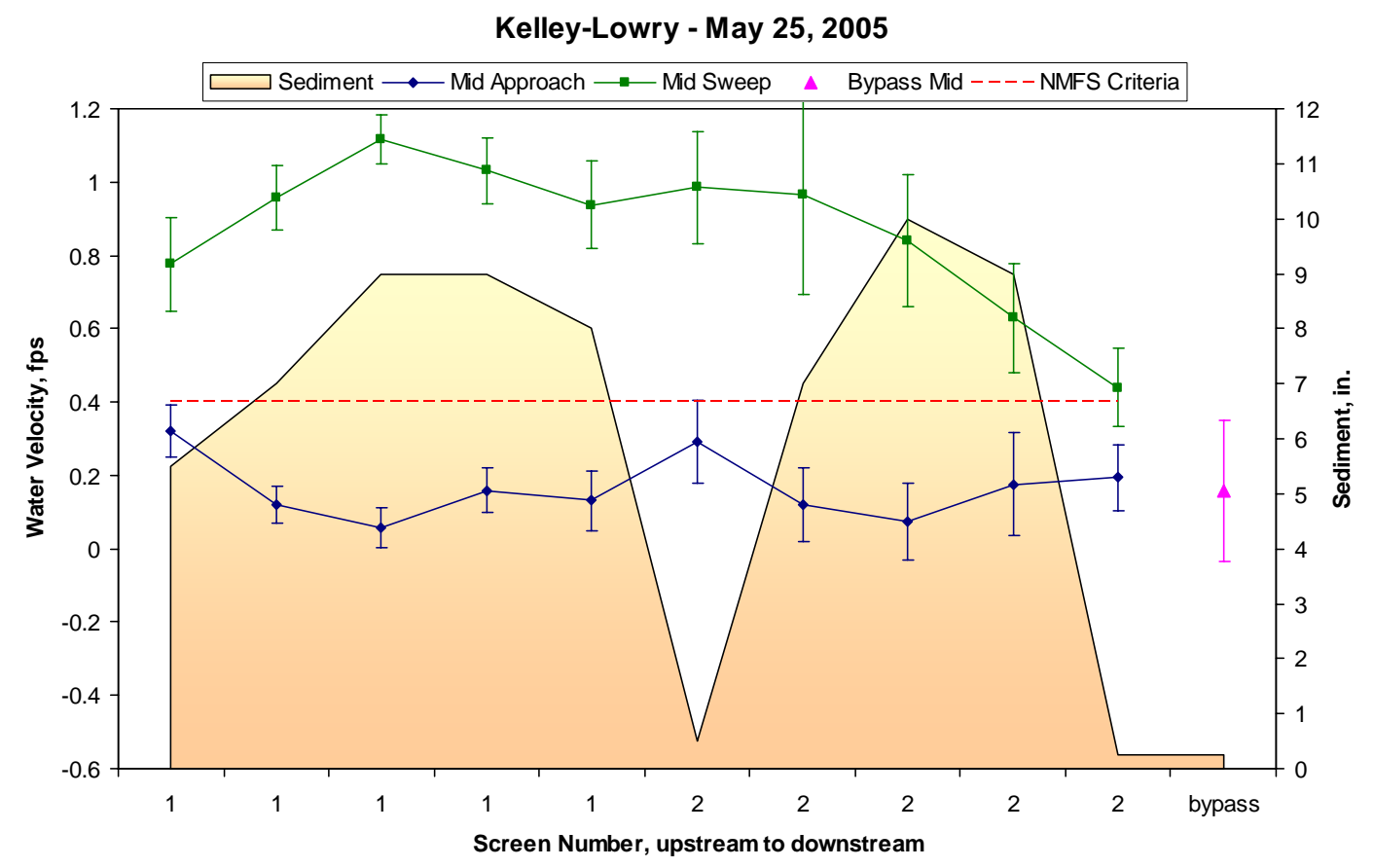

Figure 22. Kelley-Lowry water velocities and sediment accumulation, May 2005. Error bars represent turbulence.

Kelley-Lowry - June 28, 2005

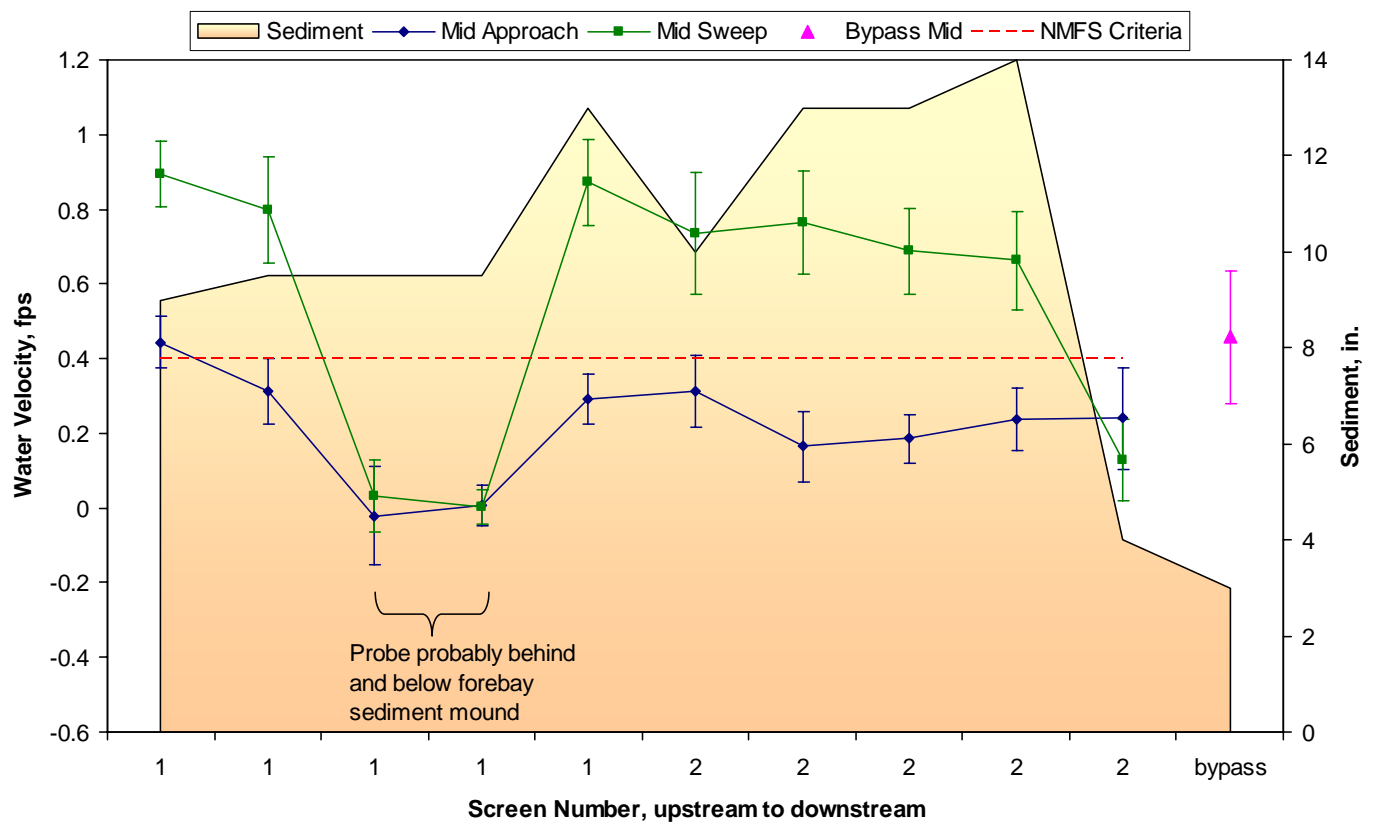

Figure 23. Kelley-Lowry water velocities and sediment accumulation, June 2005. Error bars represent turbulence. 


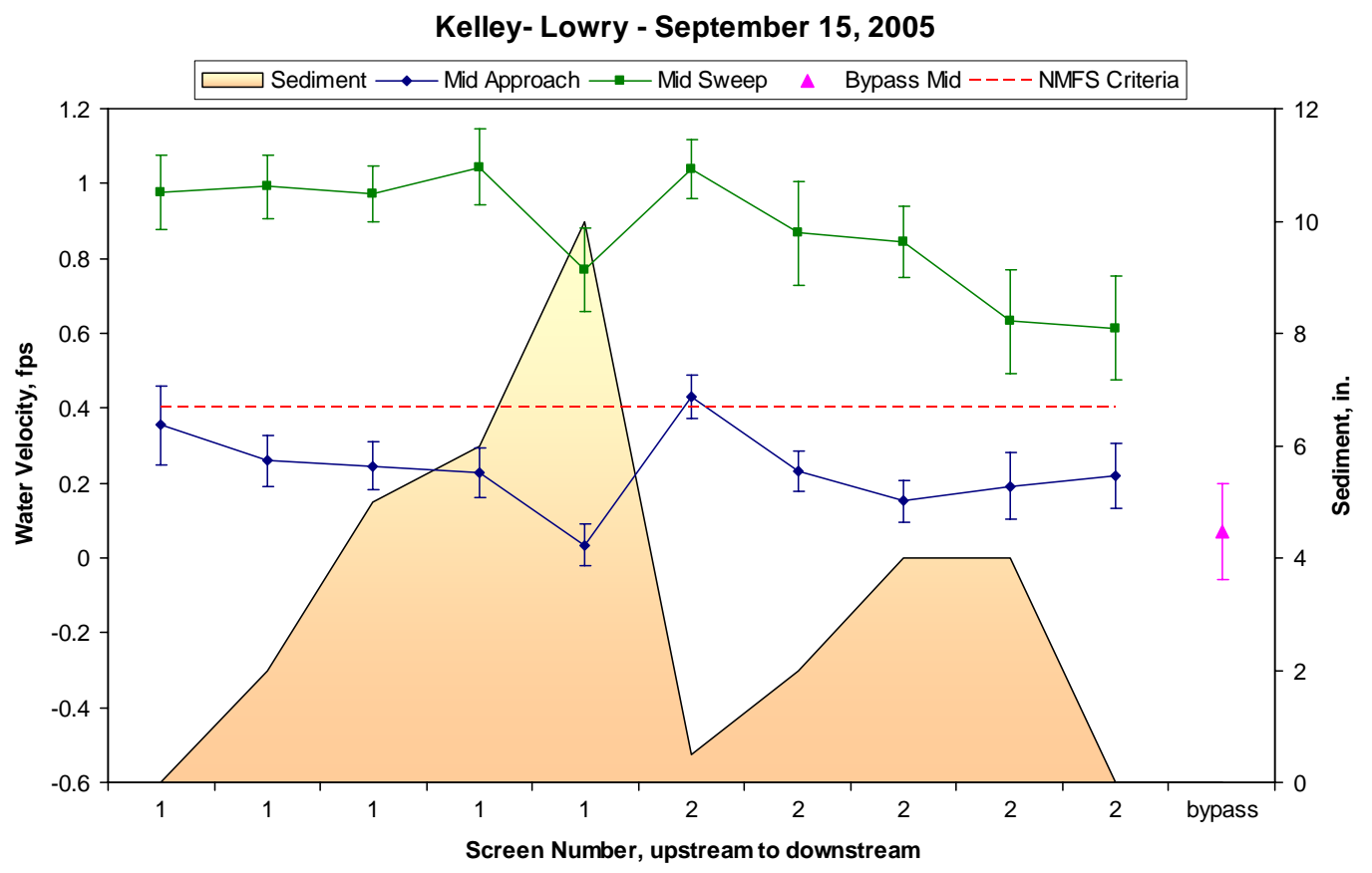

Figure 24. Kelley-Lowry water velocities and sediment accumulation, September 2005. Error bars represent turbulence.

\section{Lindsey}

The Lindsey site was evaluated on May 11, June 23, and September 19, 2005. During all surveys, $100 \%$ of approach velocity values were below the NMFS criterion of 0.4 fps (Figures 25 through 27). Sweep velocities were greater than approach velocities in June and September but were lower in May, and sweep did not increase toward the bypass during any of our evaluations. Bypass velocity was greater than the sweep velocity in May but not during the June and September surveys.

The screen was in good condition, and the drum moved leaf matter and other floating debris into the canal effectively. The downstream side seal near the bottom had bowed out slightly. It did not appear to be large enough for fingerlings to pass through but should be fixed before next spring. Submergence was between $70 \%$ and $72 \%$ during each of our surveys. Flow over the weir was generally low, at 3 in. in May and June and 1.5 in. in September, but the water moved smoothly to the outfall where the depth was always greater than $1 \mathrm{ft}$. Juvenile salmonids were hanging out in the forebay in June and September. 
Lindsey - May 11, 2005

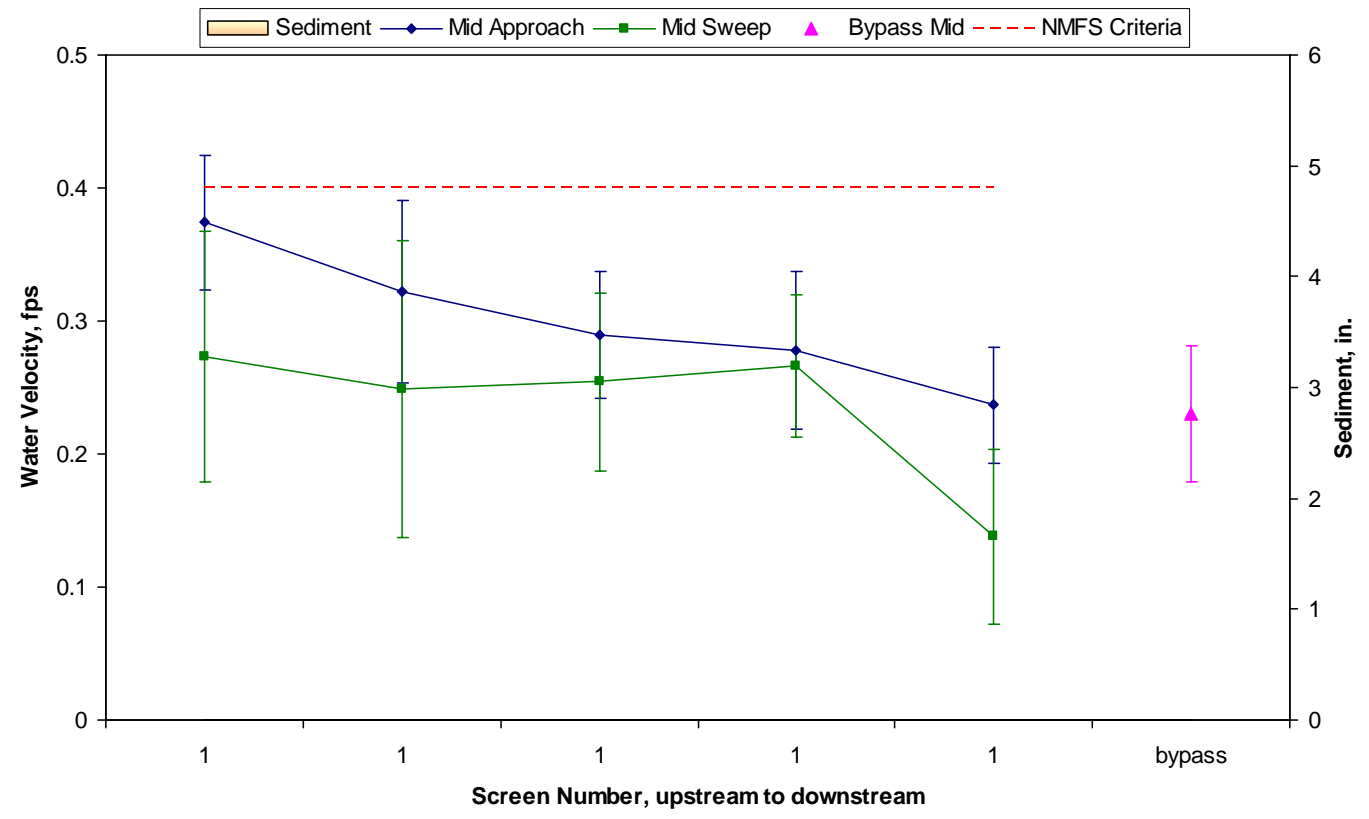

Figure 25. Lindsey water velocities and sediment accumulation, May 2005. Error bars represent turbulence.

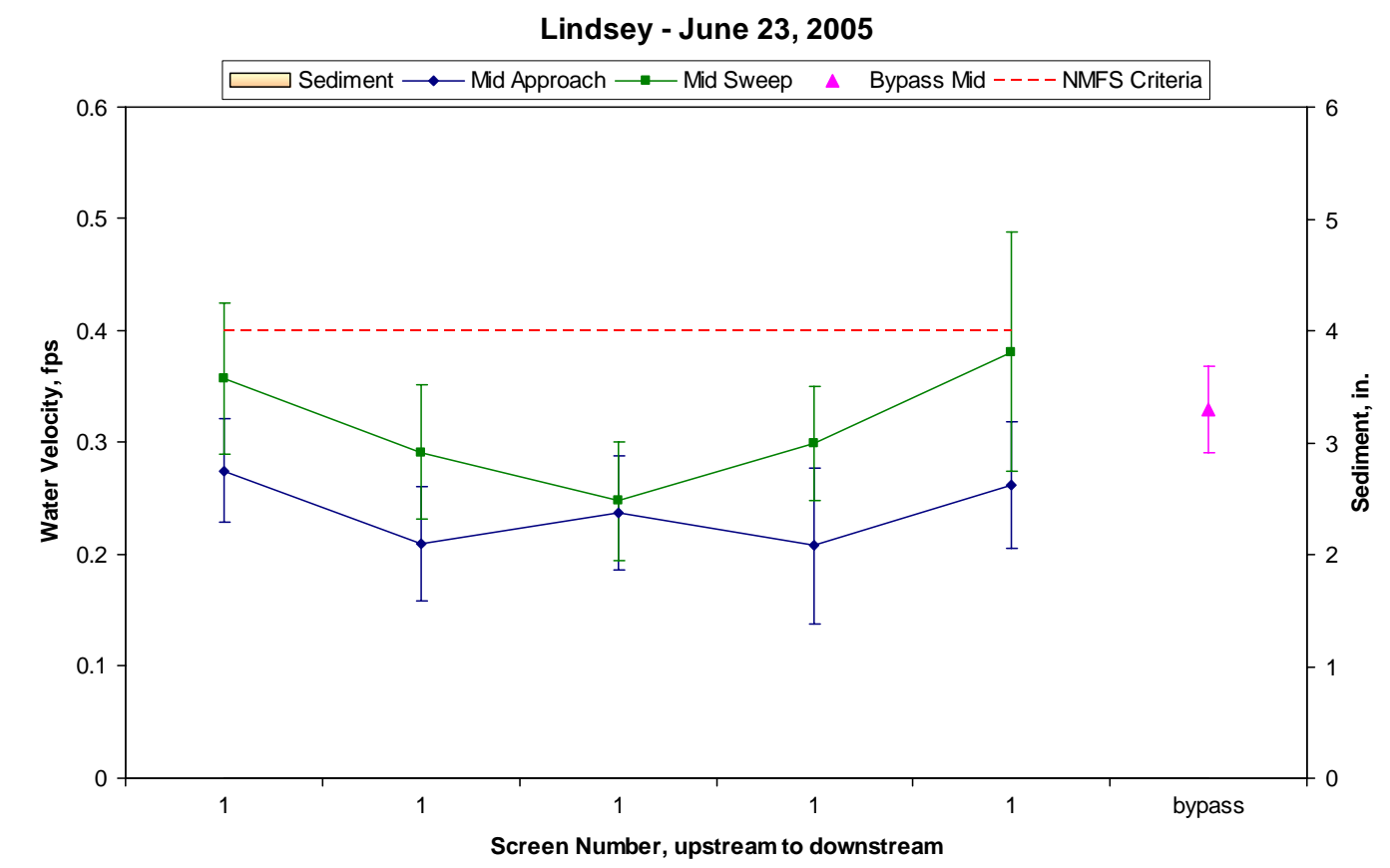

Figure 26. Lindsey water velocities and sediment accumulation, June 2005. Error bars represent turbulence. 


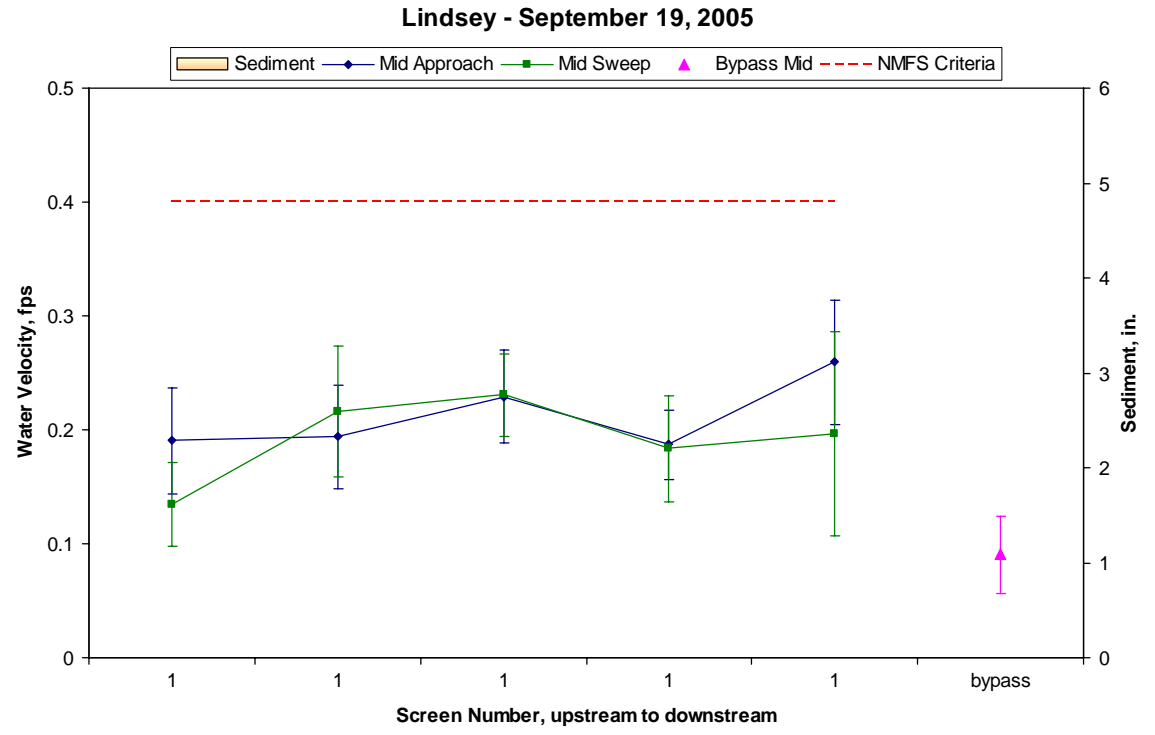

Figure 27. Lindsey water velocities and sediment accumulation, September 2005. Error bars represent turbulence.

\section{Lower Wapato Irrigation Project}

The Lower Wapato Irrigation Project (WIP) site was visited on May 9, June 21, and September 22, 2005. The previous and current water masters for the Wapato Irrigation District said the site was not used at all during the year because water was predicted to be too scarce for this stretch of Ahtanum Creek. Precautions were taken to prevent fish from entering the facility, especially in the spring. In May, boards blocked both the headgate and bypass entrance. This site can have water move up the bypass and into the forebay during higher spring stream flows, and the blocked bypass entrance prevented any possible fish movement into the forebay.

No underwater video or velocity measurements were made during any of our visits to this site this year.

\section{Naches-Cowiche}

The Naches-Cowiche site was evaluated on May 13, June 30, and September 15, 2005. During each of those visits, average sweep was greater than average approach velocities (Figures 28 through 30). Average bypass velocities were greater than average sweep in May and September but not in June, and average sweep did not increase toward the bypass during any survey. Approach values were within the NMFS criterion $95 \%$ of the time at each survey. Bypass flow seemed to move freely over the weir and through the bypass. Because the outfall is in the middle of the river, it can be inspected only when the river is low. The ecology blocks placed around the outfall in 2004 seem to help prevent rocks from blocking the outfall.

Submergence ranged from 77 to $84 \%$, not only during our visits but during most of the season as well, according to the logbook. Additional boards were placed on the diversion dam to maintain submergence during the summer months and were removed by September. A sediment control board was placed in the forebay, again to try to keep sediment away from the screens. This may help explain the 
striking reversal in sweep velocities during all site visits, with sweep higher across the first screen and lower across the second screen. This pattern has been seen before but never so strongly. Another possible cause is the development of a mud mound on the opposite side of the forebay and slightly upstream of the screens. By the end of the summer, this mound had a good stand of cattails and was no doubt affecting flow patterns through the forebay. Northern pikeminnow and chiselmouth were seen around the cattails in June.

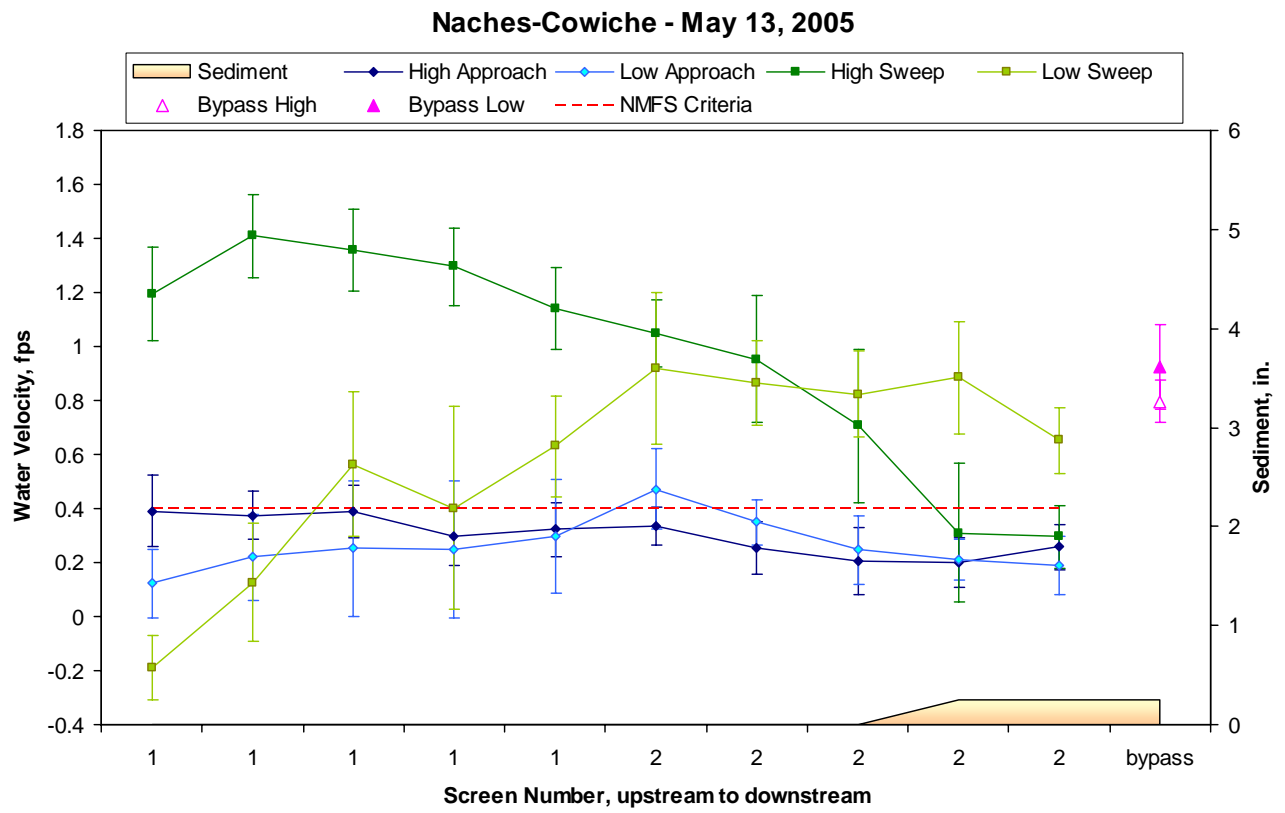

Figure 28. Naches-Cowiche water velocities and sediment accumulation, May 2005. Error bars represent turbulence.

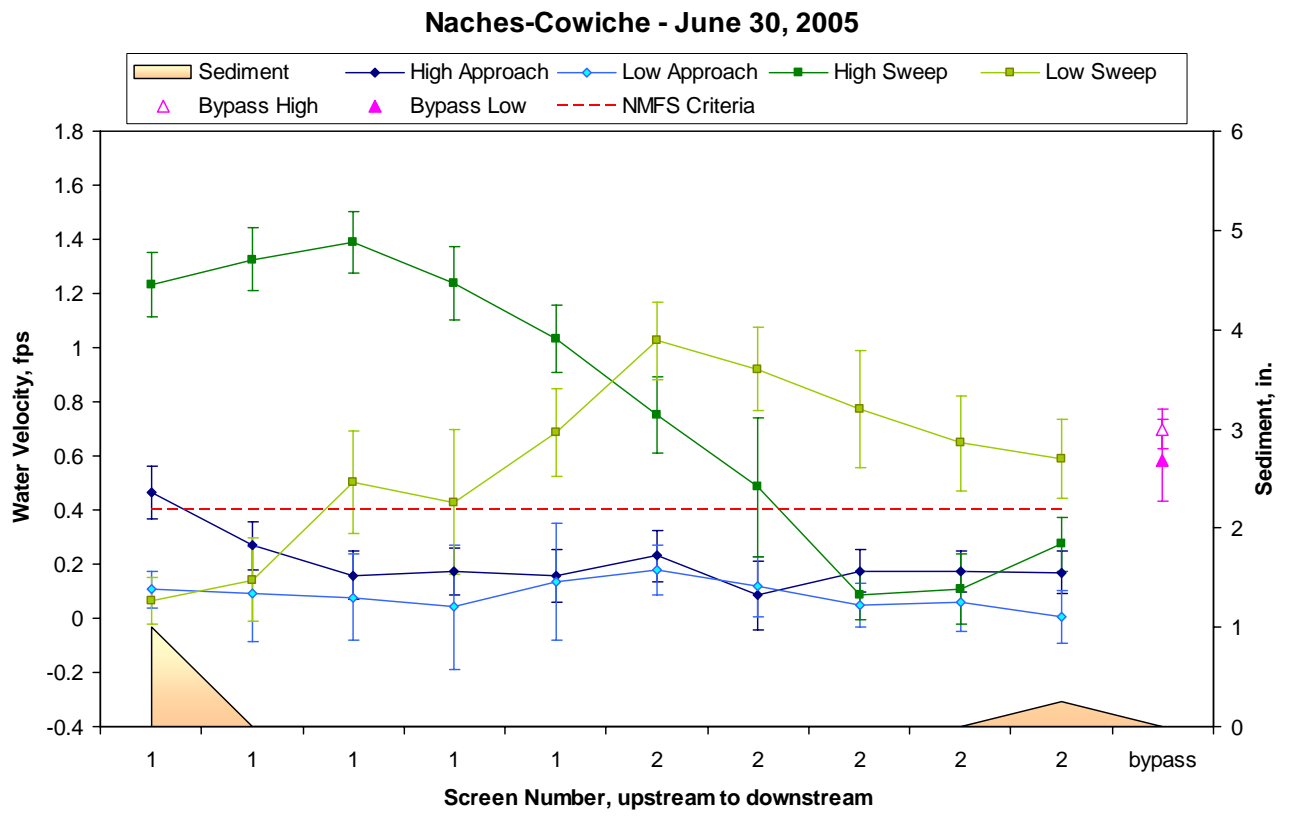

Figure 29. Naches-Cowiche water velocities and sediment accumulation, June 2005. Error bars represent turbulence. 


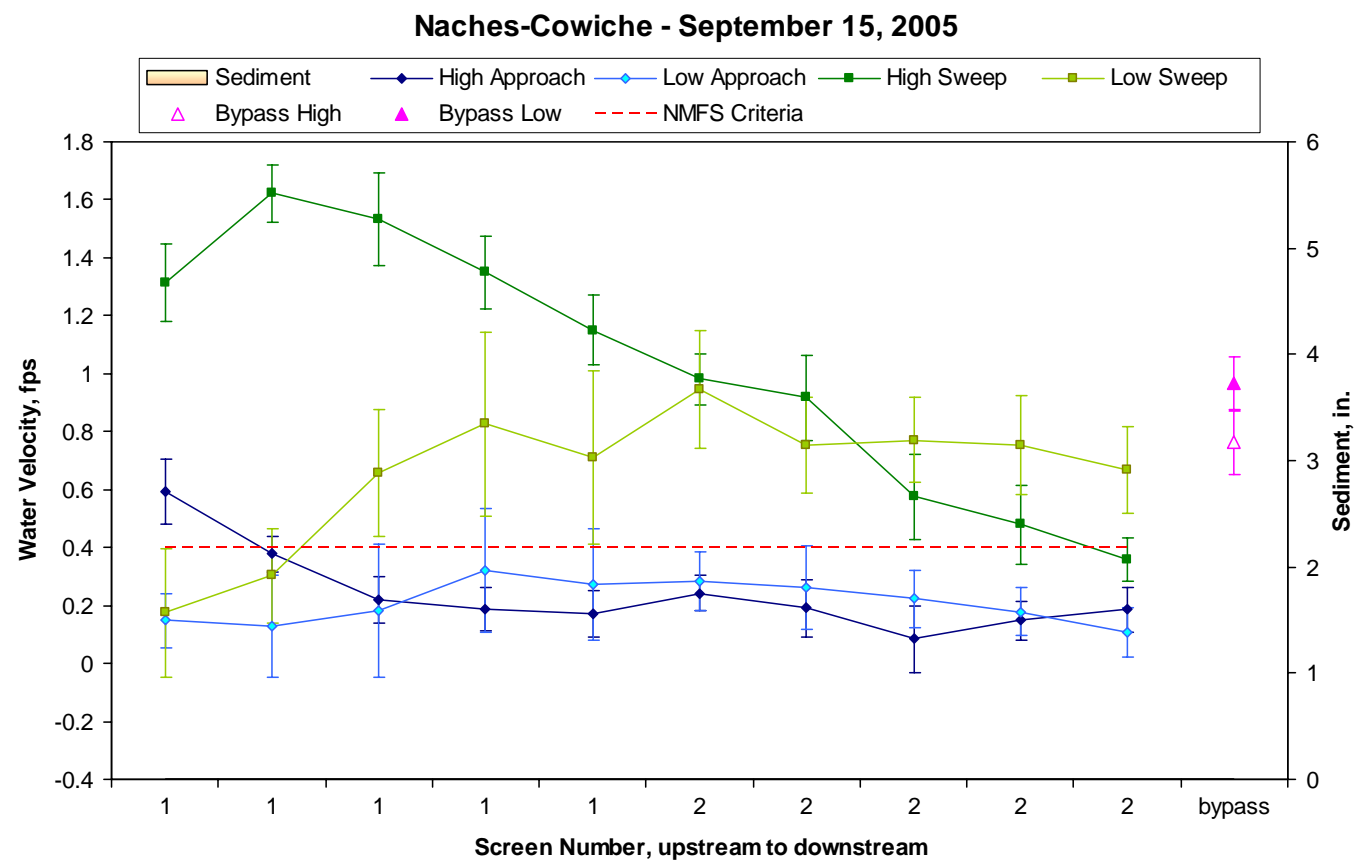

Figure 30. Naches-Cowiche water velocities and sediment accumulation, September 2005. Error bars represent turbulence.

\section{New Cascade}

We evaluated the New Cascade site on May 12, June 29, and September 14, 2005. Approach velocities met the NMFS criterion 100, 95, and 100\% of the time in May through September (Figures 31 through 33). Sweep velocities always were greater than approach velocities. Bypass velocities always were greater than sweep, which did not increase toward the bypass during any of our surveys.

In May, 86\% submergence slightly exceeded the maximum NMFS criterion of 85\%, but submergence in June and September was $84 \%$. Screens and seals were in good condition, and cheeks were caulked. Some of the cheek caulking was still effective but looked like it was starting to deteriorate by September. Screens 2, 6, 7, and 8 turned erratically, but the motors sounded fine and the drums were still effective at moving debris into the canal. Sediment covered parts of the bottom seals in May. The WDFW cleaned out the sediment in June, and only small pockets of sediment were building up at downstream corners by the time we inspected the site on June 29.

As usual, numerous fish were seen at in front of the screens, including juvenile salmonids and adult trout. Some small (3-in.) fish were seen in the aftbay in September, possibly whitefish, as well as a school of 1-in.-long fish in the canal in June. 
New Cascade - May 12, 2005

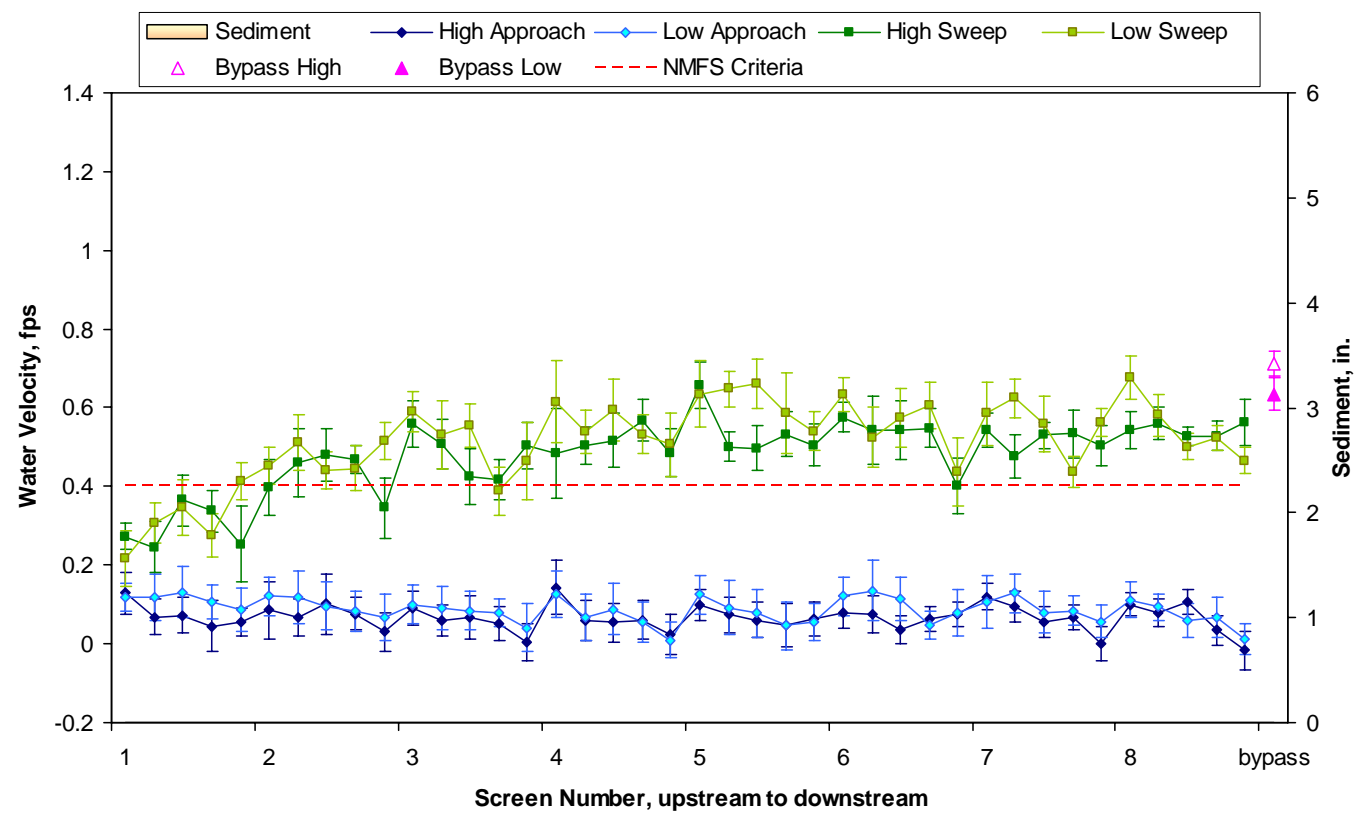

Figure 31. New Cascade water velocities and sediment accumulation, May 2005. Error bars represent turbulence.

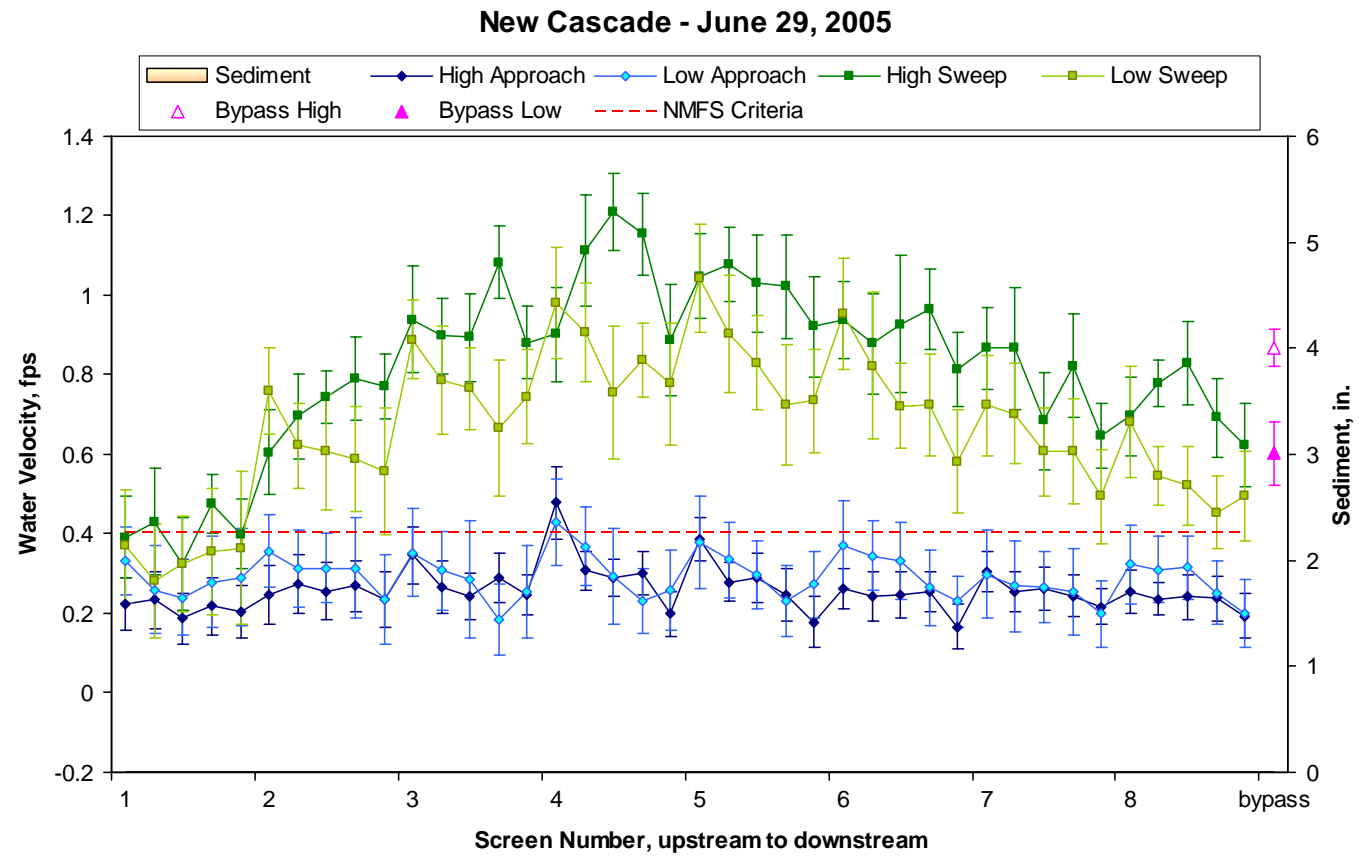

Figure 32. New Cascade water velocities and sediment accumulation, June 2005. Error bars represent turbulence. 


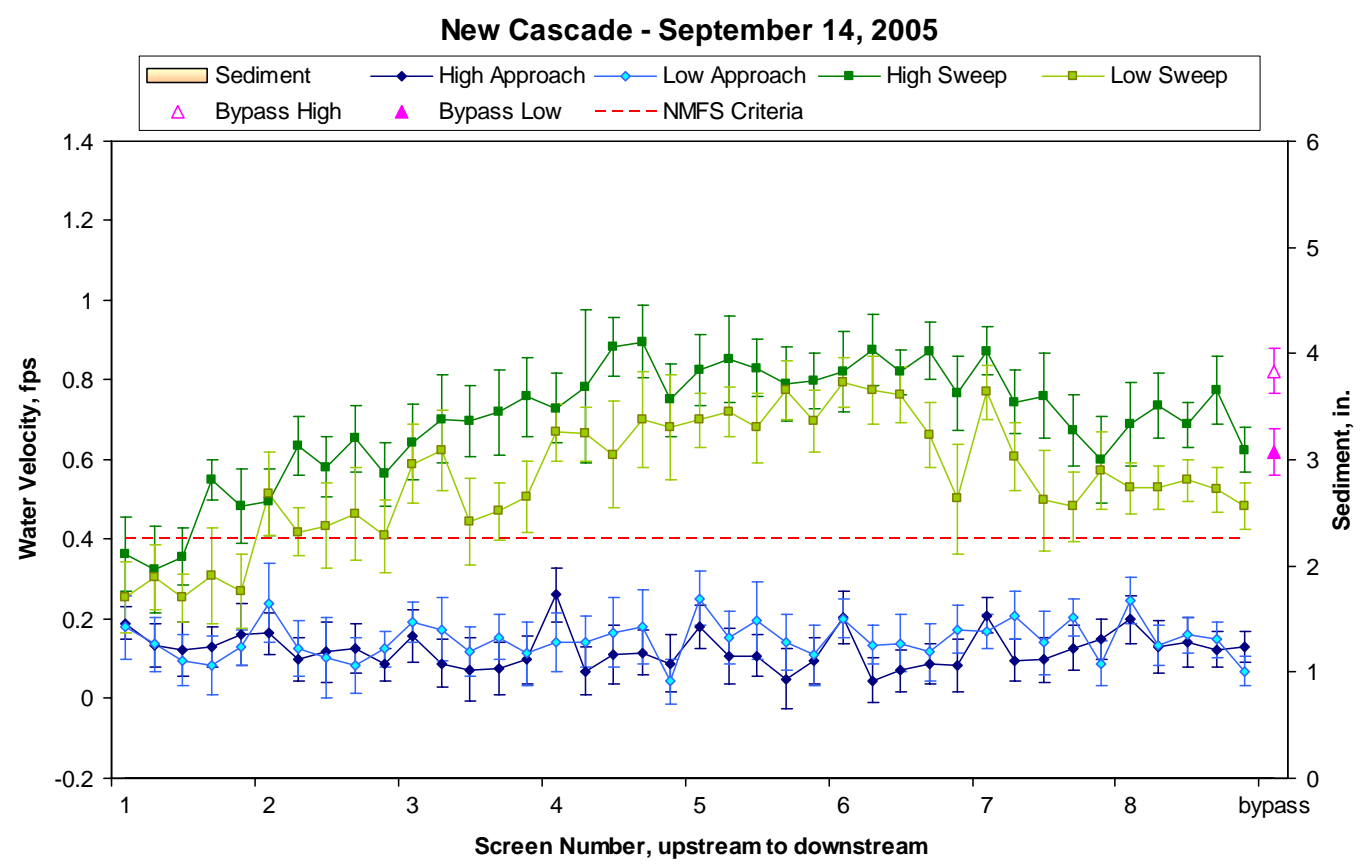

Figure 33. New Cascade water velocities and sediment accumulation, September 2005. Error bars represent turbulence.

\section{Powell-LaFortune}

Powell-LaFortune was visited multiple times in 2005, including May 13, June 28 and 30, July 14, and September 15. Velocity measurements were made in May, on June 28, and again in September. All approach measurements met the NMFS criterion, and sweep was always higher than approach velocities (Figures 34 through 36). Sweep did not increase toward the bypass during any of our evaluations and was higher than bypass velocities in June and September.

Submergence was at 75, 68, 54, 84, and 68\% in May, June, July, and September. On June 30, there was about $1 \mathrm{ft}$ of head loss across the upstream trash rack, as well as a fair amount of debris on the downstream trash rack adjacent to the screens (Figure 37). This blocked flow to the site enough that it caused low submergence and no bypass flow. The irrigation district is supposed to remove trash from the trash racks, but this does not happen often enough to ensure consistent, adequate flow for bypass and submergence. WDFW personnel often clear the trash racks when they do maintenance at the site, just to keep the site in working order. We notified the WDFW of the problem on July 1 . The agency cleaned the trash racks, and bypass flow and submergence were good on July 14 when we checked the site again.

Debris removal at the upstream trash rack has been a problem since the site was put into operation. A lot of vegetation as well as debris and garbage are caught there. The vertical bars of the trash rack are closely spaced. It may be possible to redesign the trash rack to let some of the vegetation and smaller debris pass through, to be caught on the facility trash rack. We recommend considering alternative trash rack designs and working with the irrigation company personnel to improve debris removal.

Screens and seals looked good during all surveys, and the cheeks were all caulked. The last drum screen motor was rather noisy, and there was a sheen of oil around it in May, but it seemed to turn smoothly. This was fixed before our June inspection. 


\section{Powell-LaFortune - May 13, 2005}

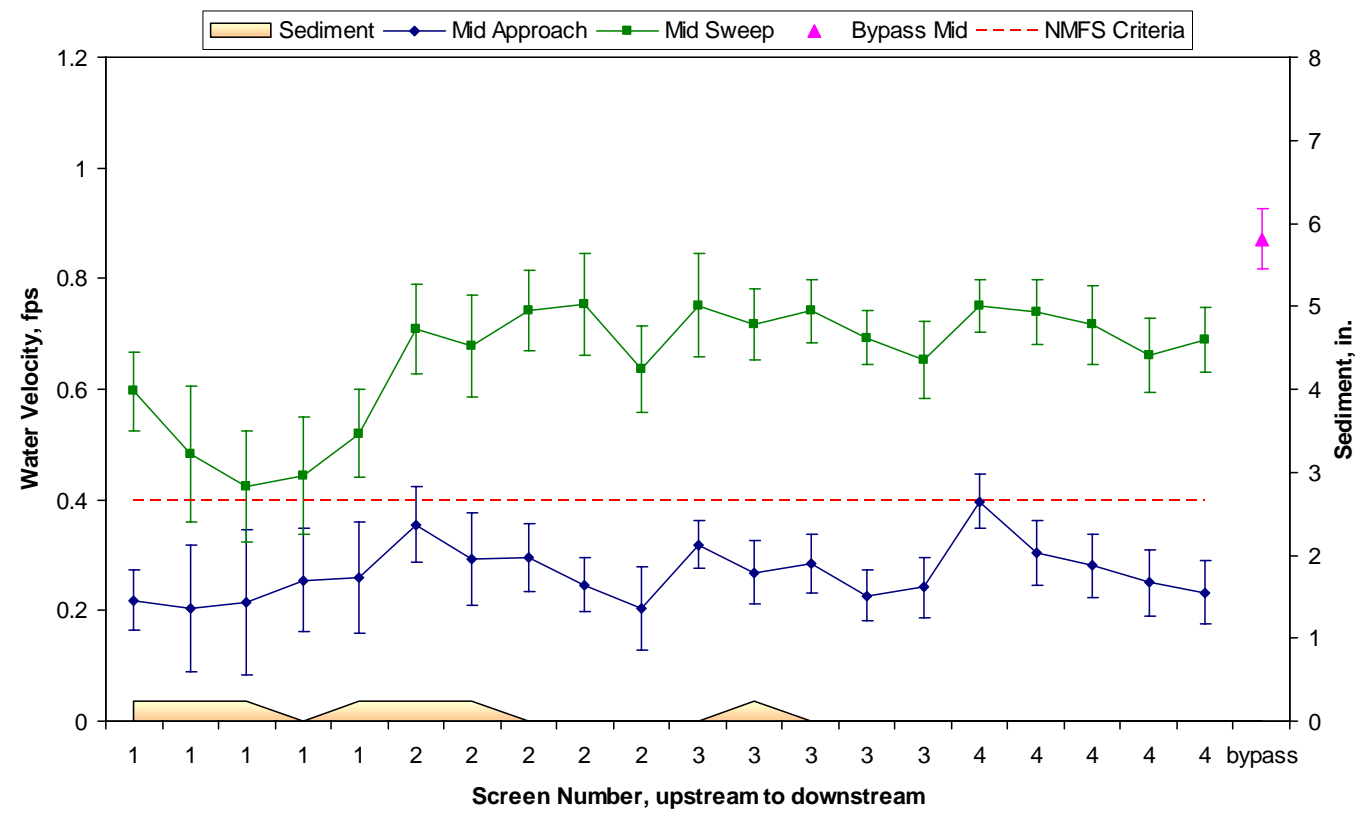

Figure 34. Powell-LaFortune water velocities and sediment accumulation, May 2005. Error bars represent turbulence.

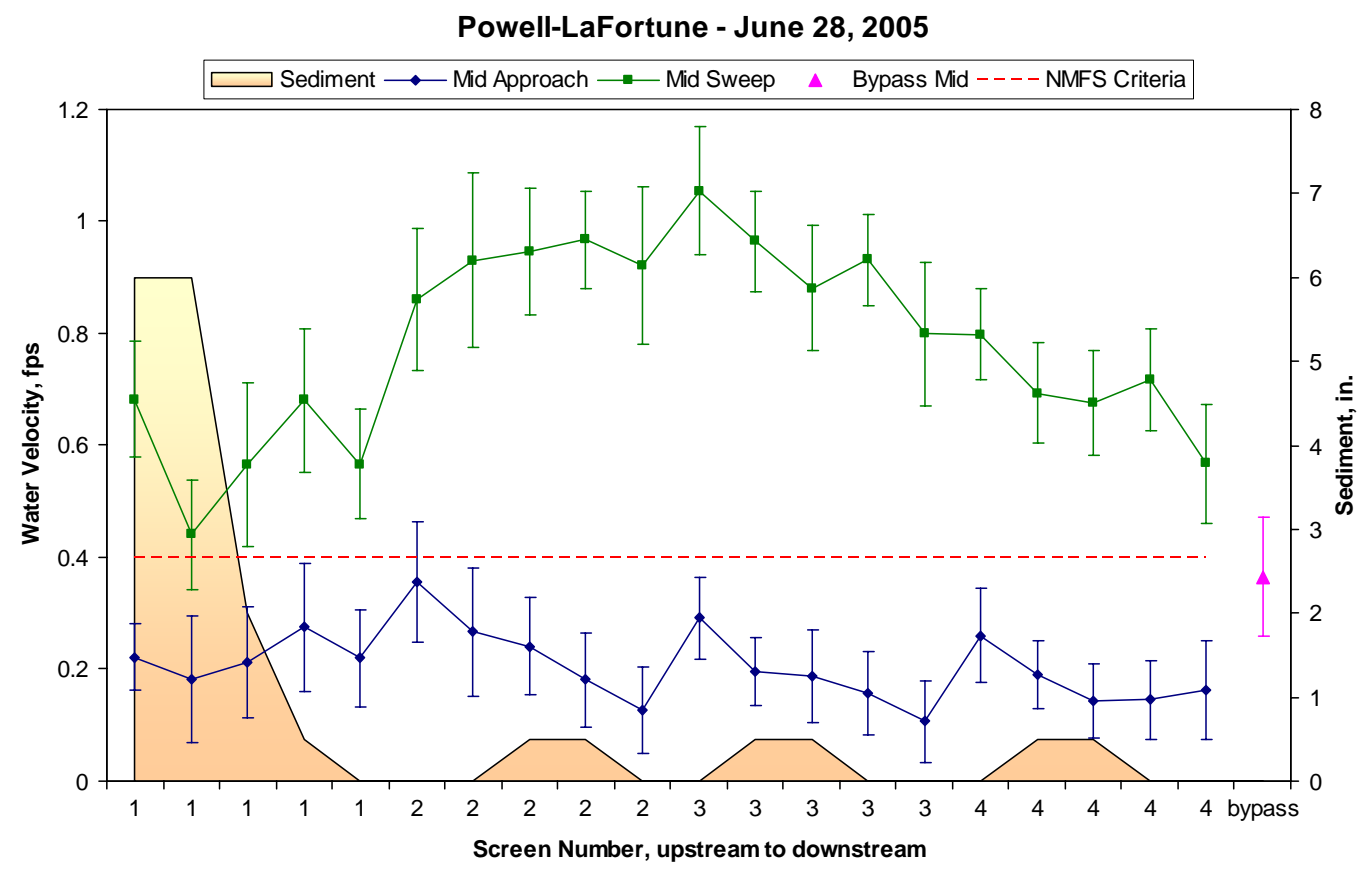

Figure 35. Powell-LaFortune water velocities and sediment accumulation, June 2005. Error bars represent turbulence. 
Powell-LaFortune - September 15, 2005

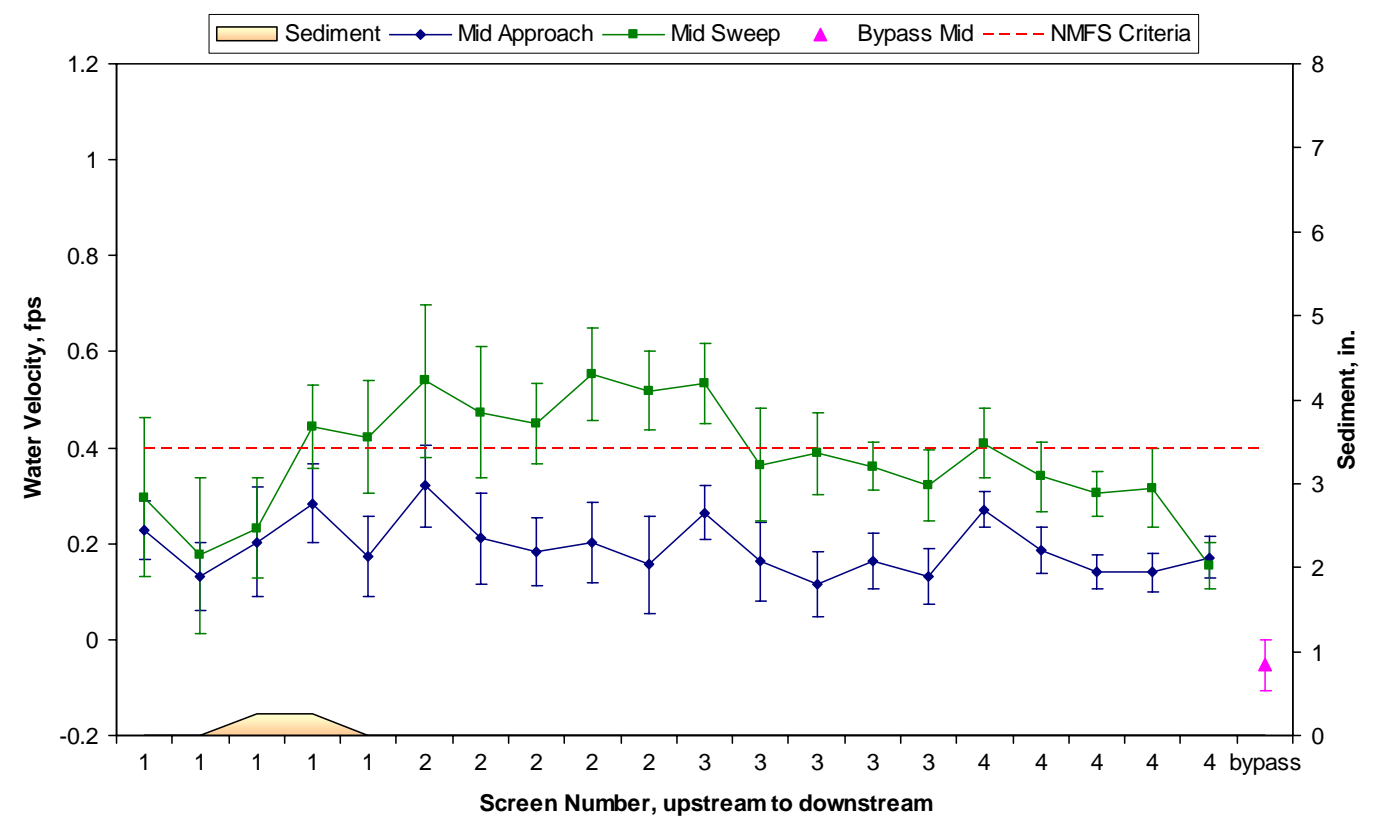

Figure 36. Powell-LaFortune water velocities and sediment accumulation, September 2005. Error bars represent turbulence.

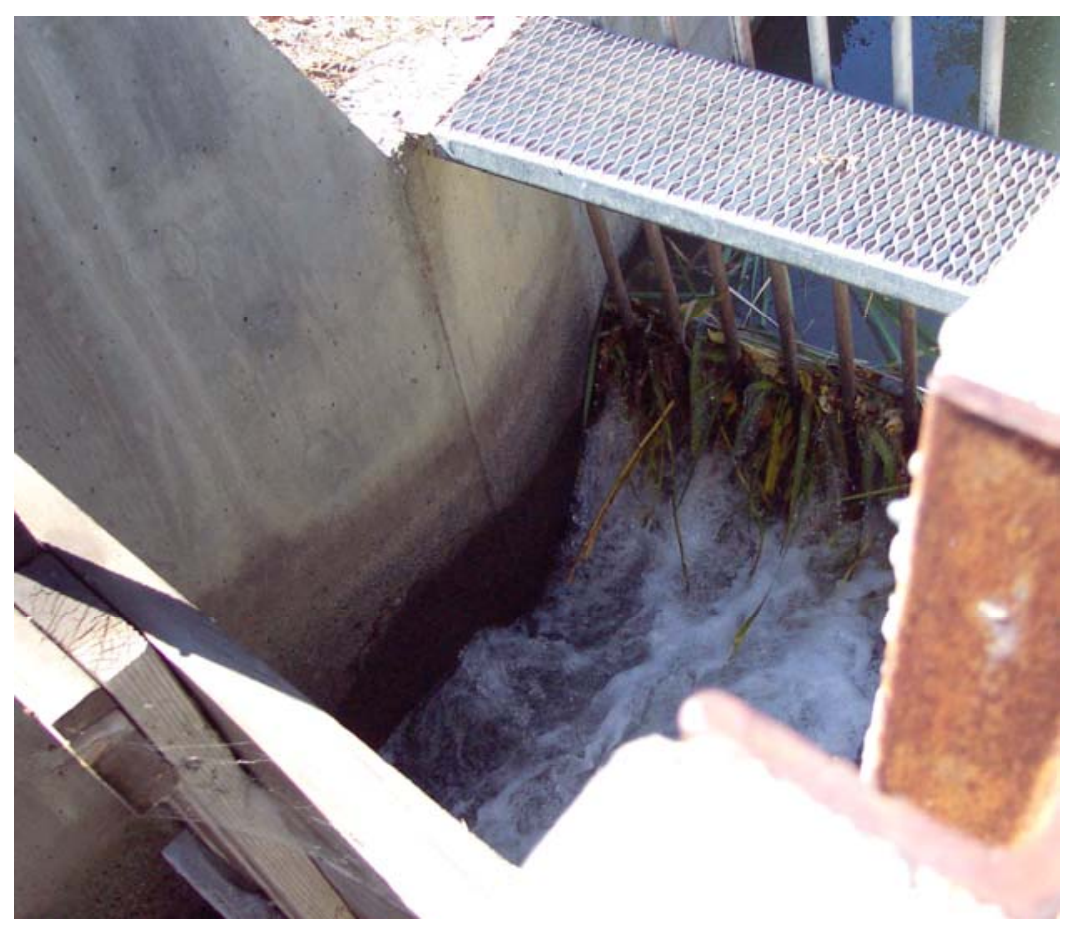

Figure 37. Upper trash rack at Powell-LaFortune partly blocked with debris. Approximately 12 in. of head loss are visible. 


\section{Snipes-Allen}

The Snipes-Allen site was inspected on May 5, June 21, and September 20, 2005. All approach velocities were below $0.4 \mathrm{fps}$, and bypass velocities always were higher than the average sweep velocities, meeting NMFS criteria (Figures 38 through 40). Sweep velocities increased toward the bypass in June and September (slightly) but not in May. Sweep was greater than approach in May and September, but approach was higher in June until the middle of the second screen.

Submergence was within the criterion during each of our visits, at 70, 77, and 83\% from May through September. Debris and sediment had built up in front of the second screen by June but was not covering the bottom seal. Seals and screen condition were good, and the cheeks were caulked.

Water moved freely through the bypass into the outfall channel. The outfall channel had more than $1 \mathrm{ft}$ of water during each of our surveys. Bypass conditions were conducive to safe fish passage during all surveys.

One interesting note was the growth of what are apparently sponges on the bottom framework for the drums (Figure 5). These were observed in 2004 but have grown noticeably since then. These should probably be removed before they impact flow patterns and seals.

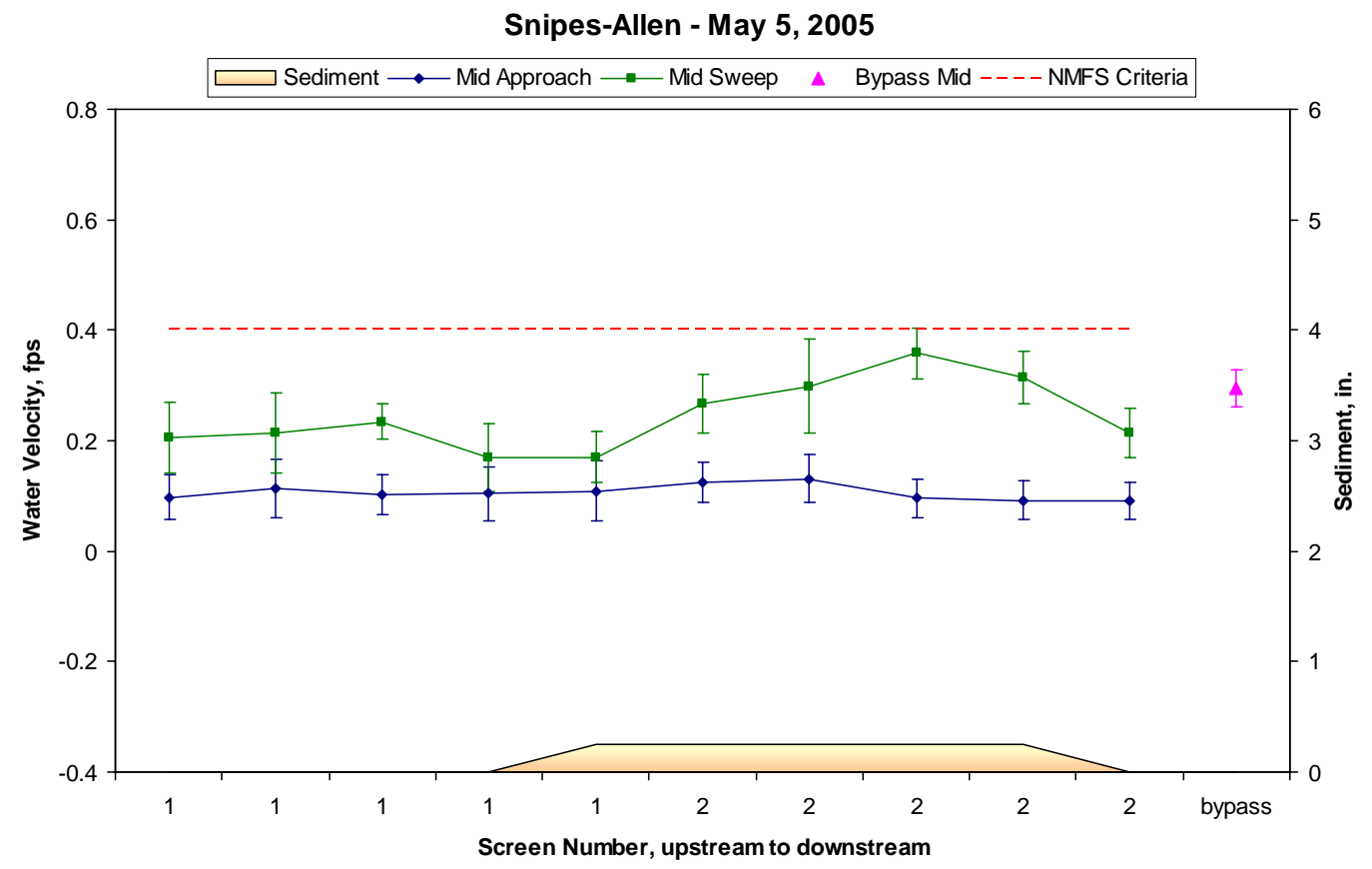

Figure 38. Snipes-Allen water velocities and sediment accumulation, May 2005. Error bars represent turbulence. 


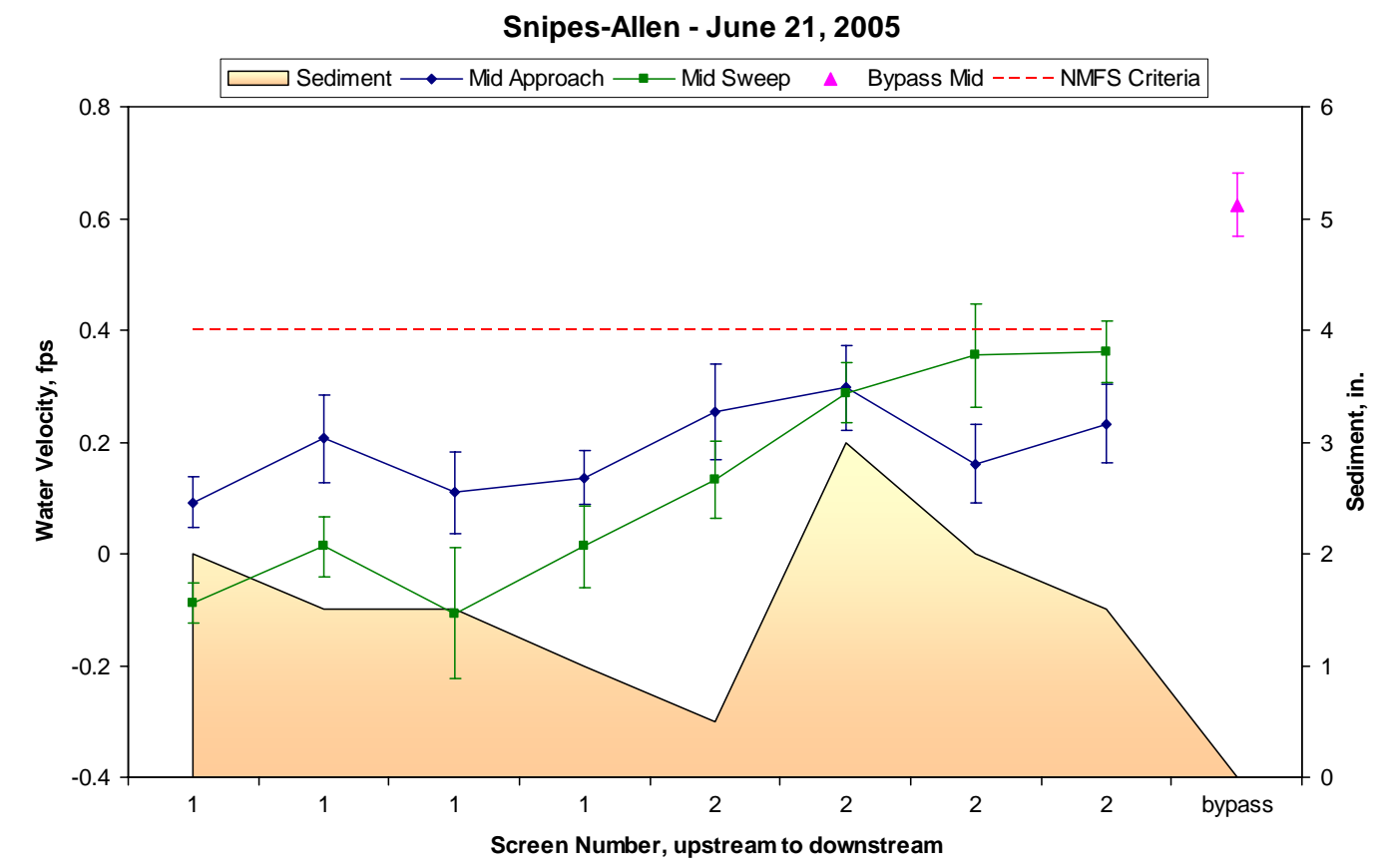

Figure 39. Snipes-Allen water velocities and sediment accumulation, June 2005. Error bars represent turbulence.

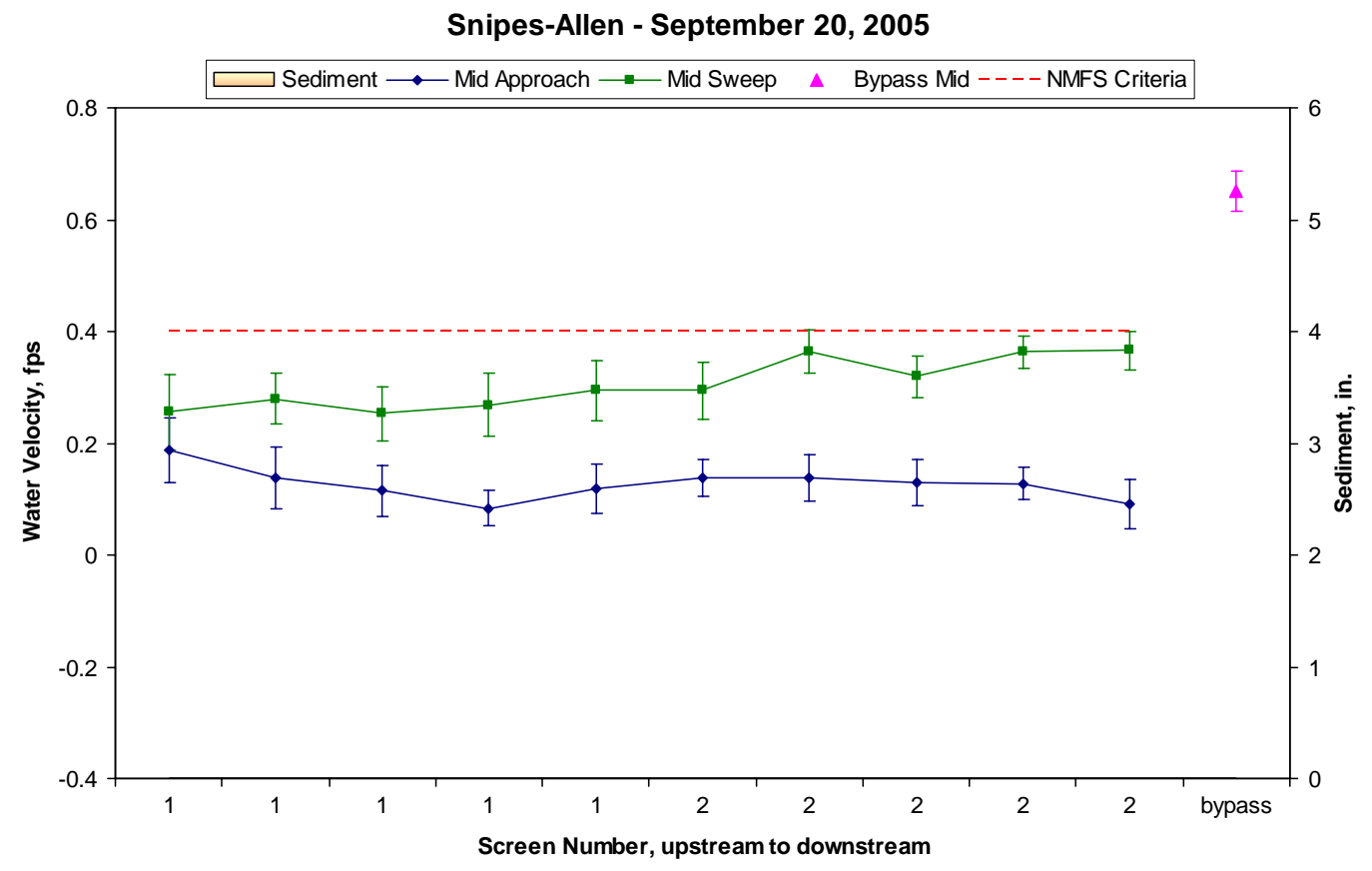

Figure 40. Snipes-Allen water velocities and sediment accumulation, September 2005. Error bars represent turbulence. 


\section{Taylor}

The Taylor site was not operating effectively during any of the inspections on May 19, June 20, or September 19, 2005. The main river channel has shifted to the far side of the river bed. A gravel dam was pushed up several different times in 2005 in an effort to improve flow to the Taylor headworks but was partly washed out each time. The site did not have adequate water during any of our surveys with submergence at 20\%, 55\%, and 50\% in May, June, and September respectively. There was an improvement in water entering the forebay in September, due in part to repairs made to reduce leakage around an overflow weir just upstream of the fish screen headgate.

There was no bypass flow during any of our visits. Flow through the bypass was controlled by boards near the bypass entrance, and the ramp and flushgate were left in the open position. The WDFW raised the boards periodically to allow fish to move out through the bypass. However, the bypass channel this year was overgrown with grass, very shallow near the river, and may not have provided safe passage for fish at such low river flows (Figure 41). Because the river channel shifted, the area at the mouth of the outfall channel is also much more likely to have inadequate water levels. Without enough water in the outfall channel, any fish flushed into the channel may not have been able to swim out to the river.

Velocity measurements were not made in May due to low water levels and little flow. Sweep was almost always less than the approach values, although in September, 2 of the 10 sweep values were greater than the approach (Figures 42 and 43). Submergence did not meet the NMFS criterion during any of our visits, although the logbook indicates there were periods in late April and early May when the gravel dams were new and submergence was good. In May, several small dead and dying fish were observed in the forebay. The dying fish were not salmonids and appeared to be diseased.

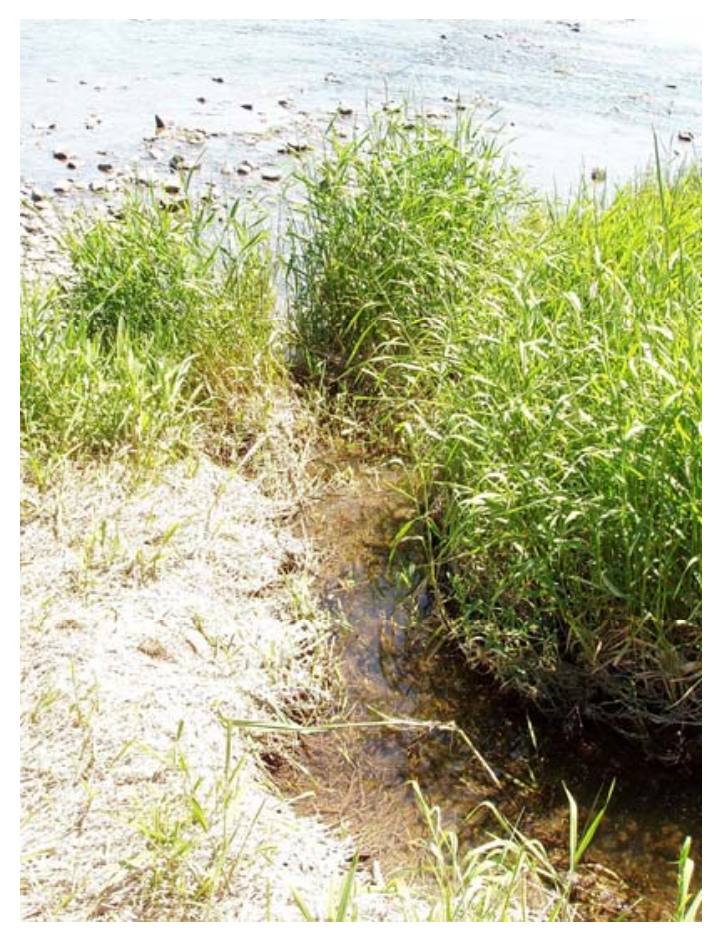

Figure 41. Taylor outfall channel and the river beyond it in June 
Taylor - June 20, 2005

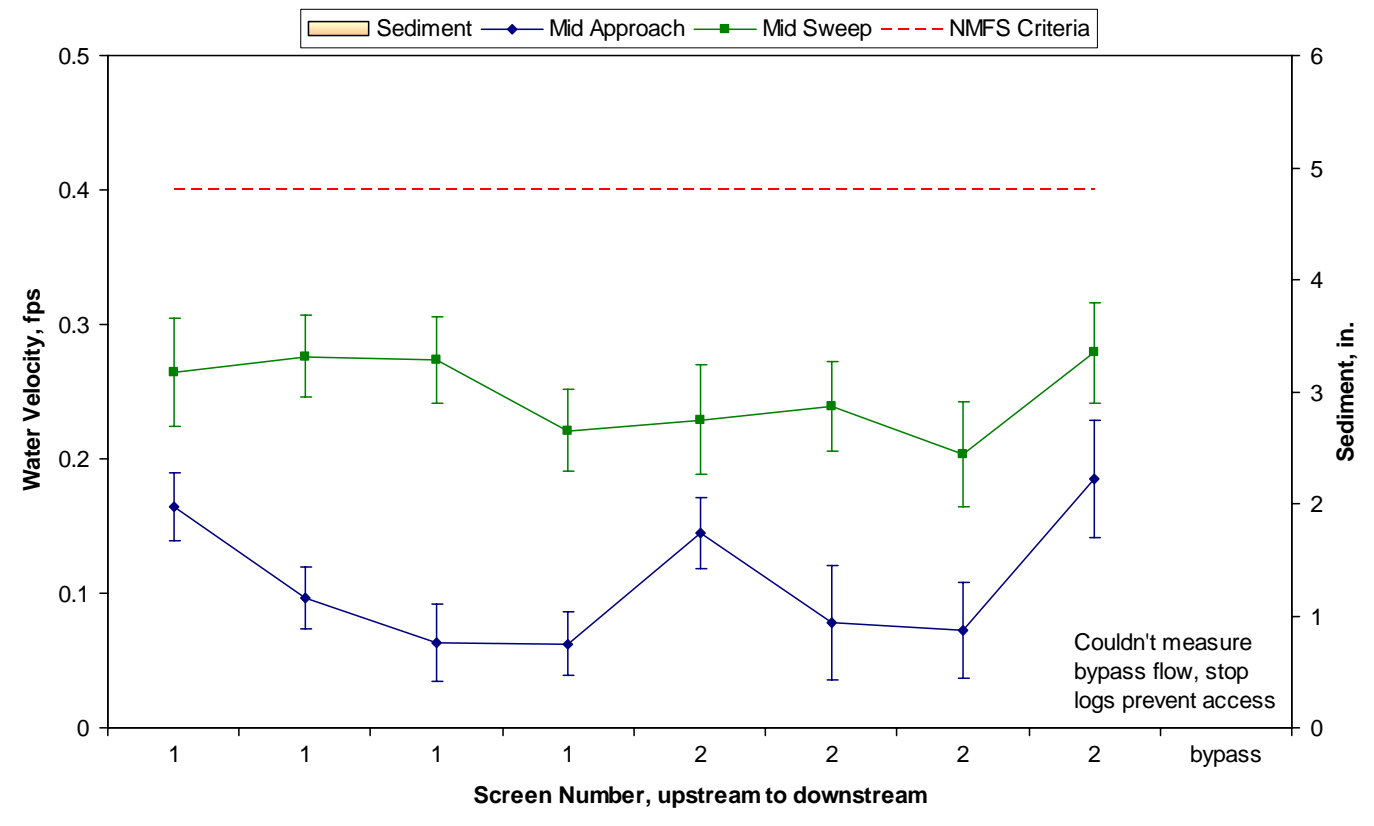

Figure 42. Taylor water velocities and sediment accumulation, June 2005. Error bars represent turbulence.

Taylor - September 19, 2005

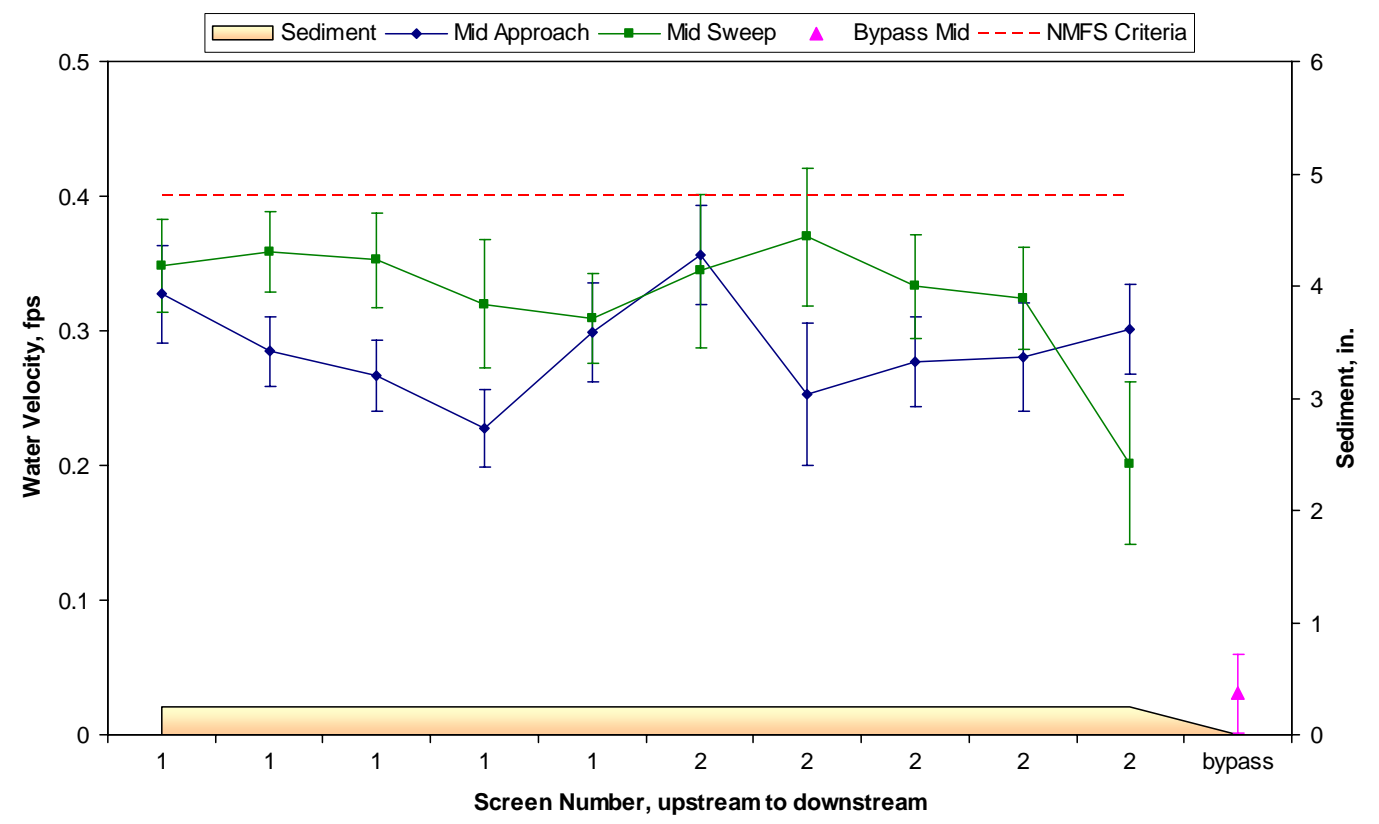

Figure 43. Taylor water velocities and sediment accumulation, September 2005. Error bars represent turbulence. 


\section{Toppenish Pump}

We visited the Toppenish Pump fish screen facility on May 17, June 24, and September 13, 2005. Velocity measurements showed sweep increased toward the bypass in May and September, although not in June (Figures 44 through 46). Bypass velocities always were greater than average sweep velocities. Sweep velocities were also greater than approach velocities except at the upstream end of the site. A large eddy at the upstream end of the facility causes approach values to be significantly higher than sweep for part or all of the first drum. The eddy also drops substantial debris in front of the first screen.

Submergence met the NMFS criterion in May and June (83\% and 76\%) but was slightly lower (62\%) than the criterion of $65 \%$ in September. Screen condition was good, with moderate to heavy algae and periphyton buildup in places, an indication that the bottom seals may not fit tightly against the screens anymore. A small outward bow in the upstream seal of screen 5 was noticed; otherwise, side seals were in good condition. Cheeks have not been caulked here, and some of the gaps between the cement and drum frame are $1 / 2 \mathrm{in}$. wide. We would recommend caulking these gaps to prevent impingement of juvenile fish.

Debris at the upstream corner of screen 1 was excessive, with up to 12 in. of sticks, plant fragments, and mud. The rest of the site had very little debris, which is an improvement over previous years. Sponges noticed along the drum frames in 2004 had grown appreciably by June 2005 (Figure 5). These should probably be removed to prevent impact to flow patterns and possibly to seals.

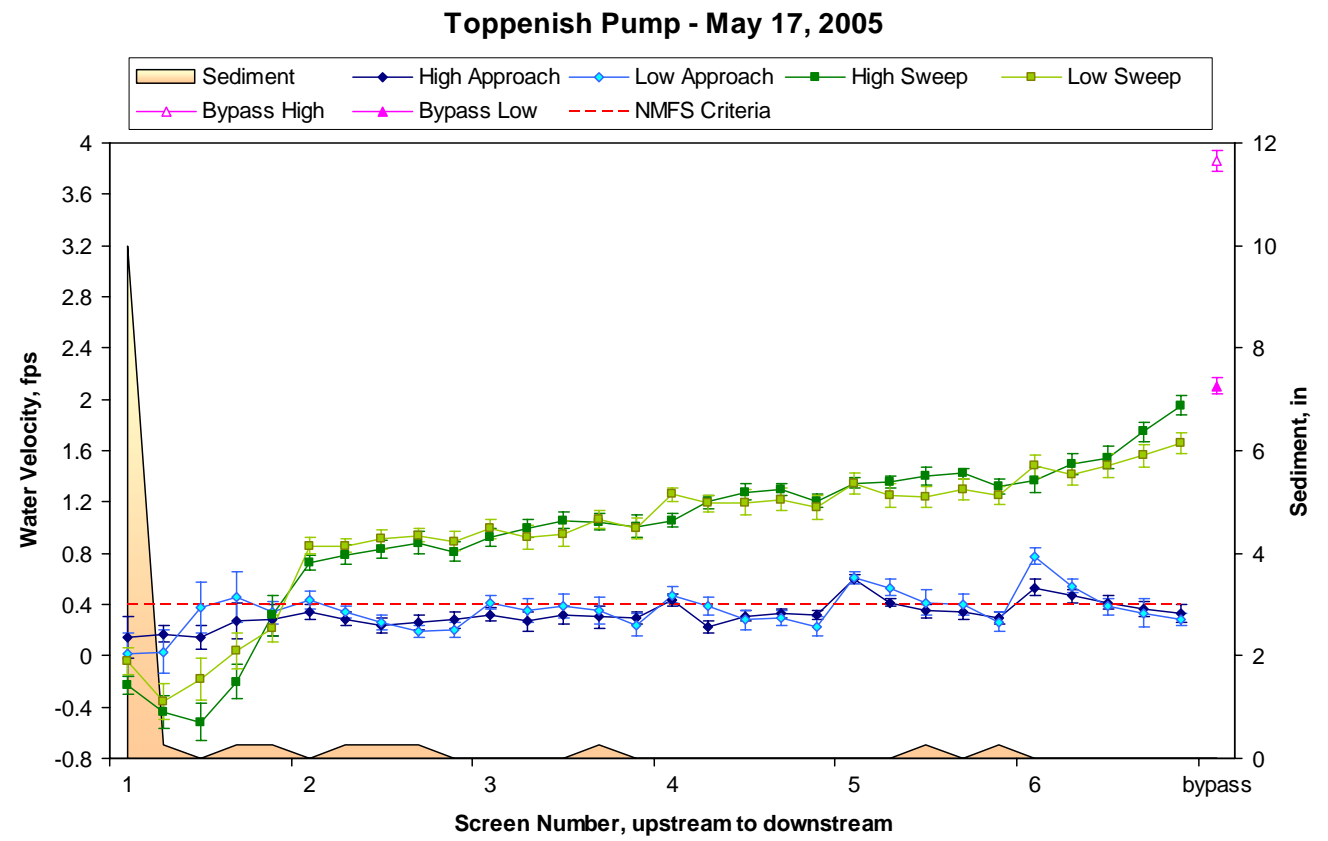

Figure 44. Toppenish Pump water velocities and sediment accumulation, May 2005. Error bars represent turbulence. 


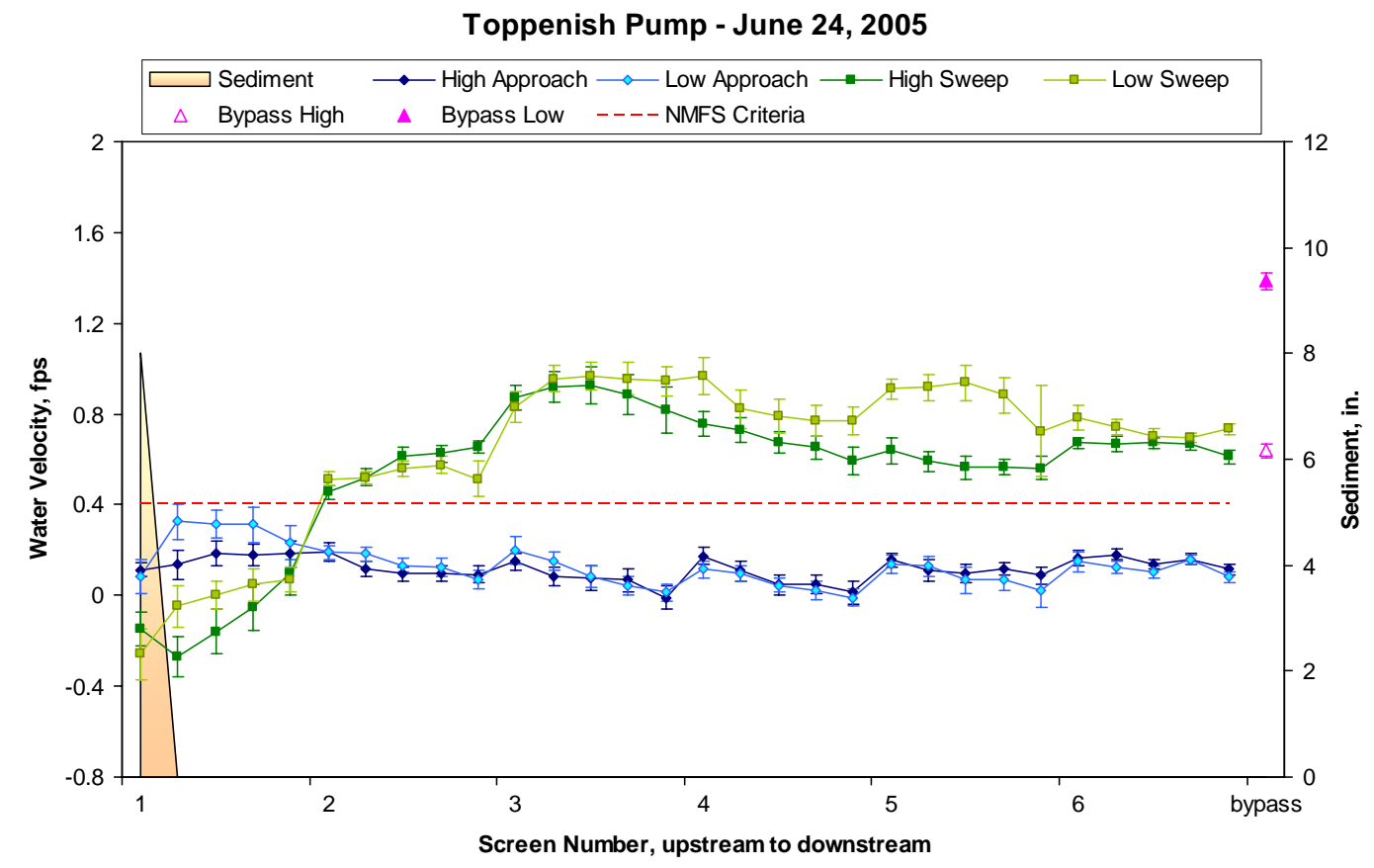

Figure 45. Toppenish Pump water velocities and sediment accumulation, June 2005. Error bars represent turbulence.

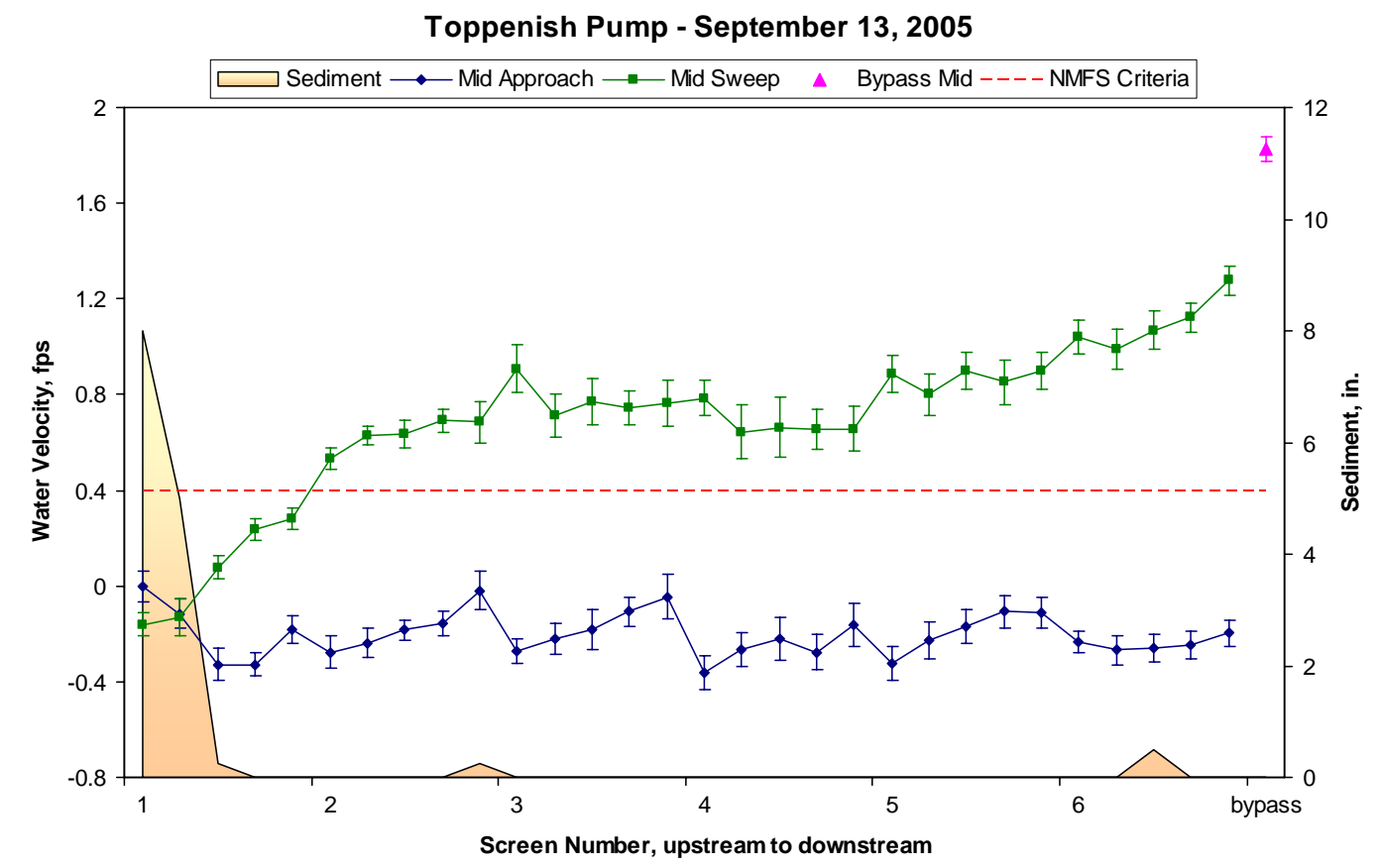

Figure 46. Toppenish Pump water velocities and sediment accumulation, September 2005. Error bars represent turbulence. 


\section{Upper Wapato Irrigation Project}

The Upper Wapato Irrigation Project (WIP) site was evaluated on May 17, June 21, and September 22, 2005. The site was shut down for the season before our visit in September. As can be seen in Figures 47 and 48, sweep velocities always were greater than approach values, and bypass velocity always was greater than sweep velocities. In May, sweep decreased toward the bypass. In June, however, the sweep increased slightly toward the bypass. Bypass flow was adequate, and the water depth at the outfall was greater than $1 \mathrm{ft}$ during our surveys.

Because of anticipated low river flows, the ramp and weir were removed from the bypass, and checkboards were used instead at the entrance to the bypass, with water flowing over, under, and between the boards. Submergence was at 55\% in May and 65\% in June. Screens were in good condition. In June, an outward bow was noticed in the downstream side seal of the second screen, and the seal was replaced by the USBR in August.

Cheeks had not been caulked in the past, but in September we found they had all been caulked during fall maintenance. This caulking prevents small fish from becoming wedged in the gap. Several fish were seen in June, including one rainbow trout and one juvenile salmonid.

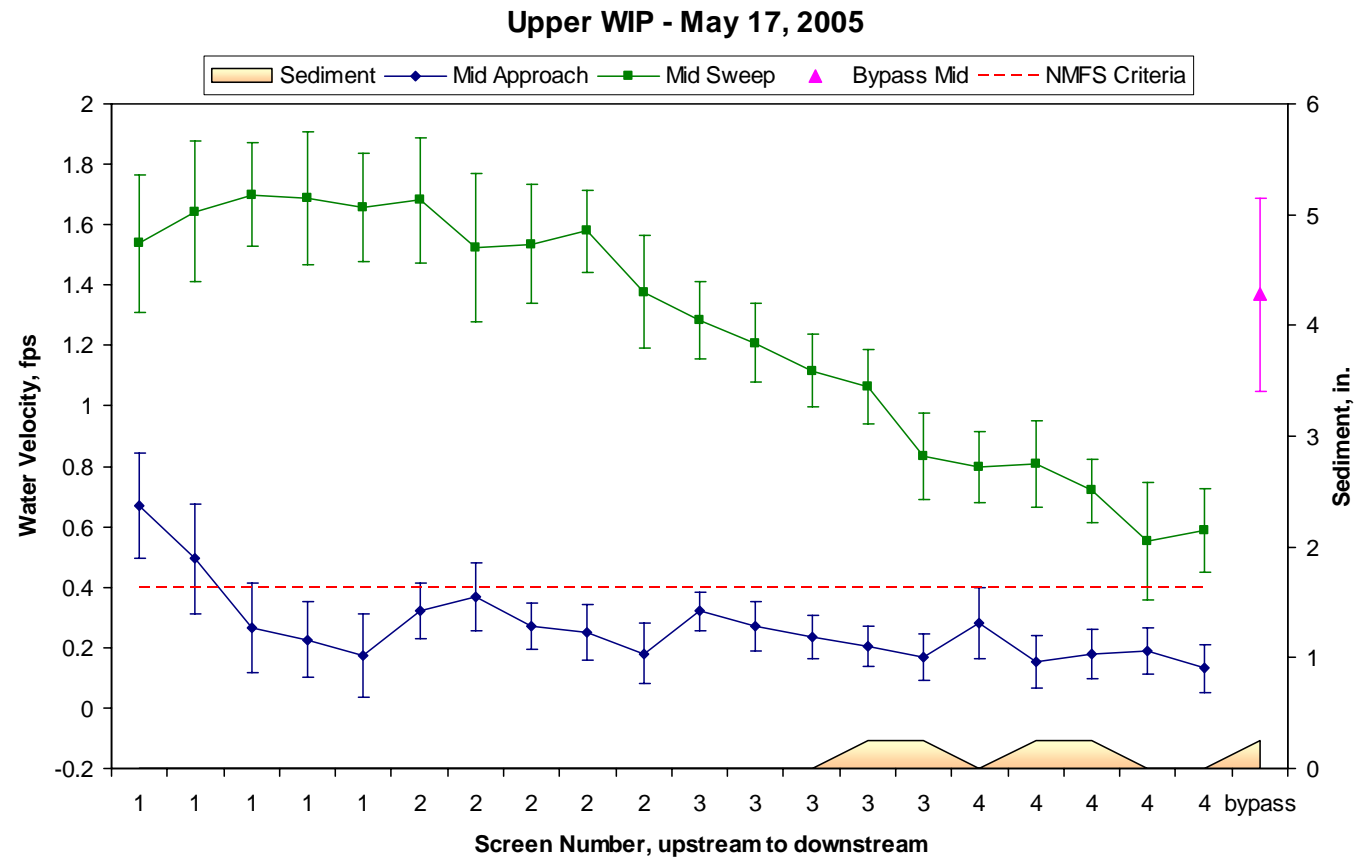

Figure 47. Upper WIP water velocities and sediment accumulation, May 2005. Error bars represent turbulence. 


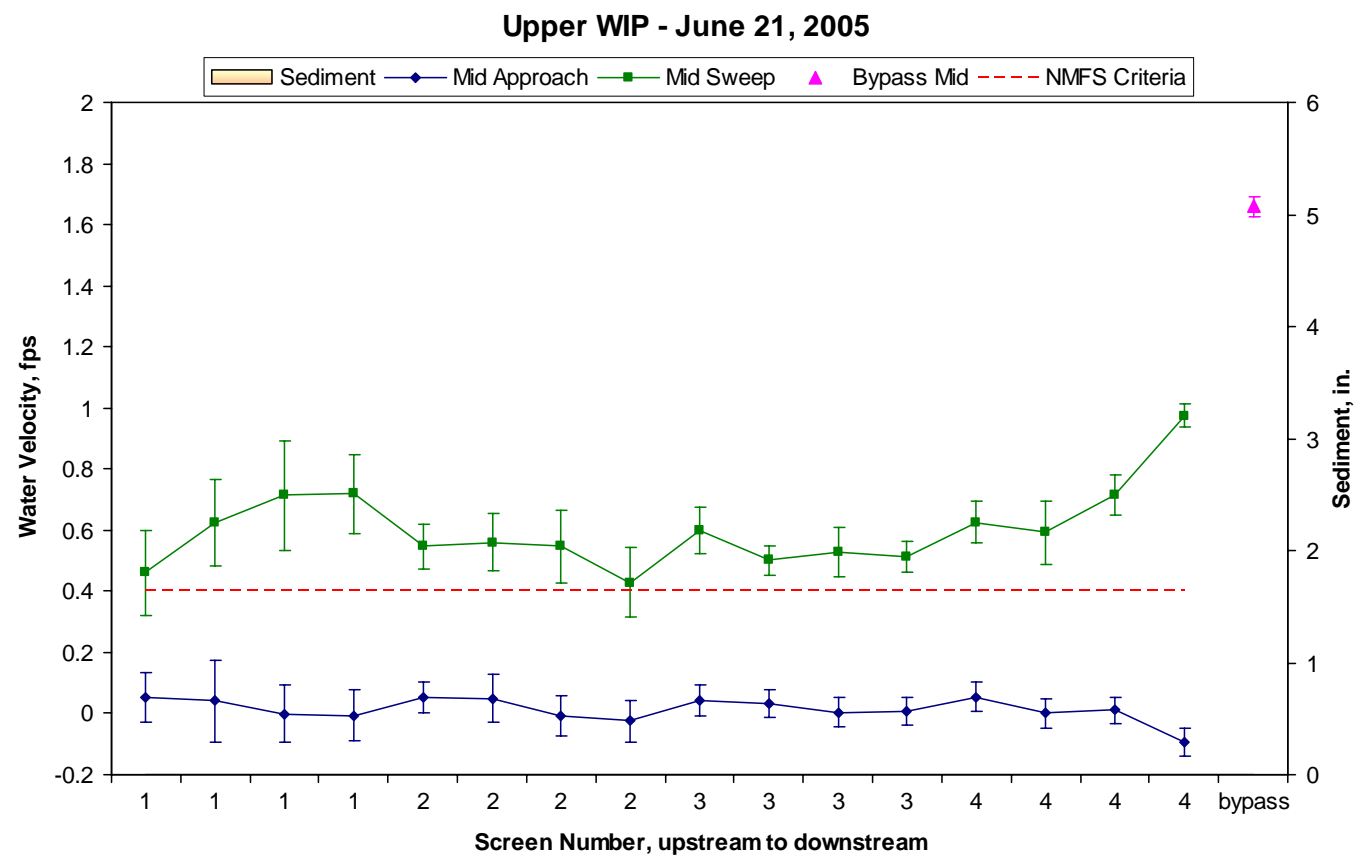

Figure 48. Upper WIP water velocities and sediment accumulation, June 2005. Error bars represent turbulence.

\section{Wilson Creek}

The Wilson Creek fish screen site was evaluated on May 12, June 29, and September 14, 2005. In May and June, sweep velocities were greater than approach velocities, increased slightly toward the bypass, and were less than the bypass velocities (Figure 49). Approach velocities and submergence met NMFS criteria during both surveys. In September, however, all flow through the head channel was moving through the screens, with no flow through the bypass, fish ladder, or checkdam. This led to a negative value for the bypass flow as water eddied into the bypass entrance and back out again. Submergence was only 55\% in September. We contacted WDFW staff about the low water at this site, which they thought was just low water levels in general and could not be changed.

Screen and seal condition was good during all surveys. Caulking along the cheeks was still functionals but is starting to deteriorate in places. Bypass conditions were conducive to the safe passage of fish in May and June. There was much less plant debris accumulation in the forebay this year compared to previous years. 


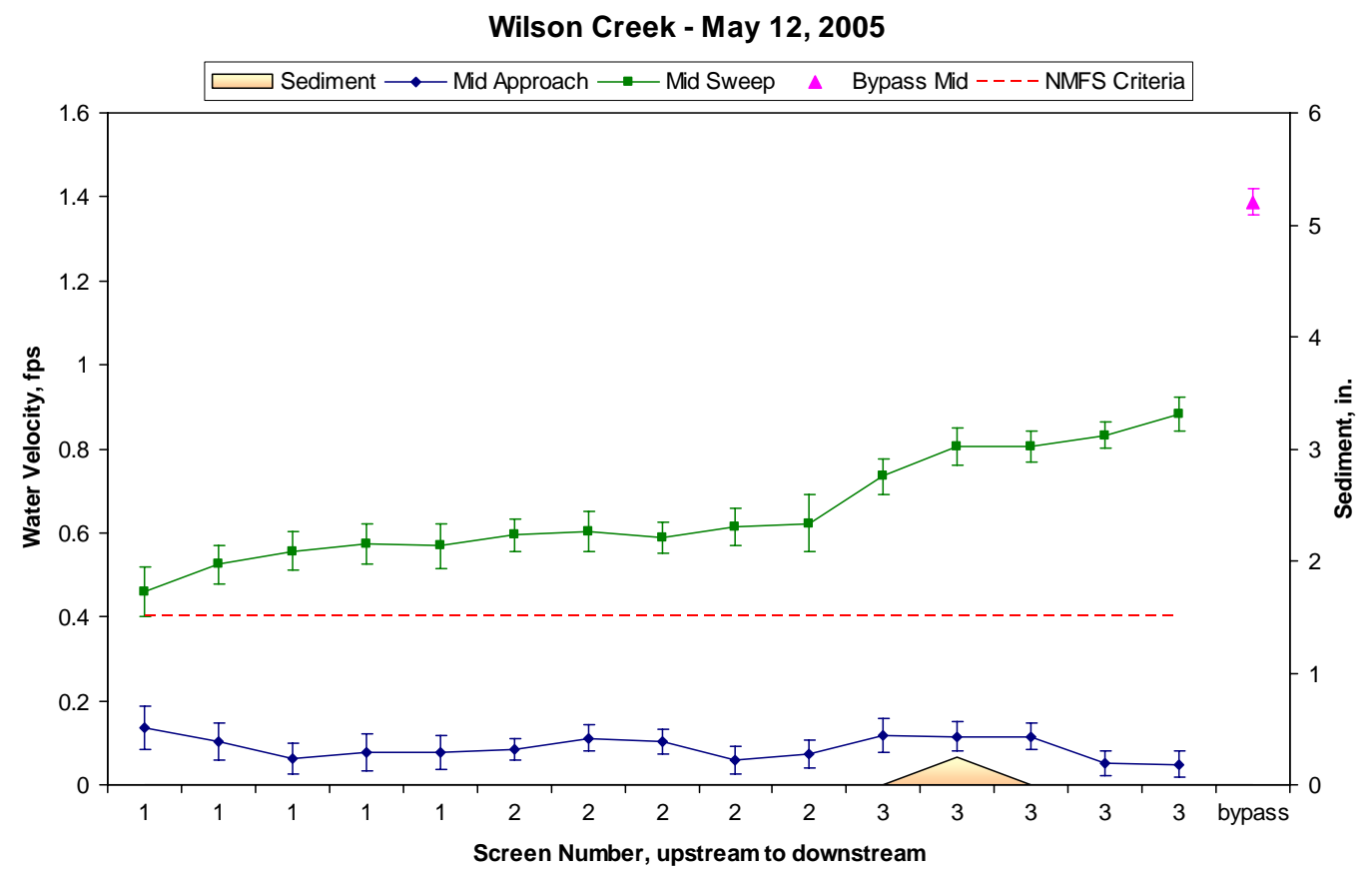

Figure 49. Wilson Creek water velocities and sediment accumulation, May 2005. Error bars represent turbulence.

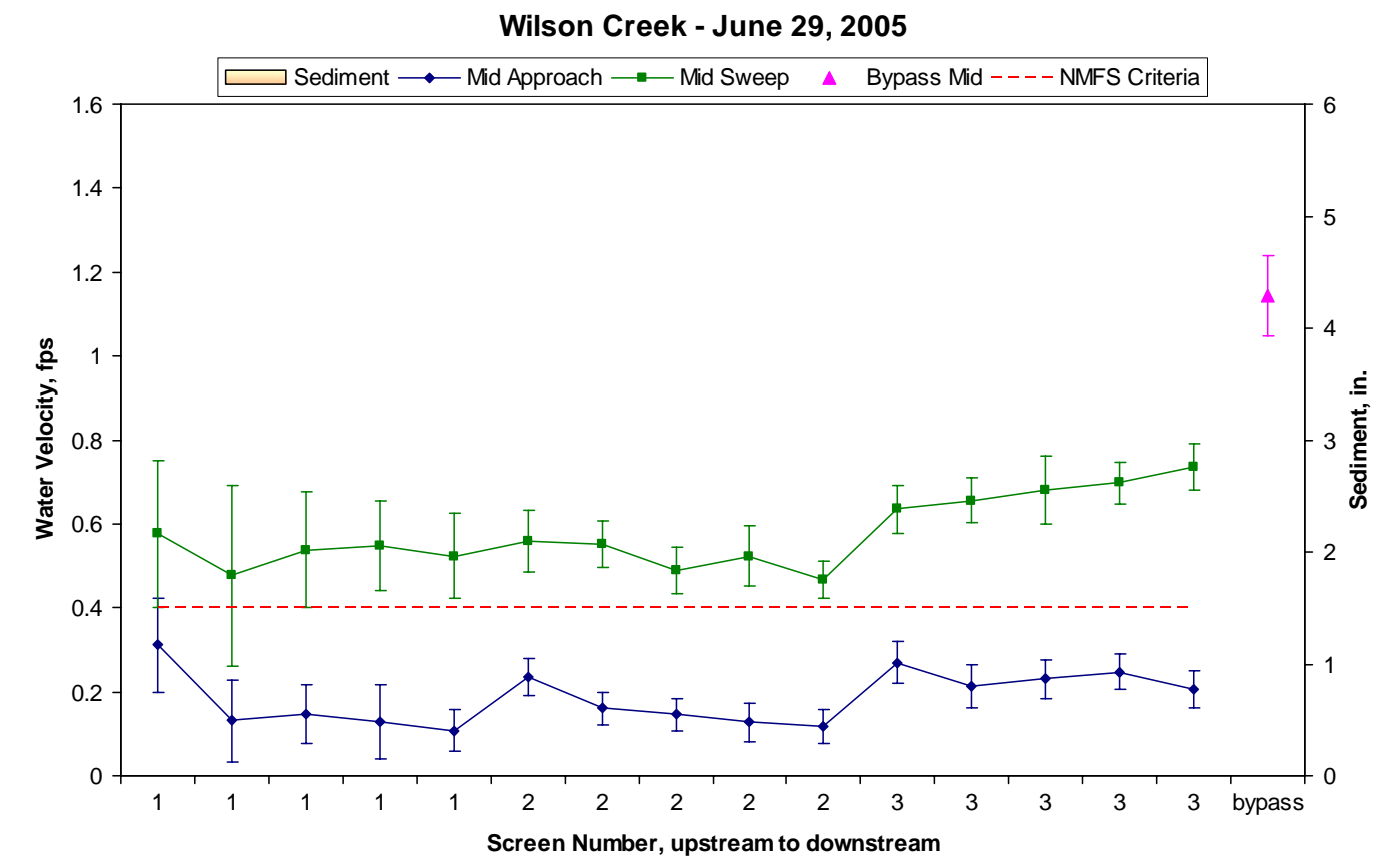

Figure 50. Wilson Creek water velocities and sediment accumulation, June 2005. Error bars represent turbulence. 


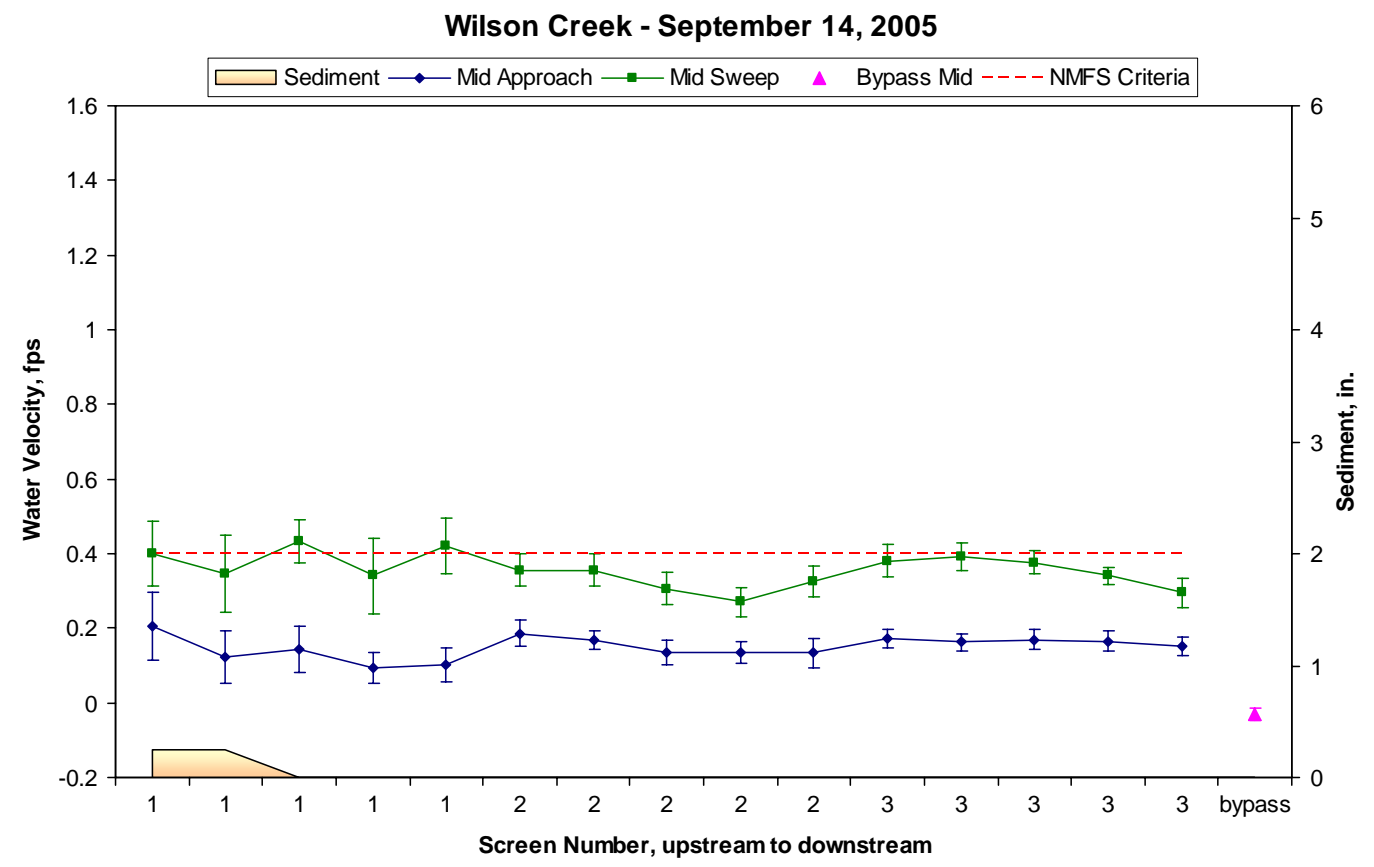

Figure 51. Wilson Creek water velocities and sediment accumulation, September 2005. Error bars represent turbulence.

\subsection{Vertical Flat-Plate Screens}

Eight of the Phase II fish screen facilities we evaluate in the Yakima River basin are vertical flat-plate screens. Velocity measurements at flat-plate screens are usually about 6 in. to 8 in. in front of the screens because of the configuration of the railing for the automated brushes. Our evaluations of the sites with this type of screen are described in the following paragraphs.

\section{Ellensburg Mill}

The Ellensburg Mill site was inspected on May 12, June 29, and September 14, 2005. Approach velocities were fairly low, as is usual for this site, and easily below the NMFS criterion during each of our inspections (Figures 52, 53, and 54). Sweep was generally greater than approach except the lower measurements at screen 1 , which were lower than approach velocities. Sweep velocities increased toward the bypass, and bypass velocities were always greater than the sweep velocities.

Boards were set across the bottom of the entrance to the forebay, just downstream of the trash rack, in an effort to reduce the amount of sediment entering the forebay. Sediment in front of the first screen was relatively high in May but may have been there before the boards were put in place. The WDFW cleared the silt out of the forebay on June 16, and the site was still very clean on June 29. In fact, June was one of the first times we could see all the fish, primarily chiselmouth, congregating in the forebay before spawning. More than 20 whitefish or dace were seen in the forebay in May, and 50 or more yellow perch were seen in September. 
Brushes worked well to keep large debris away but do not prevent algae and periphyton from growing in fairly large patches. The bypass worked well this year, with water moving freely over the weir and through the bypass pipe. Water depth at the outfall was always $1 \mathrm{ft}$ or more.

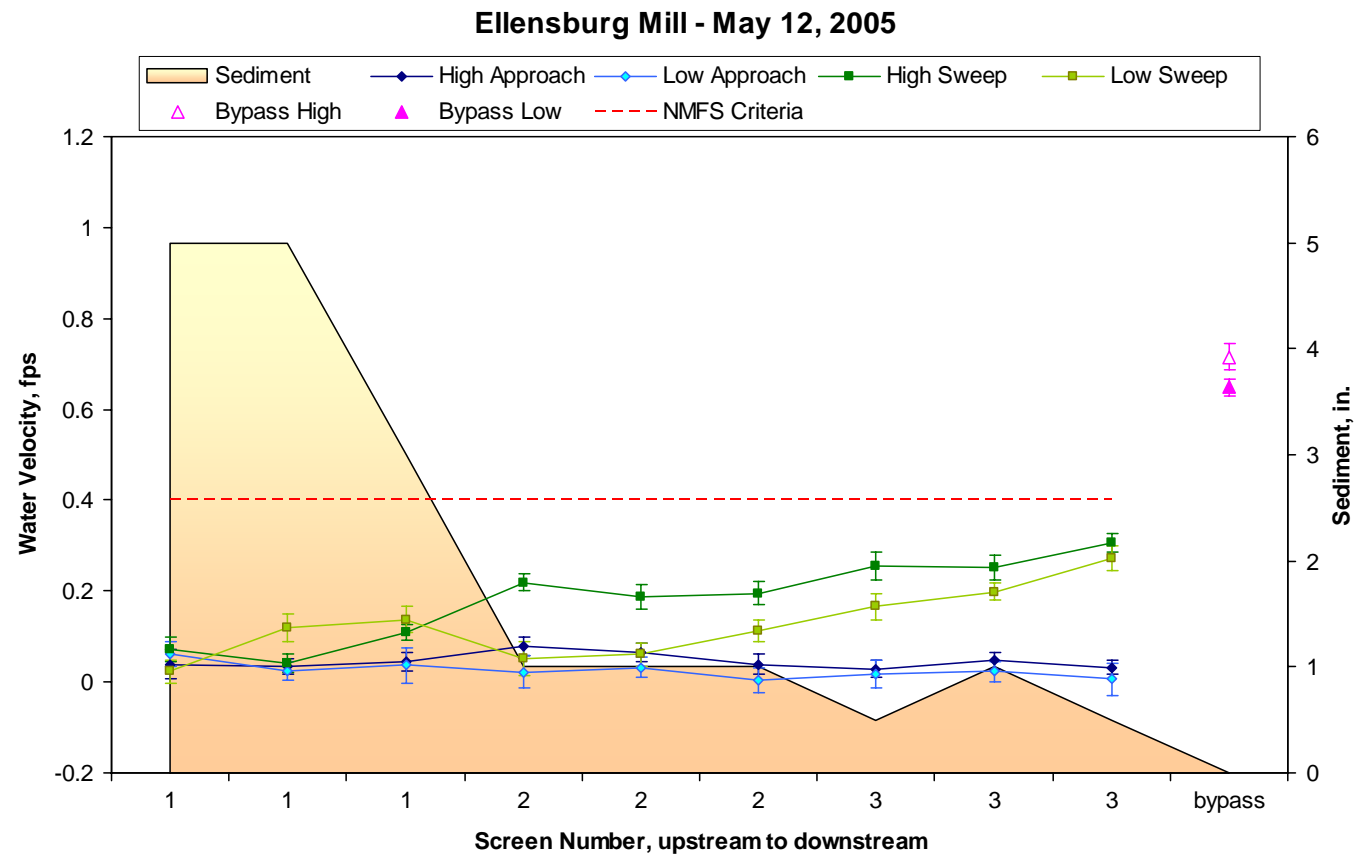

Figure 52. Ellensburg Mill water velocities and sediment accumulation, May 2005. Error bars represent turbulence.

Ellensburg Mill - June 29, 2005

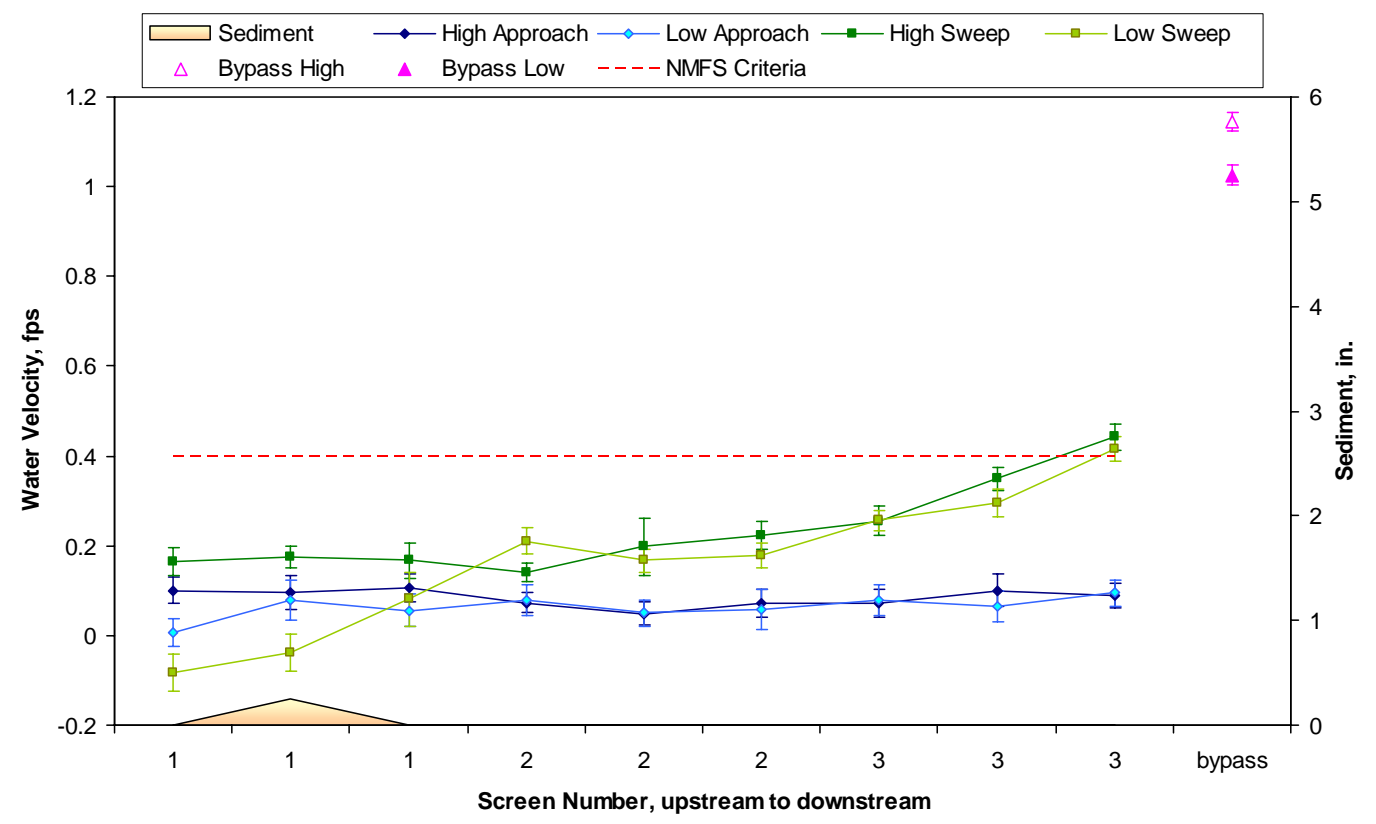

Figure 53. Ellensburg Mill water velocities and sediment accumulation, June 2005. Error bars represent turbulence. 


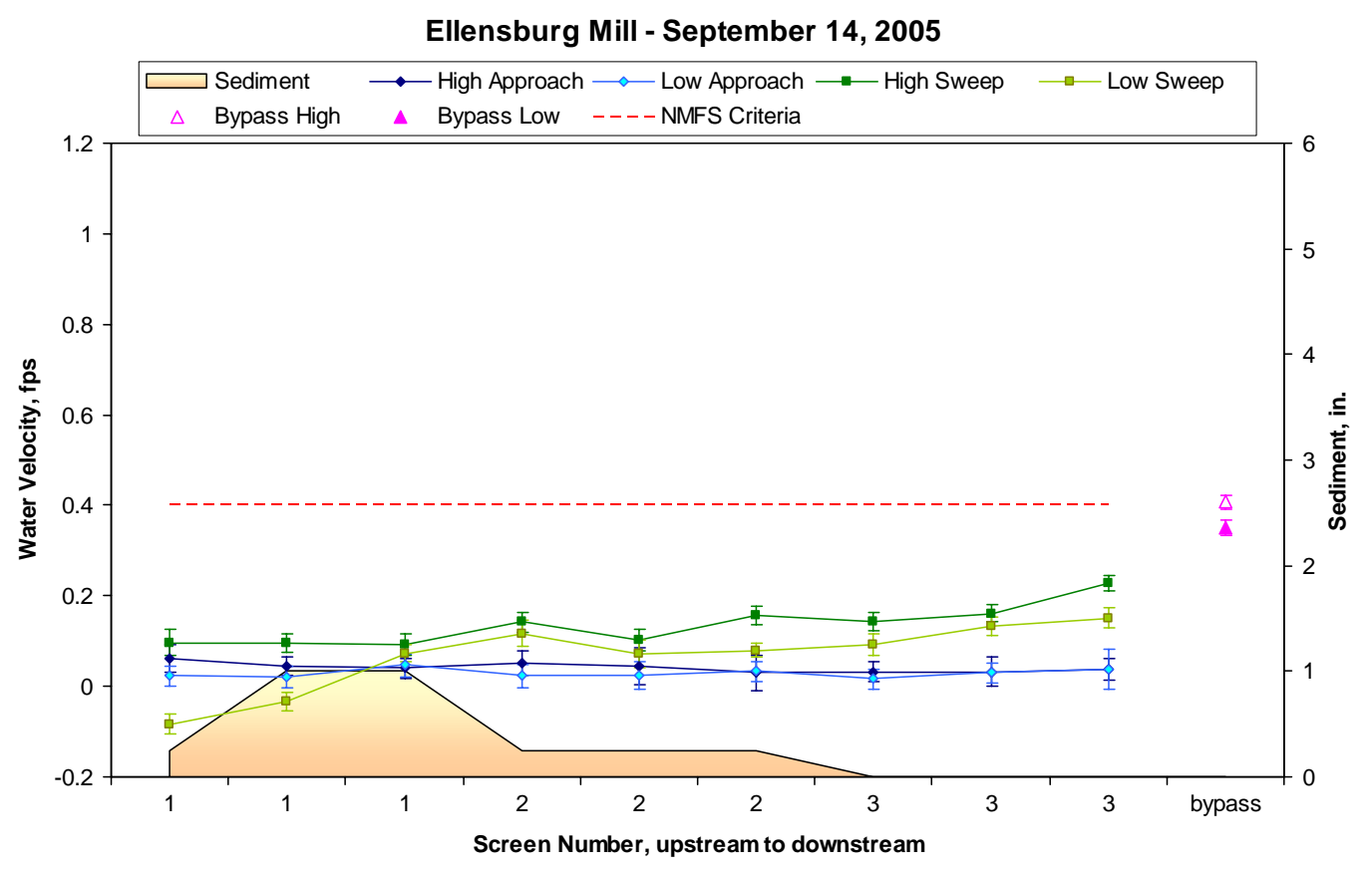

Figure 54. Ellensburg Mill water velocities and sediment accumulation, September 2005. Error bars represent turbulence.

\section{Fruitvale}

The Fruitvale site was inspected on May 13, June 30, and September 15, 2005. Approach velocities met the NMFS criterion 92, 100, and 100\% of the time in May, June, and September, respectively (Figures 55, 56, and 57). Sweep values were less than approach values at the upstream end of the first screen during each inspection as well as at the downstream end of the second screen in May. Bypass velocities were higher than sweep in May and September, but there was no bypass flow in June. Sweep increased toward the bypass in May and September as well, but not in June.

In June, river levels were low, the main channel had shifted away from the diversion dam, and the City of Yakima was not allowed to push its dam any further out into the river. The city installed a large pump in the aftbay at the nearby Old Union screen site and pumped water into the forebay at Fruitvale (Figure 58). This brought submergence up to 55\%, but that was not enough submergence to allow bypass flow. Flow in the forebay was very turbulent, especially at the upstream end (Figure 56). We notified the WDFW of the lack of bypass flow and the fact that juvenile salmonids were found in the forebay. This led to a biological evaluation of the site and its operations to determine whether there was danger to juvenile fish. Fishery biologists indicated the channel leading to Fruitvale is good salmonid rearing habitat and that fish would be safe in that channel as long as no threats were caused by debris buildup at the screens themselves. The WDFW opened the flushgate periodically to allow fish in the forebay to move out. At some point in late August or early September, the pump was removed from Old Union aftbay. Normal operation of Fruitvale had resumed by the time we visited the site on September 15.

Screen condition was good during all surveys. Seal condition was adequate, with a few small spots missing caulk along the bottom, but these probably do not pose a problem for fish. 
Fruitvale - May 13, 2005

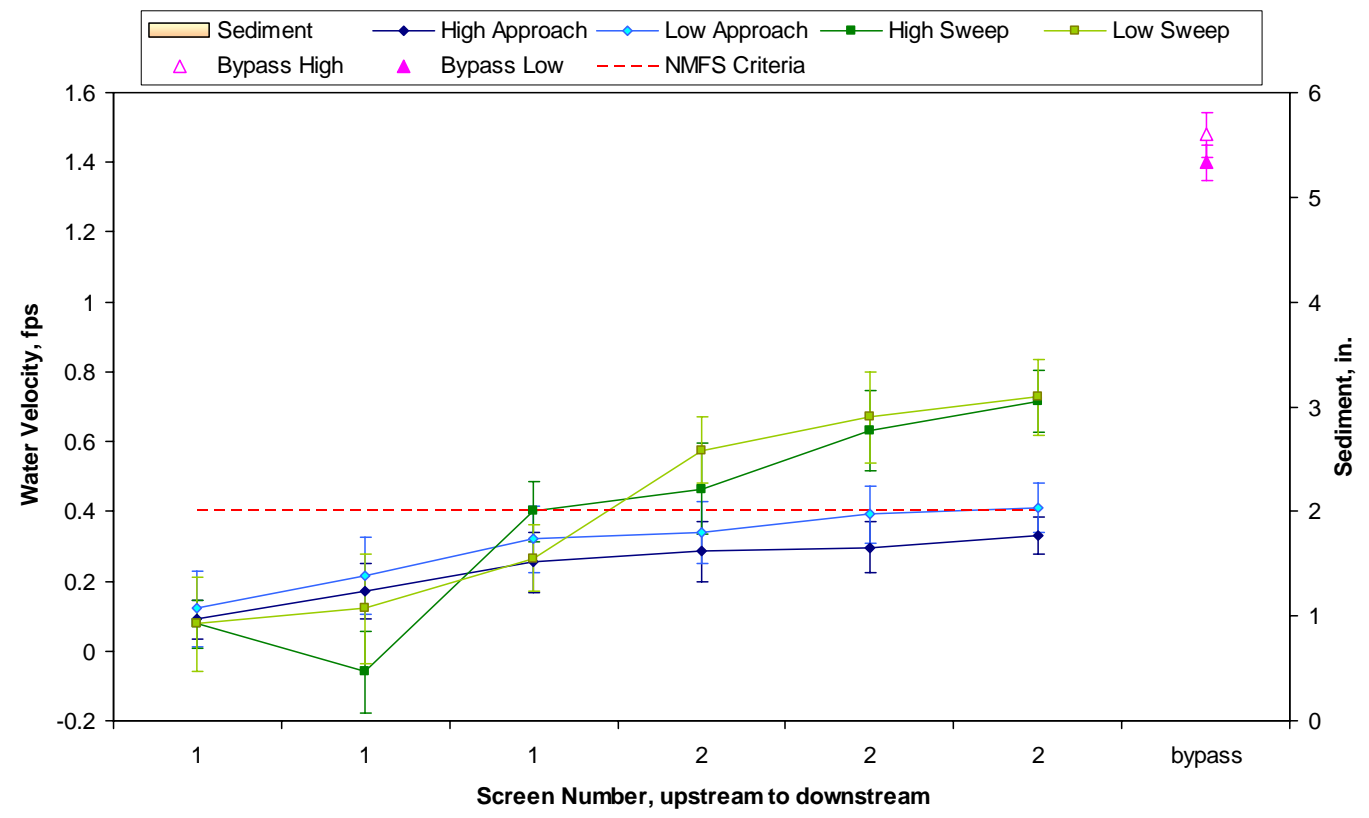

Figure 55. Fruitvale water velocities and sediment accumulation, May 2005. Error bars represent turbulence.

Fruitvale - June 30, 2005

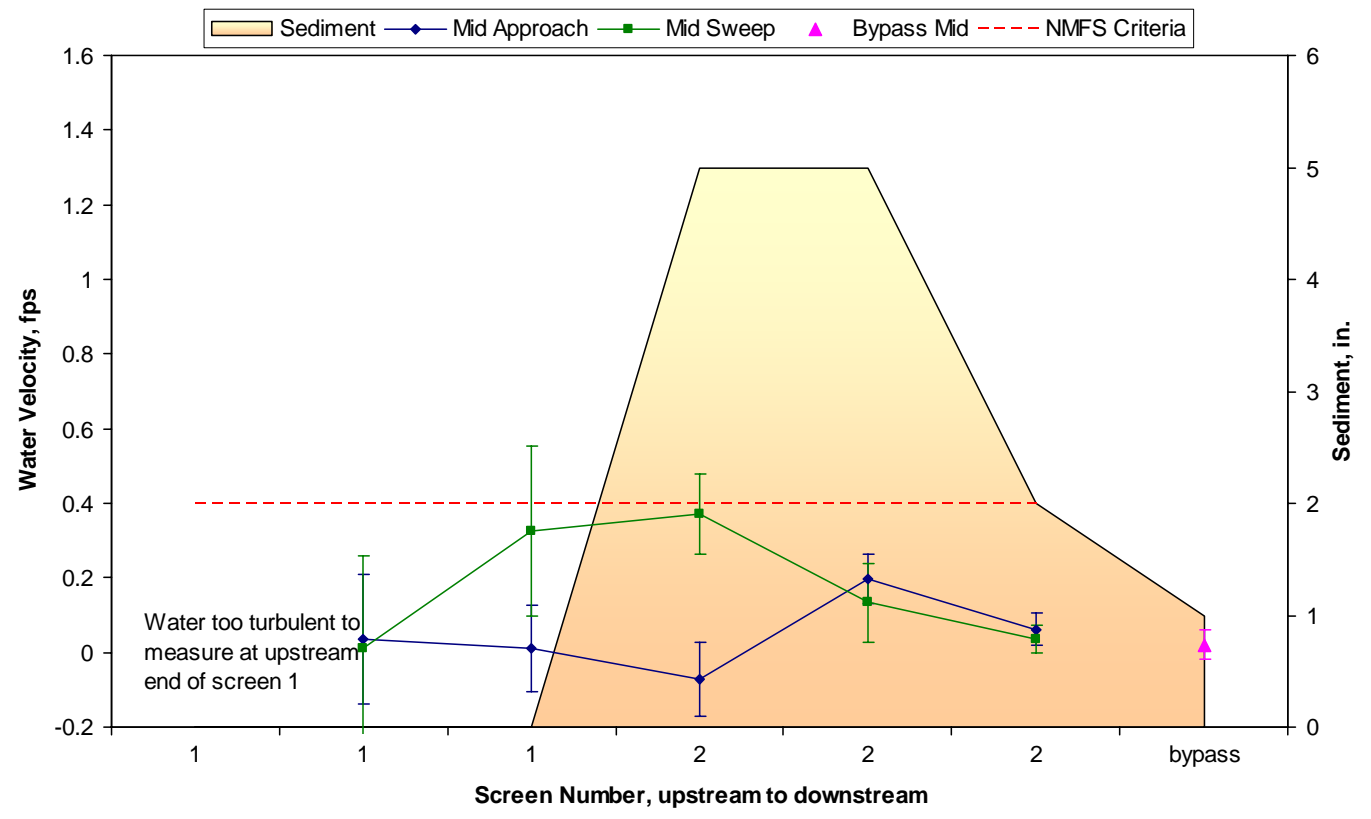

Figure 56. Fruitvale water velocities and sediment accumulation, June 2005. Error bars represent turbulence. 
Fruitvale -September 15, 2005

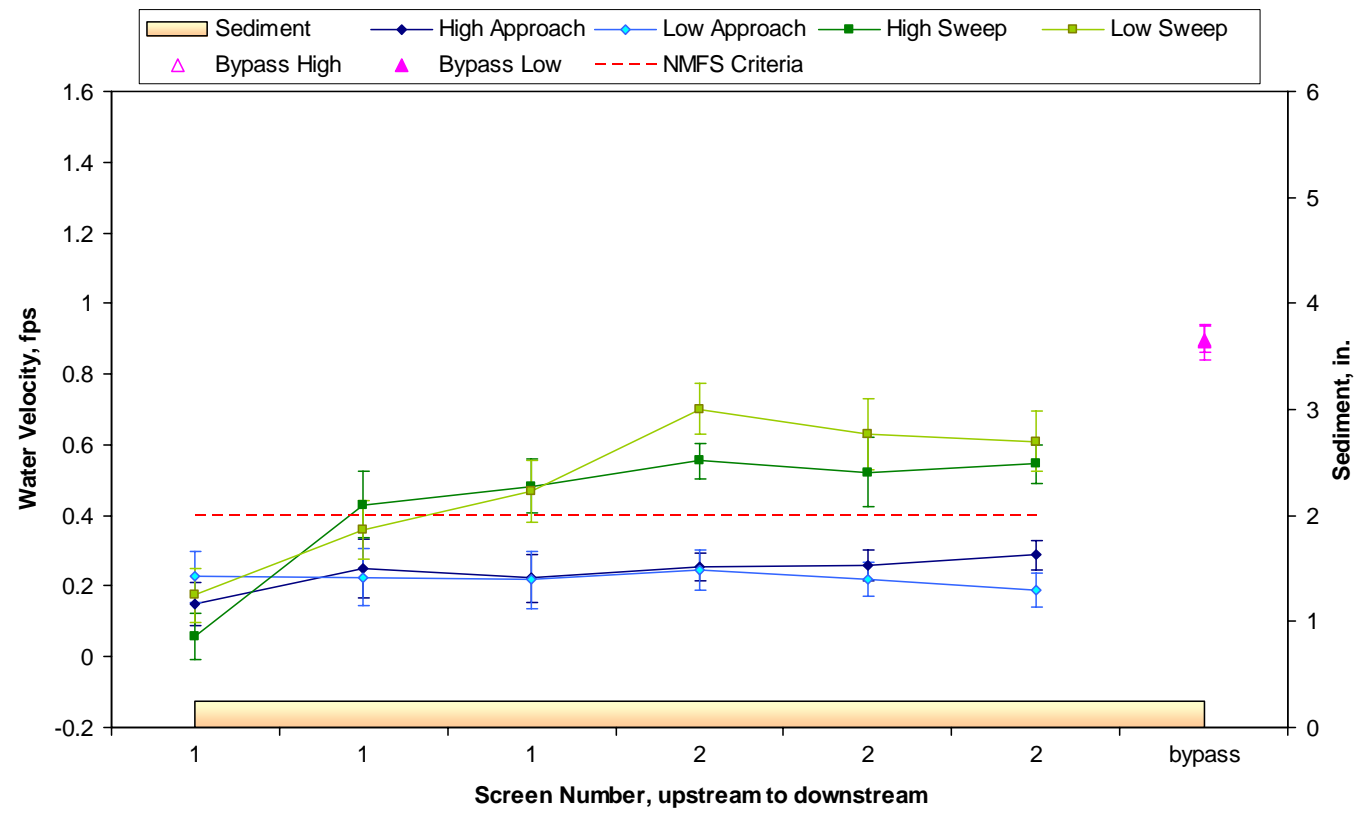

Figure 57. Fruitvale water velocities and sediment accumulation, September 2005. Error bars represent turbulence.

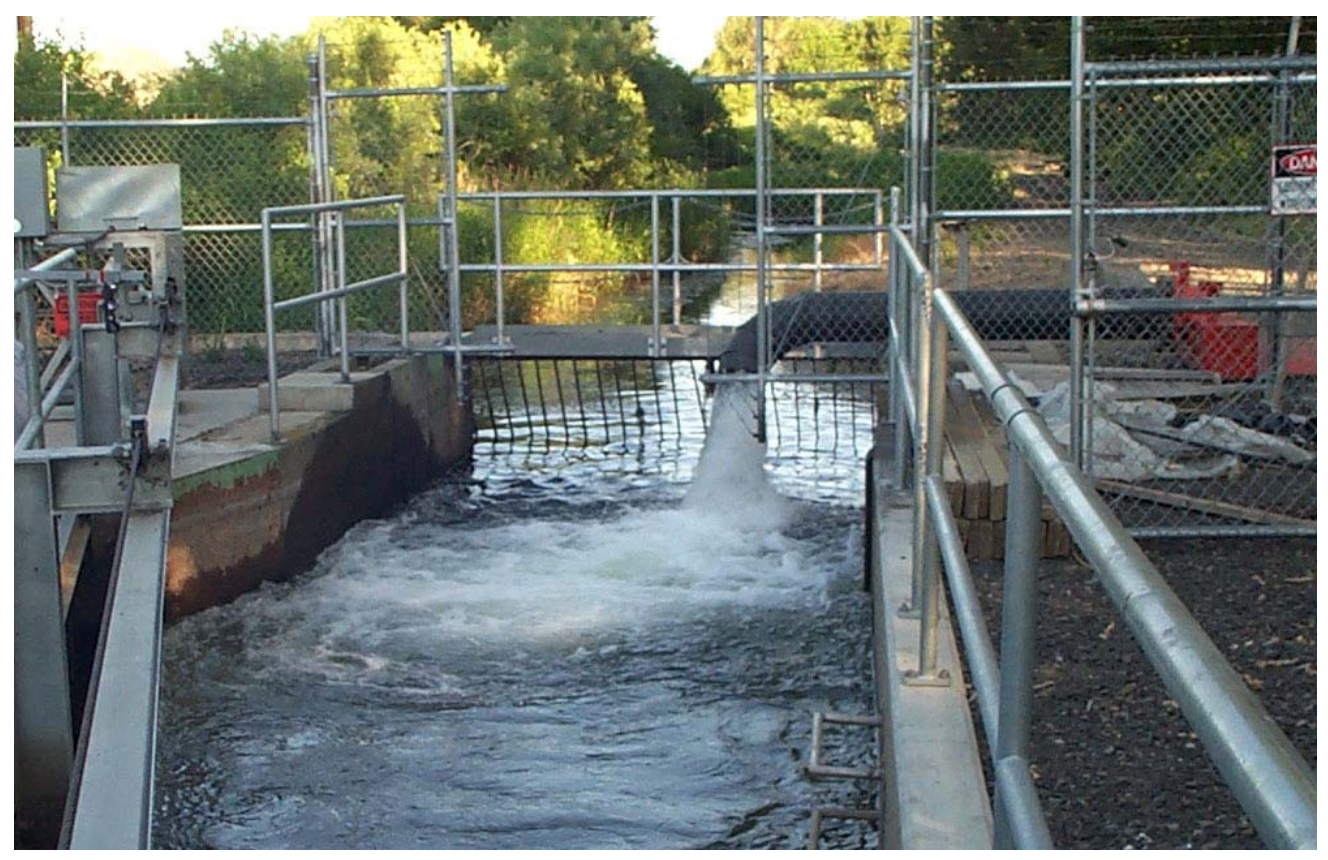

Figure 58. Water being piped in from the Old Union screen site into the Fruitvale forebay. View upstream from bypass. 


\section{Naches-Selah}

The Naches-Selah site was evaluated on May 26, June 28, and September 29, 2005. Sweep velocities always were higher than approach velocities but did not increase toward the bypass (Figures 59, 60, and 61). Bypass velocities were always less than the average sweep. Approaches met the NMFS criterion 94, 36, and 100\% of the time in May, June, and September, respectively. Submergence and depth of water over the weir were essentially the same in May and June, and canal flows were slightly higher in May (124.7 cfs versus $123.1 \mathrm{cfs}$ ). However, the approach values were markedly different between these two evaluations. The only difference we found was a slight increase in head loss across the screen in June, with the differences between forebay and aftbay gages 0.05 in May and 0.13 in June. The NMFS (1995) recommends cleaning screens when head differentials of 0.1 are reached, to prevent approach hot spots. Brushes were set to run with a 7-minute delay on this date, and the screens looked clean. We notified WDFW staff of the high approach values on June 28, but they felt the site was running as designed and there was nothing more to be done. High approach values have been a consistent problem for the Naches-Selah site in the past. In 2006, we would like to look at design flows for the diversion and bypass as well as the operating procedures for the screens at this site, and work together with WDFW personnel to see whether changes to louver positions or other facility settings can be made to keep the site within criteria.

Screen condition was good throughout the year. Seal condition also was good, although what appeared to be significant deterioration of the cement beneath the bottom seal could be seen in two places. The WDFW has been notified of these potential problem areas. Juvenile salmonids were abundant in the forebay during each of the surveys this year.

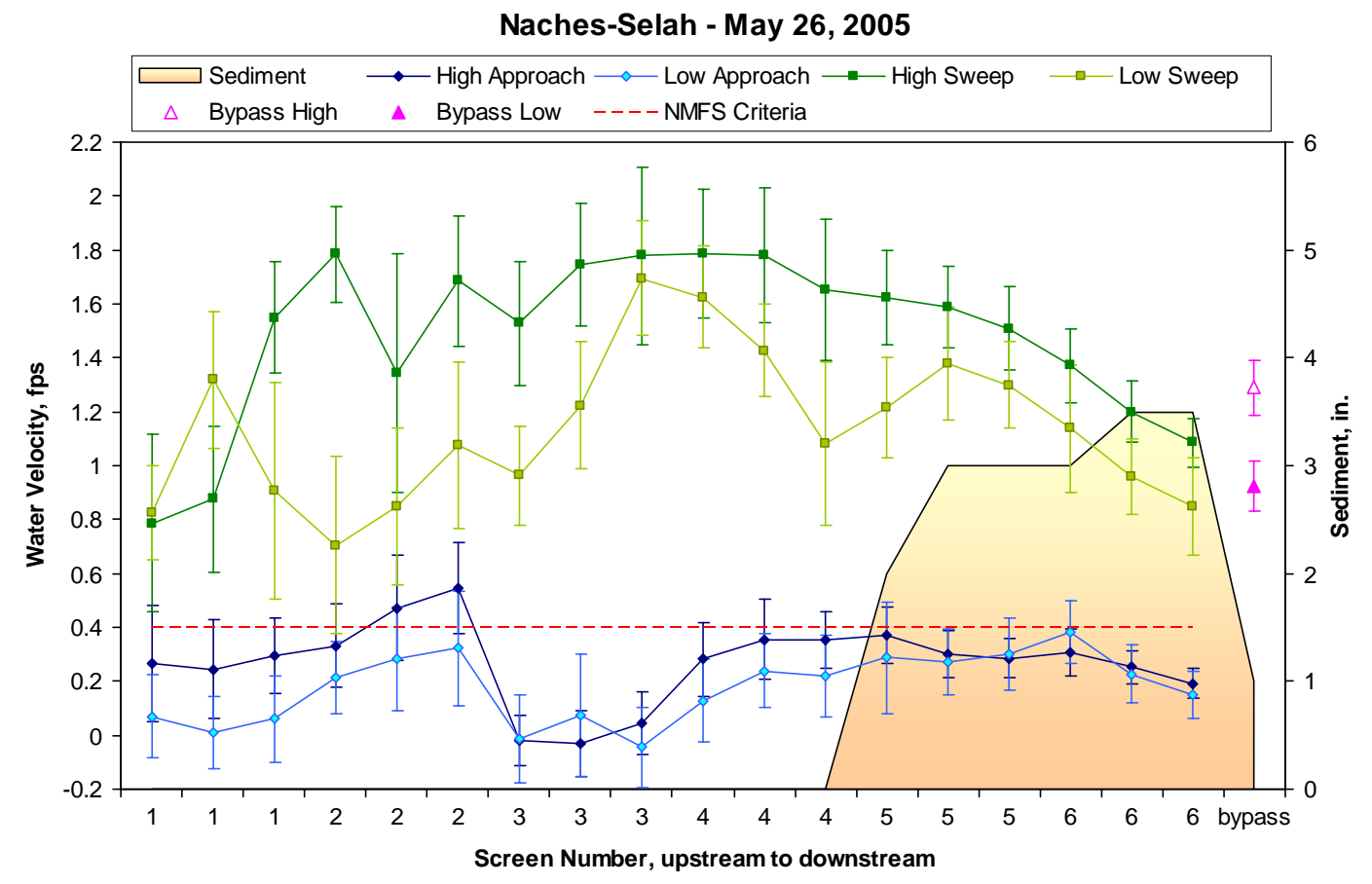

Figure 59. Naches-Selah water velocities and sediment accumulation, May 2005. Error bars represent turbulence. 


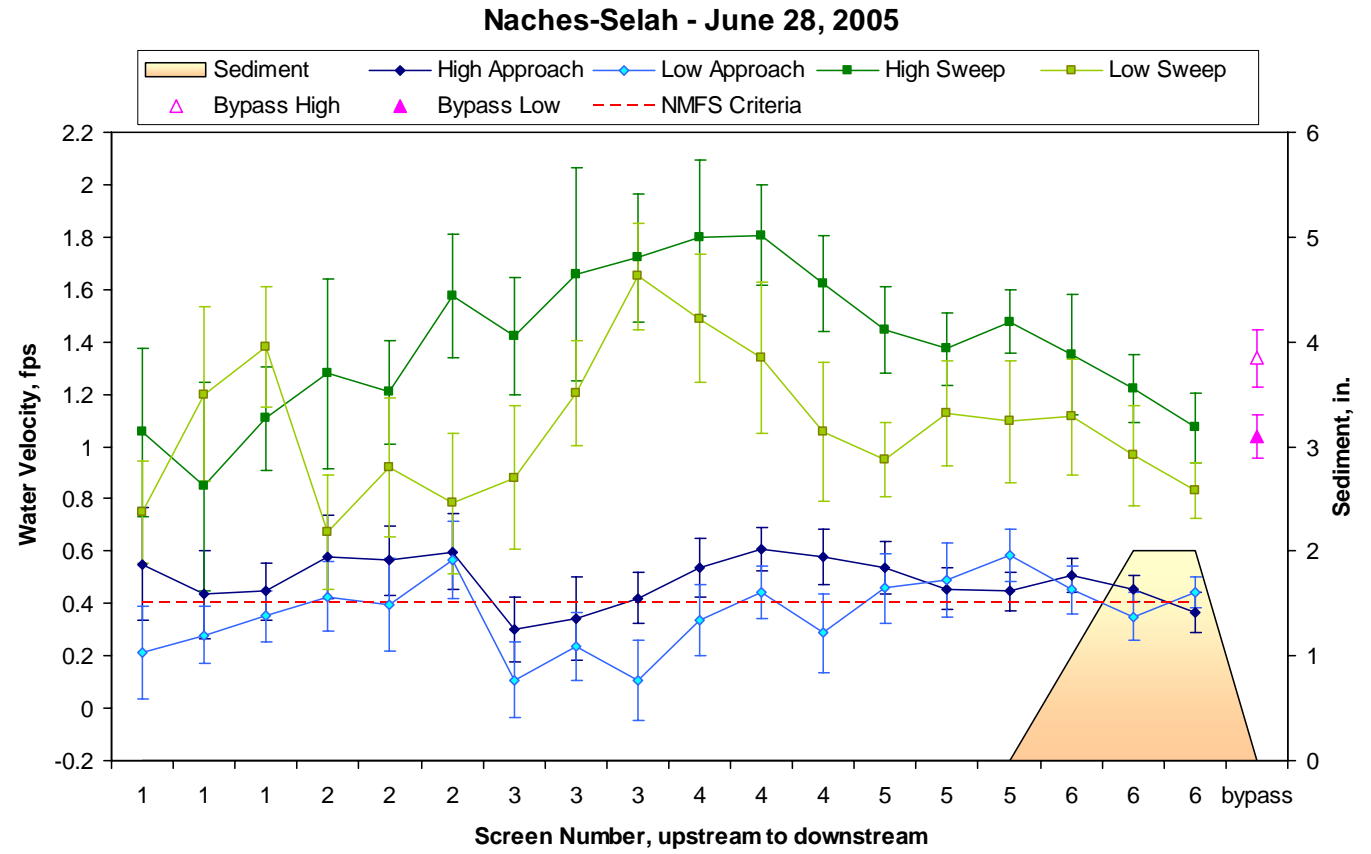

Figure 60. Naches-Selah water velocities and sediment accumulation, June 2005. Error bars represent turbulence.

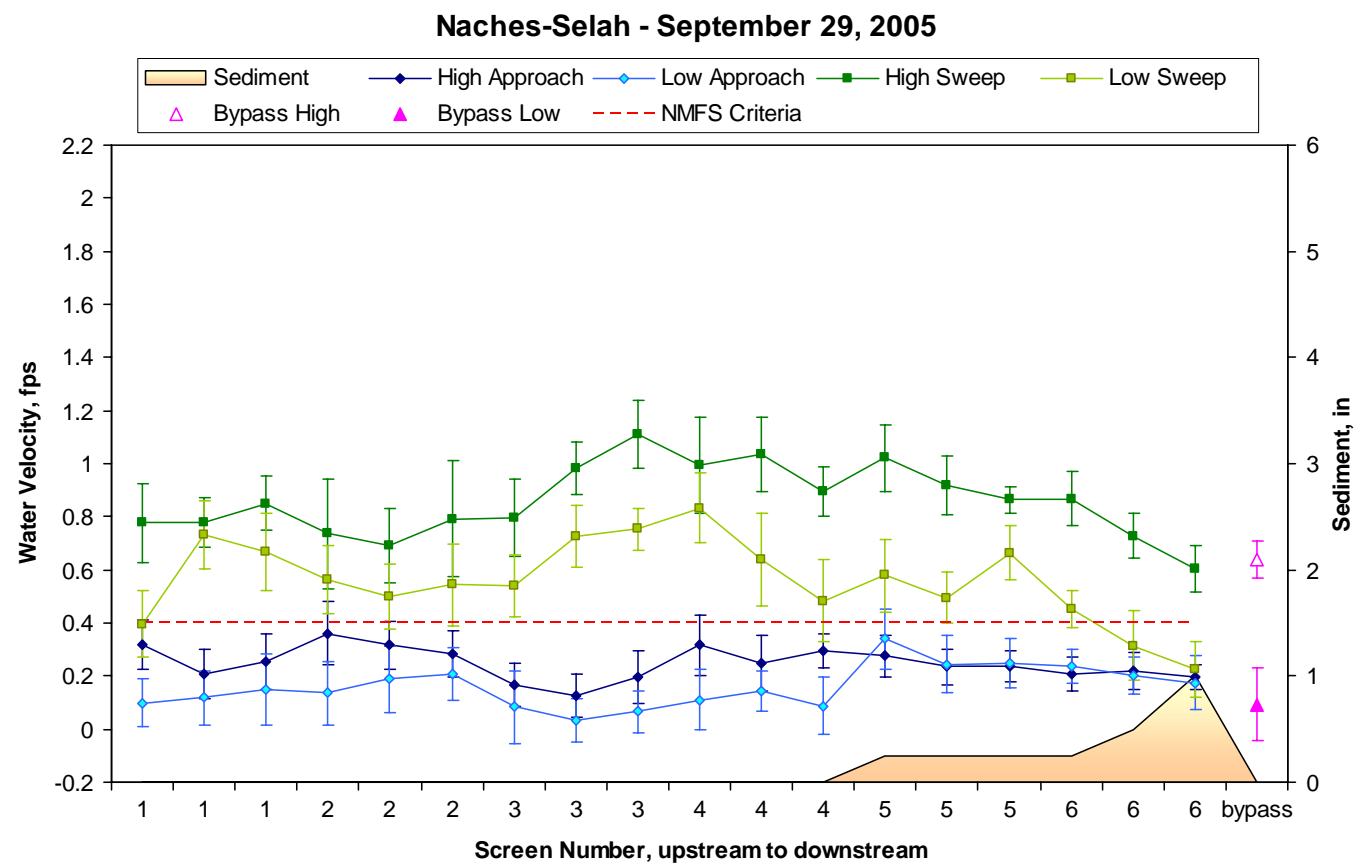

Figure 61. Naches-Selah water velocities and sediment accumulation, September 2005. Error bars represent turbulence. 


\section{Packwood}

We evaluated the Packwood fish screen site on May 12, June 29, and September 14, 2005. As at most flat-plat screen sites, the rail along which the brushes move extends out toward the forebay. At Packwood, the same brush rail extends into the bypass area, preventing measurement of bypass velocities. A paddlewheel powers the brushes and cannot be turned off during measurements, which may cause some fluctuations during velocity measurements.

Sweep increased toward the bypass during every visit (Figures 62, 63, and 64). Sweep was greater than approach 83, 100, and 83\% of the time in May, June, and September, respectively. Approach velocities always were below the NMFS criterion of $0.4 \mathrm{fps}$. The bypass was generally clear of debris and had adequate flow over the weir to provide fish passage. The mouth of the outfall channel had a significant amount of woody debris all the way across, which could prevent adult fish from moving into the river. The WDFW removed this debris at least once in 2005, but it builds back up over time. This should be watched to ensure fish of all sizes can move safely back to the river.

Screen condition was good during all surveys. Caulking was not readily evident along the downstream seal of the second screen and along the bottom seal, although the screens appeared to fit snugly against the cement. Small fish seen in the aftbay may have been stickleback. Juvenile salmonids were seen in the forebay in June. This site does not have gages, a logbook, or datasheets on site with information on design flows and operating criteria. We would recommend a logbox for the latter two items and gages, if possible.

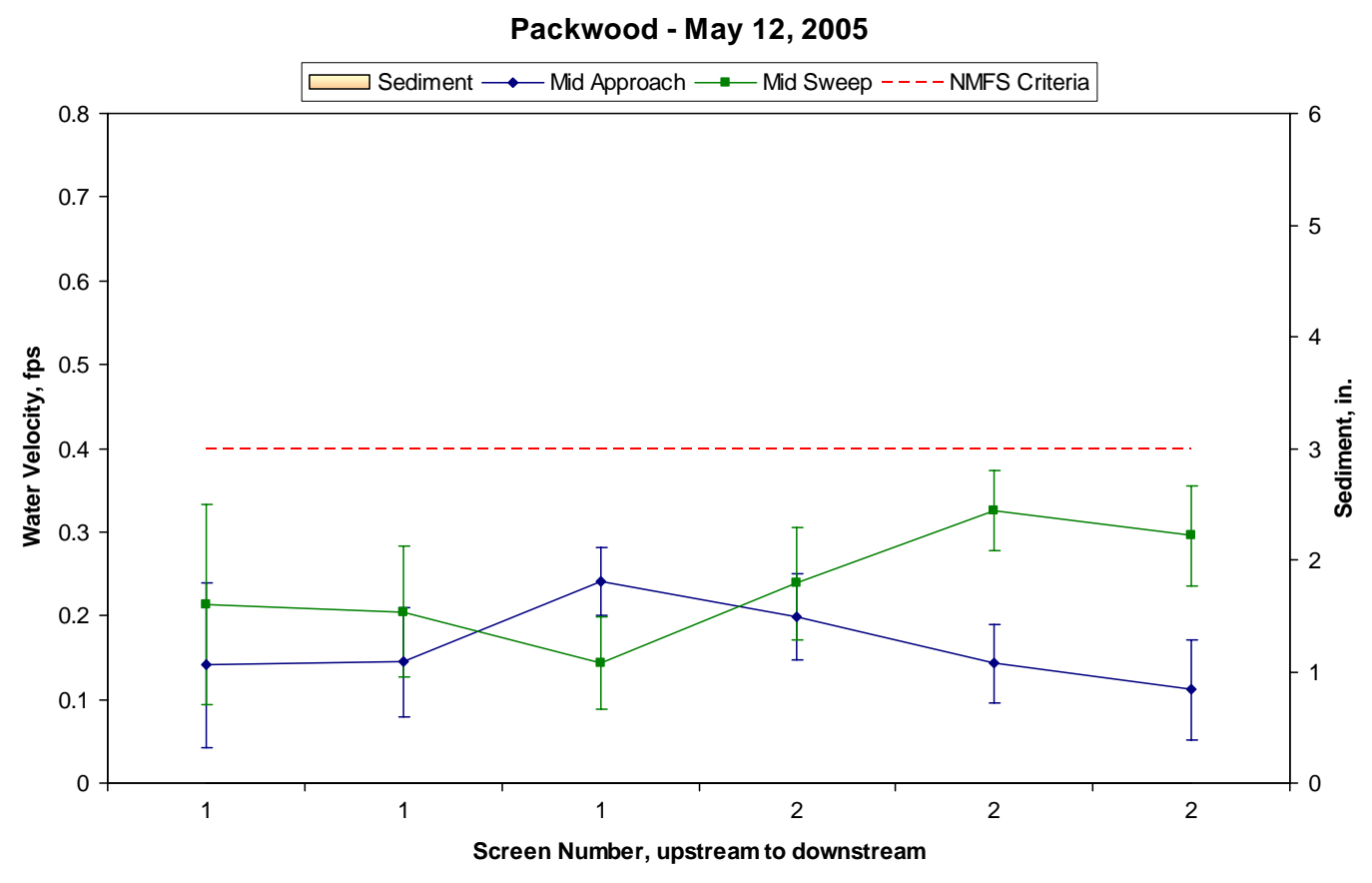

Figure 62. Packwood water velocities and sediment accumulation, May 2005. Error bars represent turbulence. 


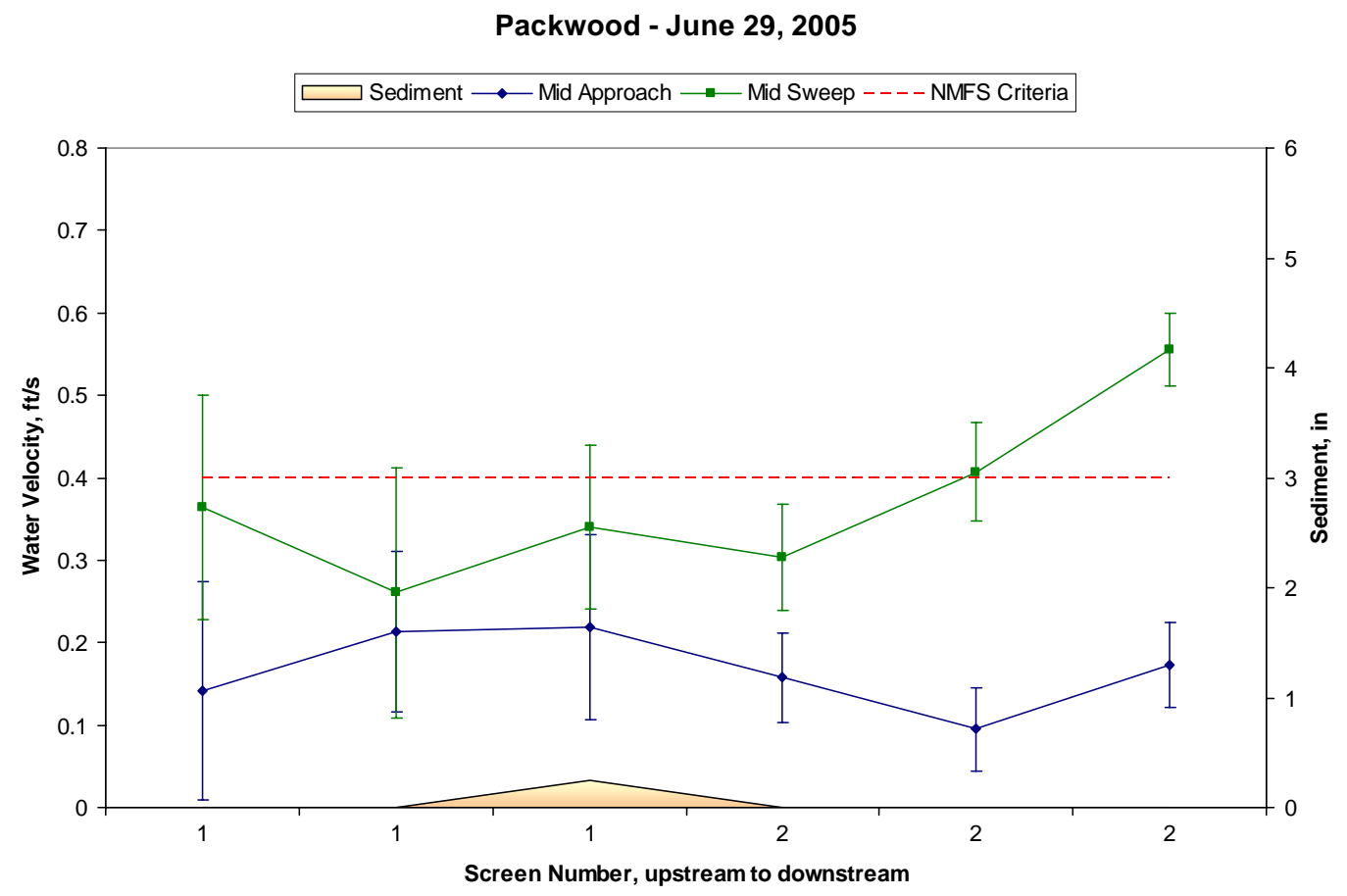

Figure 63. Packwood water velocities and sediment accumulation, June 2005. Error bars represent turbulence.

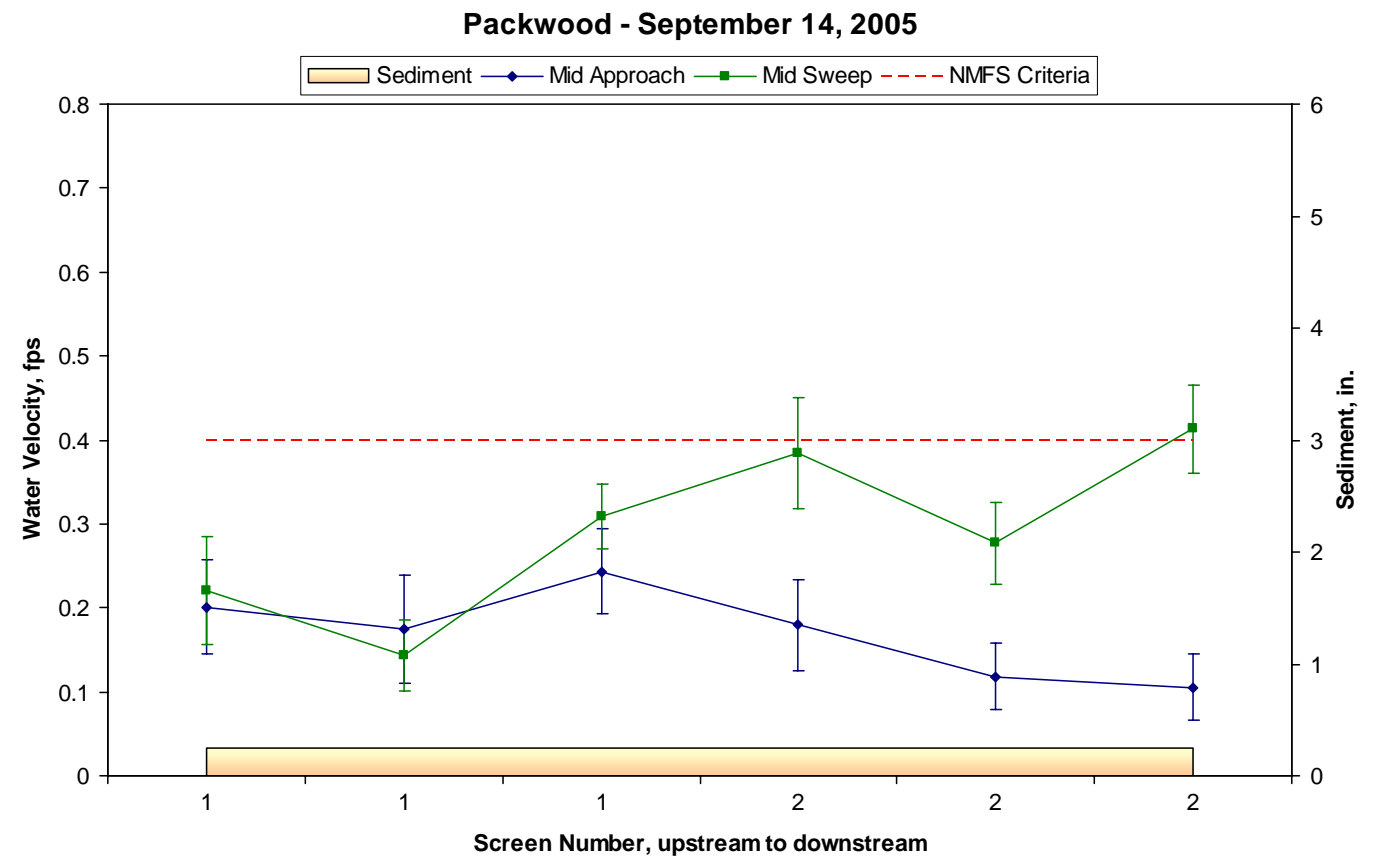

Figure 64. Packwood water velocities and sediment accumulation, September 2005. Error bars represent turbulence. 


\section{Selah-Moxee}

This site was inspected on May 19, June 20, and September 19. Sweep velocities always were higher than approach values and increased slightly toward the bypass in May and September (Figures 65, 66, and 67). In May, 63\% of the approach values were below the NMFS criterion, with all the high approach values in the higher part of the water column. There was abundant aquatic plant growth in the forebay in May, and we feel this slowed water in the lower part of the water column, forcing the water to move more quickly in the upper water column. We notified WDFW personnel of the high approaches on May 24, and they cleaned out the forebay in June. In June and September, all approach values met the criterion.

Bypass velocities always were greater than the average sweep velocities. Water moved smoothly and freely over the weir and through the outfall pipe. The ramp was up in May although the flushgate was closed. We saw no fish hiding under the ramp, and in June the ramp was closed again.

Brushes worked effectively to remove large debris. There was some buildup of algae in patches by September, indicating the brushes were not hitting the screens with equal pressure throughout. There are no gages at this site yet. Gages should be installed to make operational measurements consistent among all users.

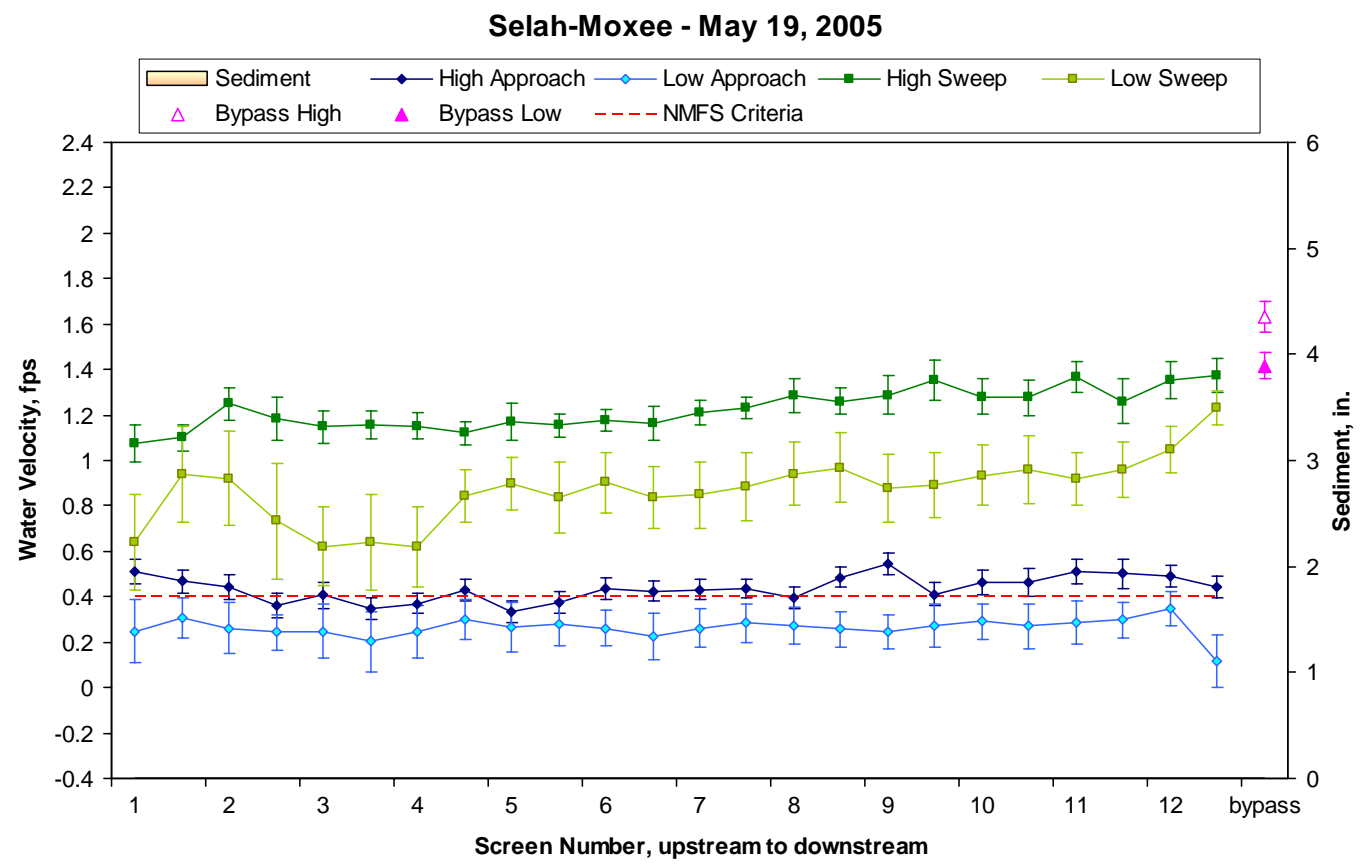

Figure 65. Selah-Moxee water velocities and sediment accumulation, May 2005. Error bars represent turbulence. 
Selah-Moxee - June 20, 2005

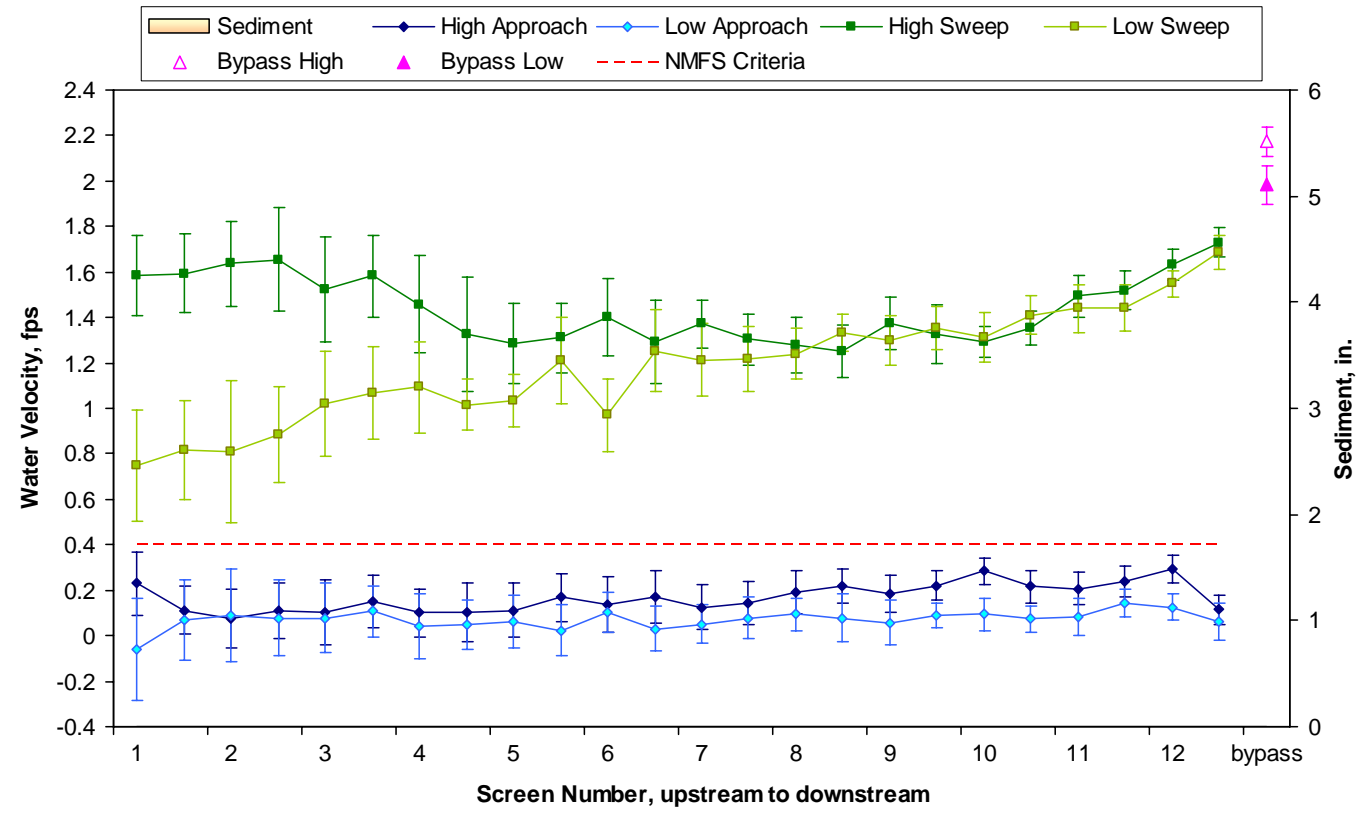

Figure 66. Selah-Moxee water velocities and sediment accumulation, June 2005. Error bars represent turbulence.

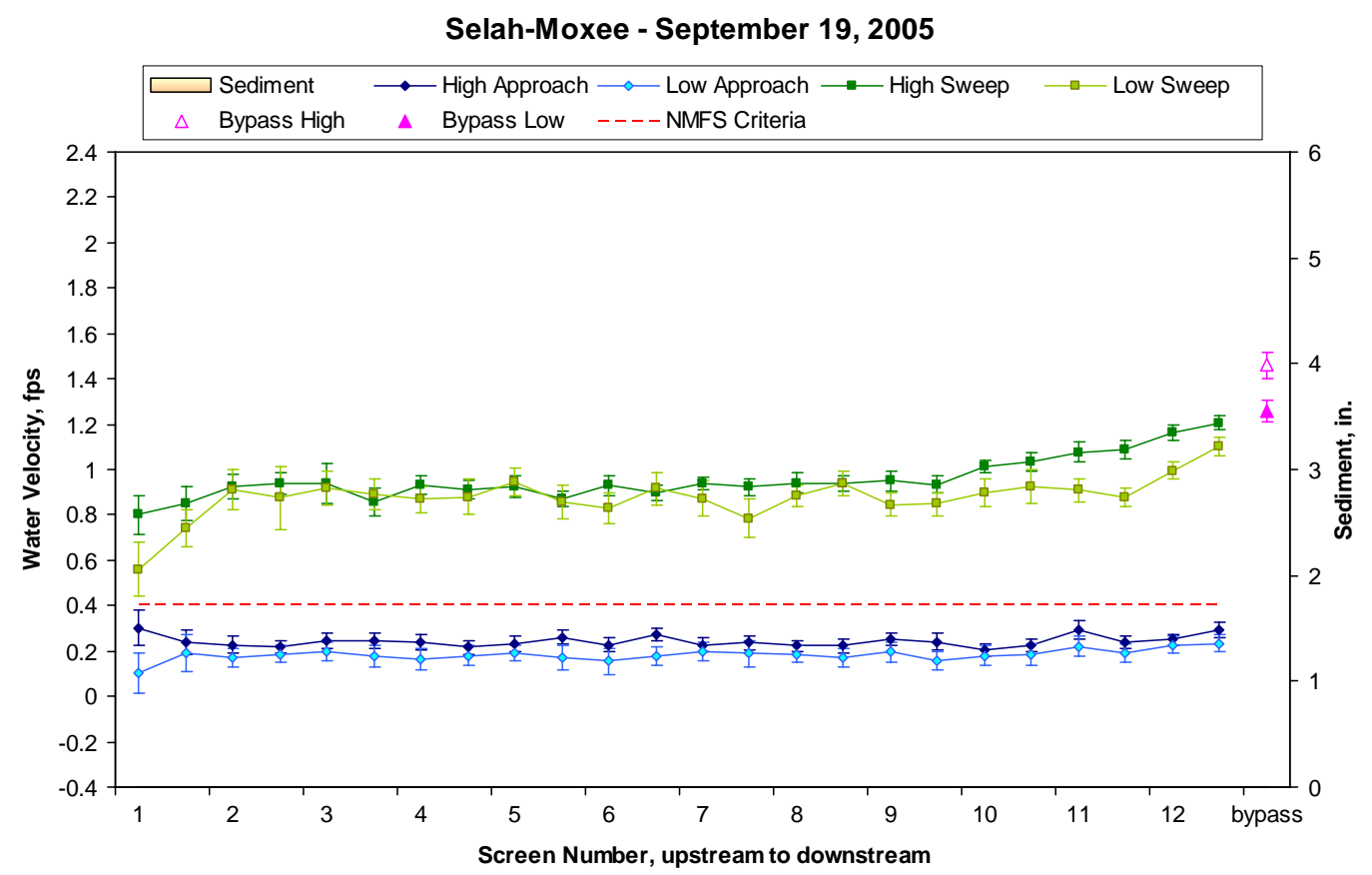

Figure 67. Selah-Moxee water velocities and sediment accumulation, September 2005. Error bars represent turbulence. 


\section{Union Gap}

Our evaluations of the Union Gap site took place on May 19, June 24, and September 13, 2005. We found sweep velocities always greater than approach values and also higher than bypass velocities in May and June (Figures 68 and 69). Bypass velocities were higher than the average sweep velocity in September (Figure 70). Approach velocities met the NMFS criterion 100, 46, and 100\% of the time in May, June, and September, respectively. Excessive approach values are a recurring problem at Union Gap. In 2006, we would like to look at design flows for the diversion and bypass as well as the operating procedures for the screens at this site, and work together with WDFW personnel to see whether changes to position or other facility settings can be made to keep the site within criteria.

There was good bypass flow during each of our inspections, and water moved freely over the weir and into the outfall channel. Screen and seal condition was also good during each of the surveys. The brush was effective in cleaning the screens.

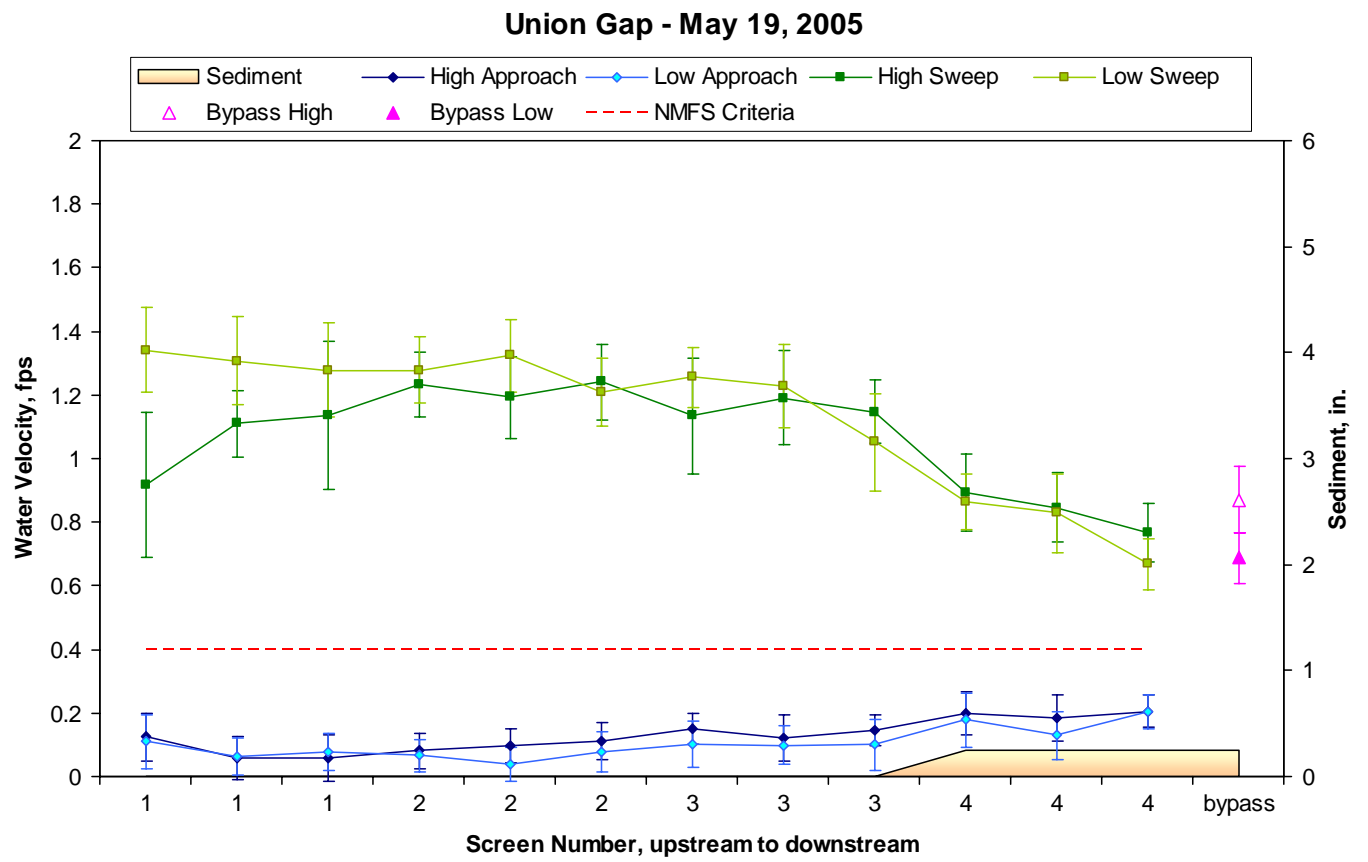

Figure 68. Union Gap water velocities and sediment accumulation, May 2005. Error bars represent turbulence. 


\section{Union Gap - June 24, 2005}

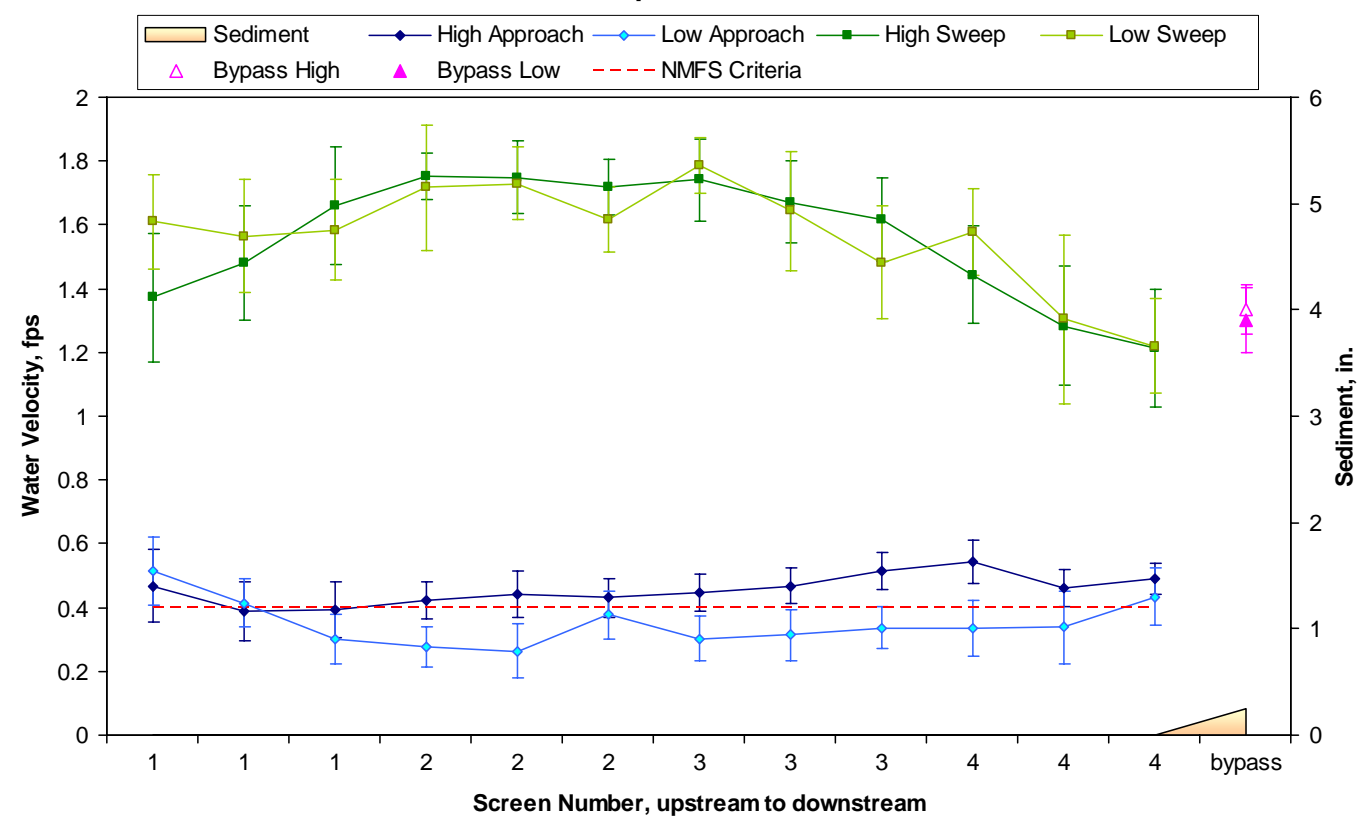

Figure 69. Union Gap water velocities and sediment accumulation, June 2005. Error bars represent turbulence.

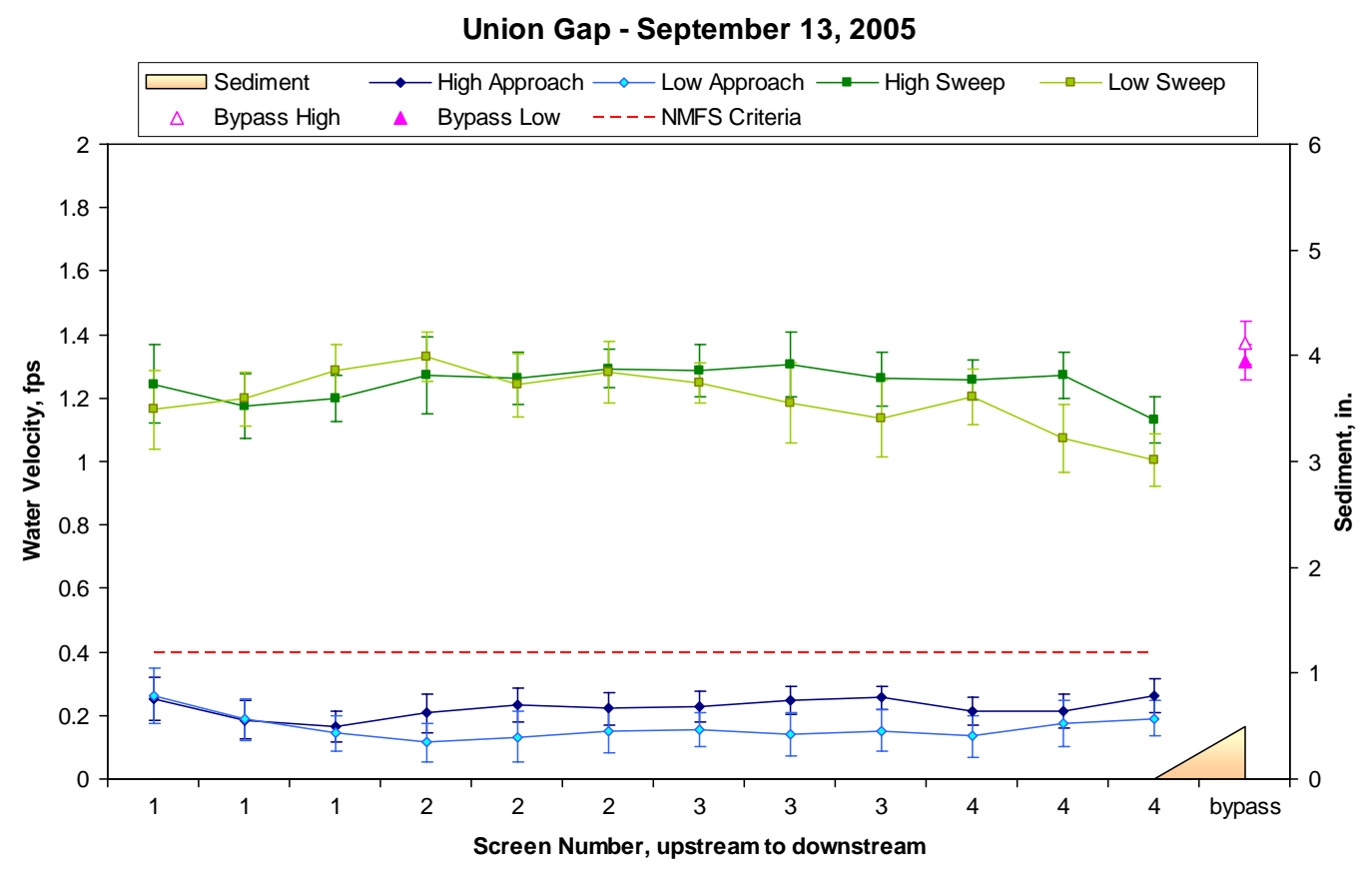

Figure 70. Union Gap water velocities and sediment accumulation, September 2005. Error bars represent turbulence. 


\section{Yakima-Tieton}

We inspected the Yakima-Tieton site on May 11, June 23, and September 20, 2005. Sweep velocities always were greater than approach velocities but did not increase toward the bypass during any of our inspections (Figures 71, 72, and 73). Bypass velocities always were greater than or equal to the average sweep. Approach velocities met the NMFS criterion 67, 97, and 61\% of the time in May, June, and September, respectively. High approach values have occurred several times in the past few years at Yakima-Tieton. In 2006, we would like to look at design flows for the diversion and bypass as well as the operating procedures for the screens at this site, and work together with USBR personnel to see whether changes to louver position or other facility settings can be made to keep the site within criteria.

Water flowed freely through the bypass. There is no ramp here, and the flushgate is left up so that all bypass water passes under the flushgate, taking sediment with it. Water levels were very low in May, with submergence around $29 \%$.

Caulking is pulling loose in numerous places along the bottom of the screens, leaving long strands of caulk waving in the current. We did not detect any gaps between the frame and cement large enough for fish to get through. The brushes were effective in keeping the screens clean. The new access bridge across the river saves a lot of time and effort when carrying equipment and is much safer than the old footbridge.

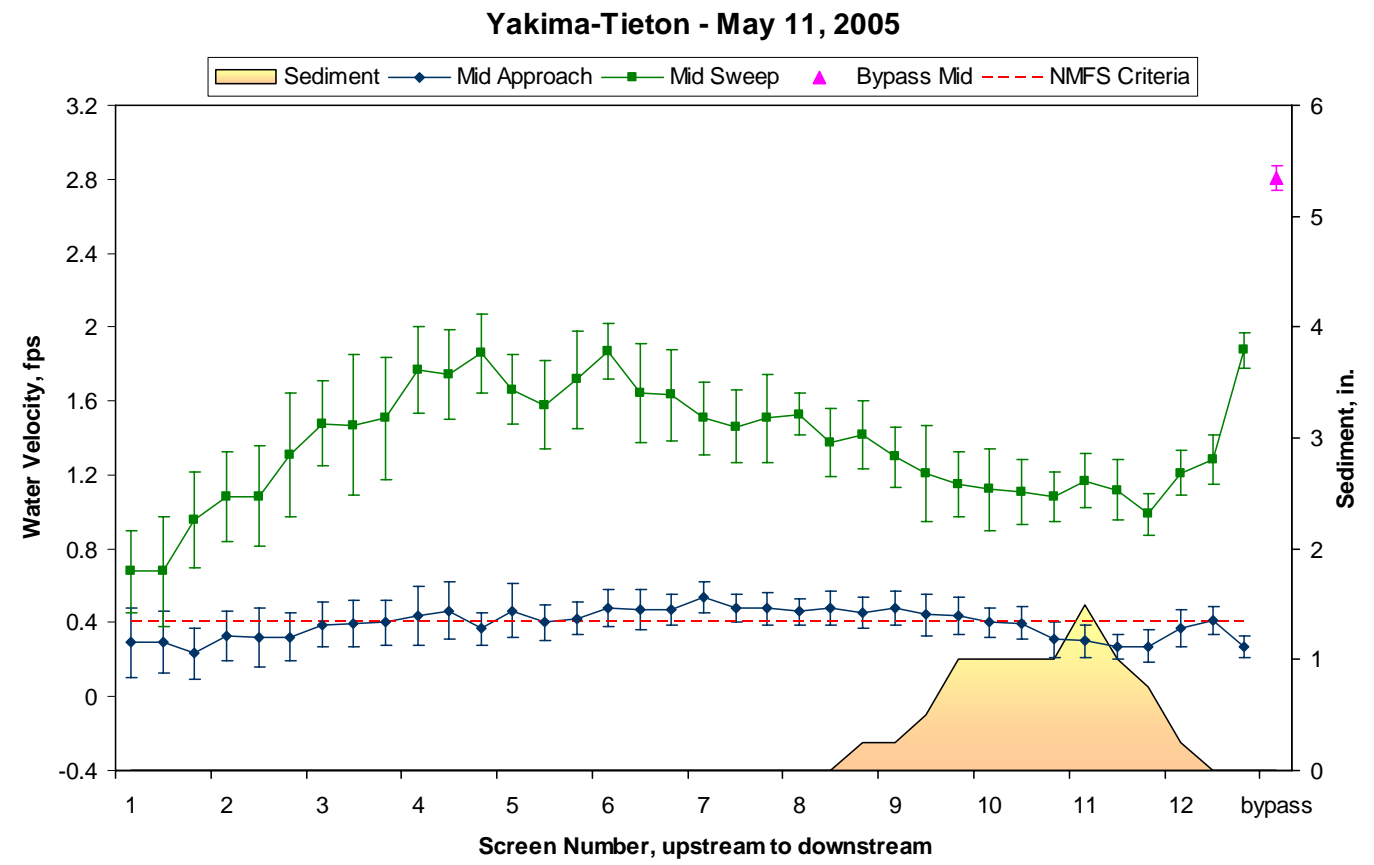

Figure 71. Yakima-Tieton water velocities and sediment accumulation, May 2005. Error bars represent turbulence. 


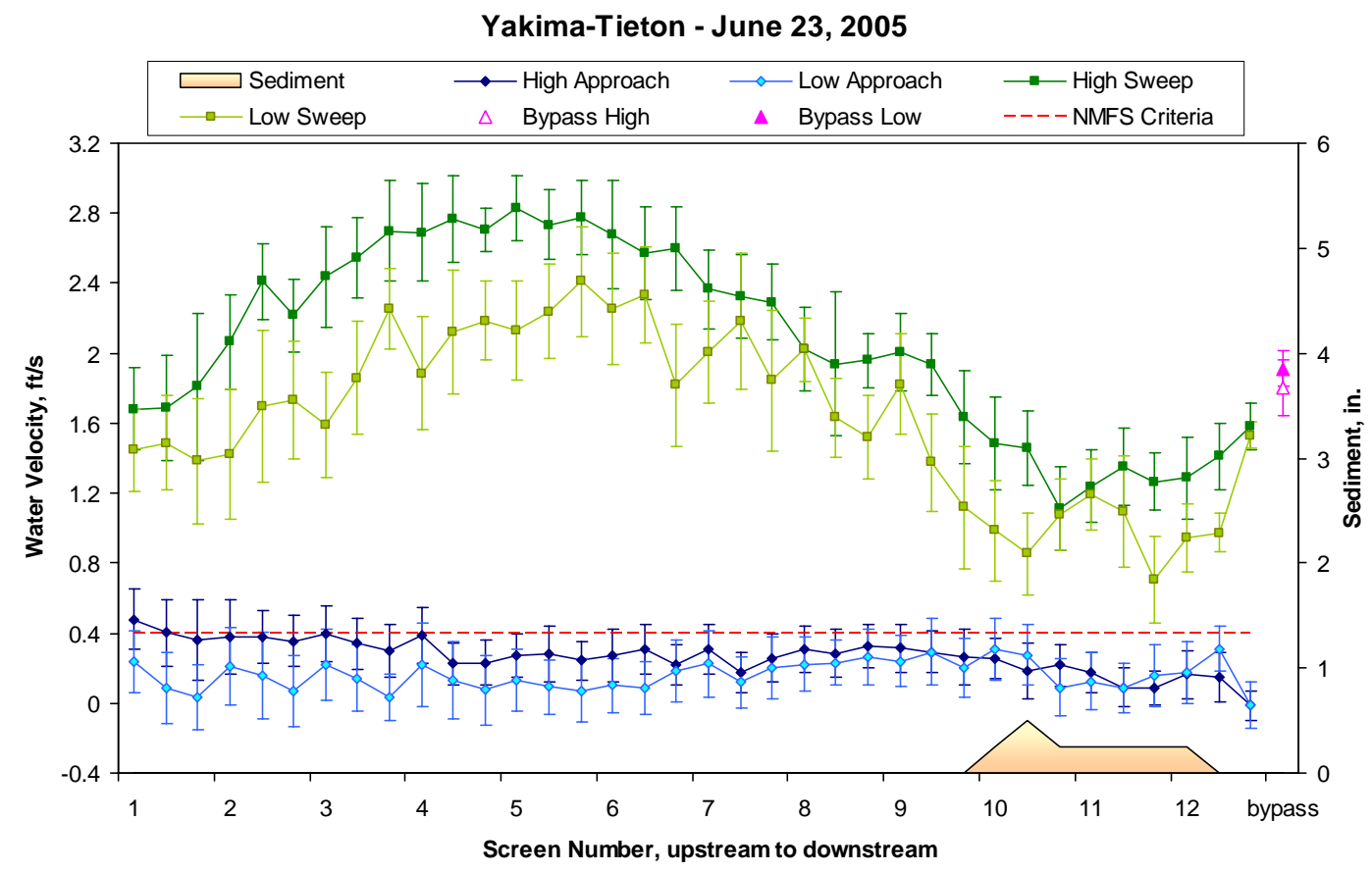

Figure 72. Yakima-Tieton water velocities and sediment accumulation, June 2005. Error bars represent turbulence.

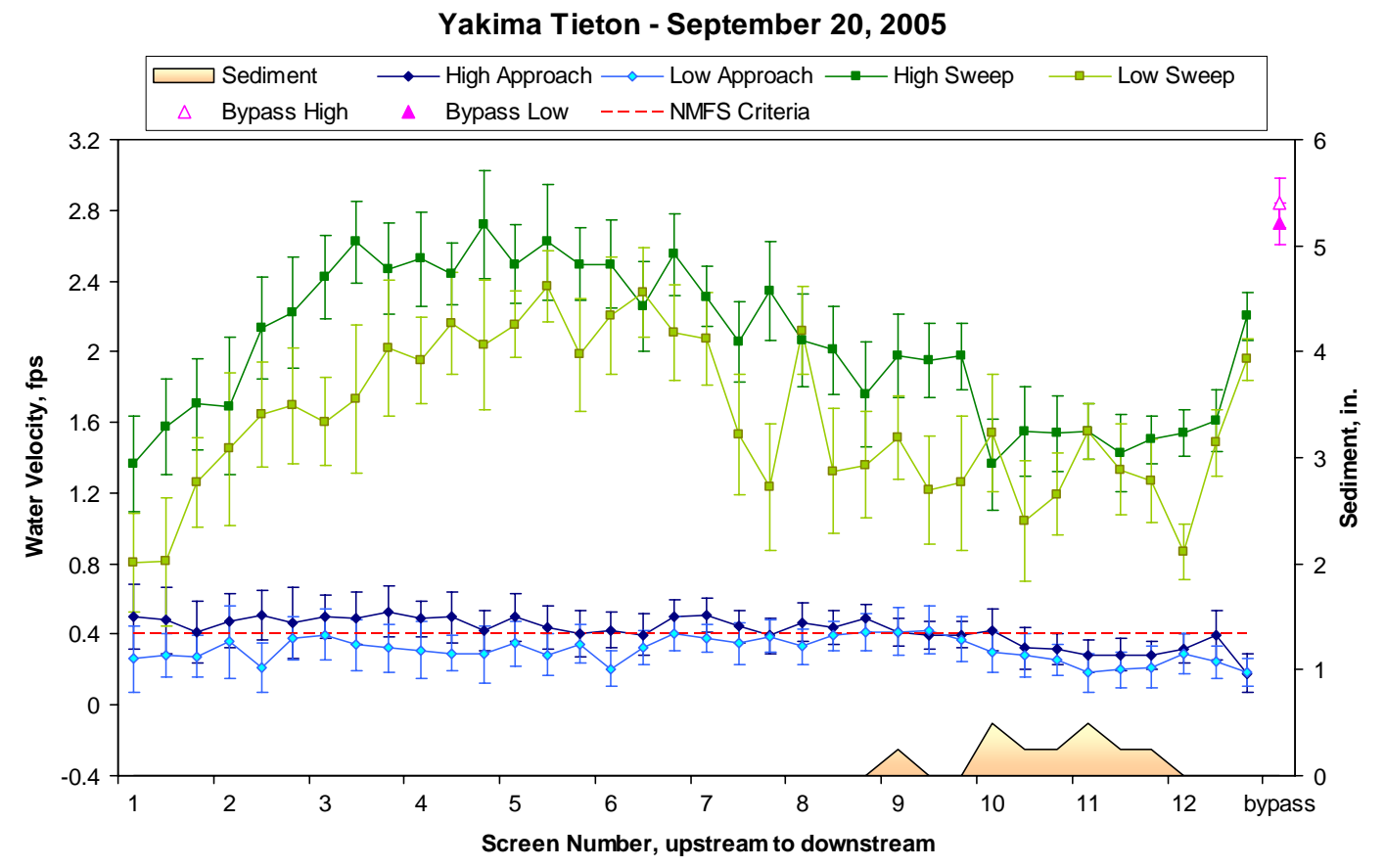

Figure 73. Yakima-Tieton water velocities and sediment accumulation, September 2005. Error bars represent turbulence. 


\section{Younger}

Inspections of the Younger fish screen site occurred on May 12, June 29, July 14, and September 14, 2005. Velocity measurements were conducted in May, June, and July. The site was essentially shut down for the season in September, and no velocity measurements were made. Sweep velocities always were greater than approach velocities, but sweep did not increase toward the bypass (Figures 74, 75, and 76). Approach velocities met the NMFS criterion $100 \%$ of the time in May and July. In June, however, approach velocities met the criterion only $17 \%$ of the time. We notified WDFW staff on June 30, and they added some checkboards to the forebay to increase submergence. We reevaluated the site on July 14 and found approach velocities greatly improved (Figure 76).

This site has three sets of checkboards in the forebay to provide submergence. At times, one set of checkboards has fewer boards, creating a notch for bypass flow. At other times, all three sets are equal in height, and there is marginal bypass flow over the tops of the boards. In June and July, we tried measuring bypass flow by placing the probe in the notch in the checkboards; these velocities are shown on the plots (Figures 75 and 76).

Screen condition was good during all surveys. Caulk is missing around the edges of the screens in several places, but the screens fit snugly to the cement, so the missing caulk probably poses no problem to fish. The brushes seem to keep the screen clear of debris, although sticks and balls of vegetation tend to get pushed back and forth between the brushes.

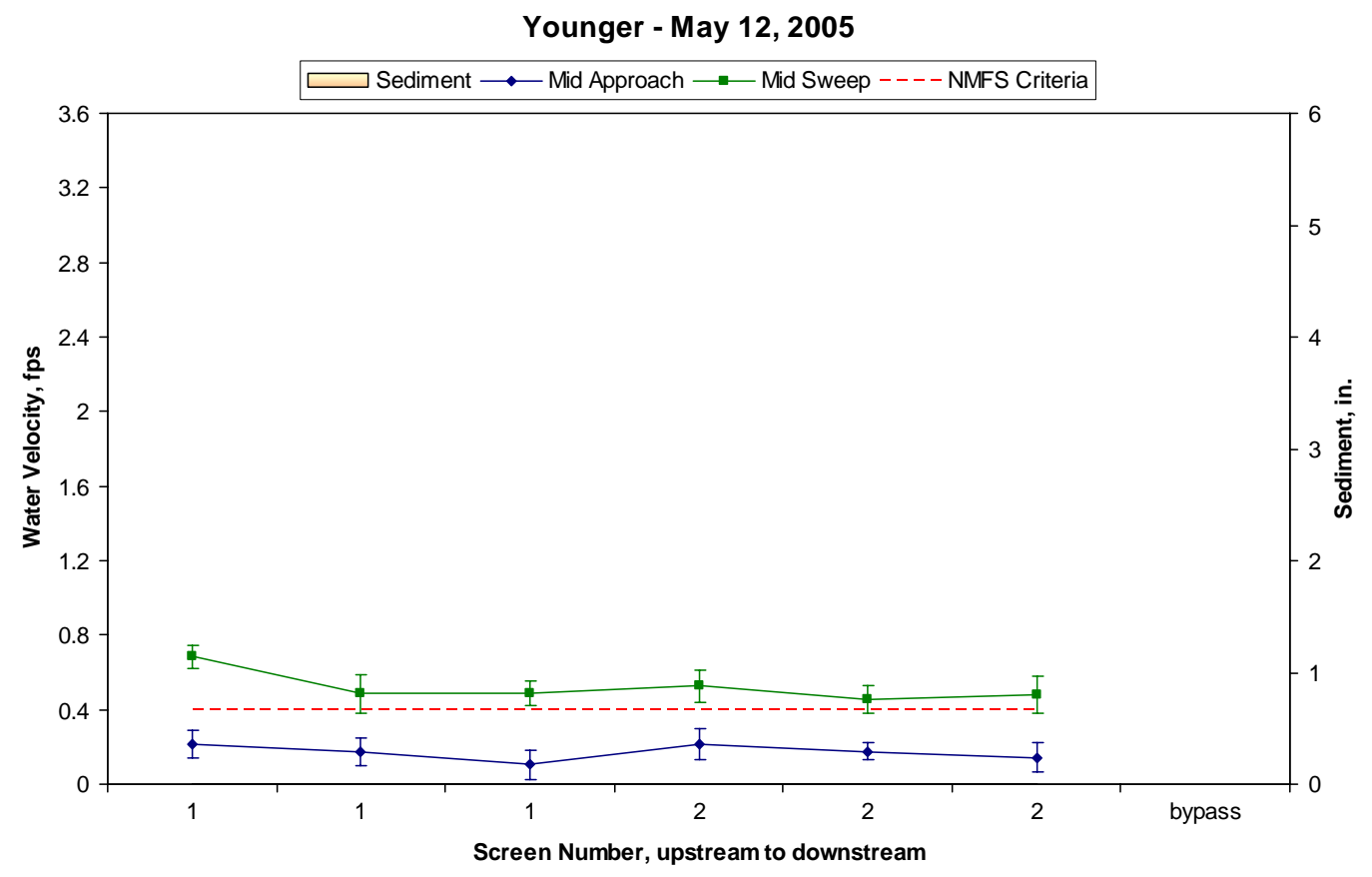

Figure 74. Younger water velocities and sediment accumulation, May 2005. Error bars represent turbulence. 
Younger - June 29, 2005

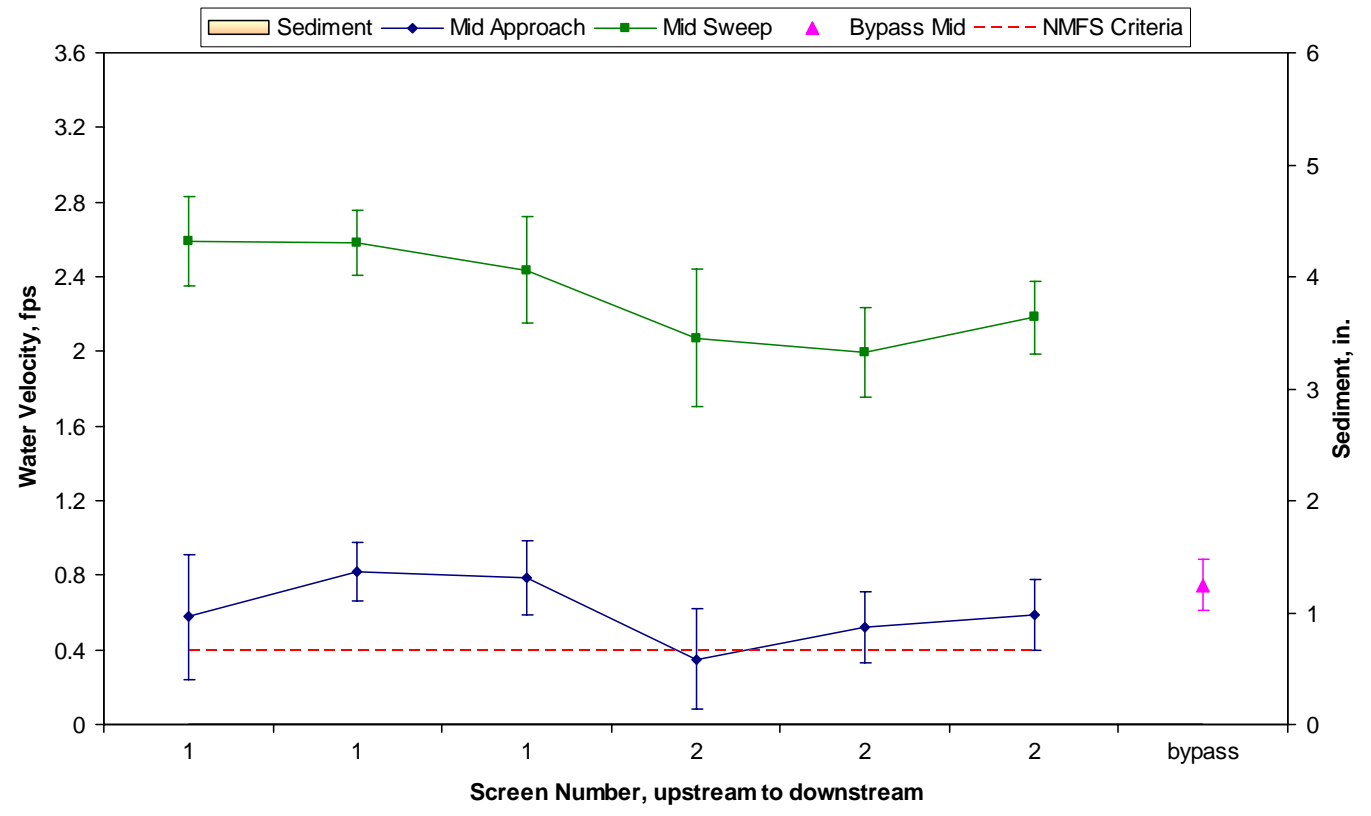

Figure 75. Younger water velocities and sediment accumulation, June 2005. Error bars represent turbulence.

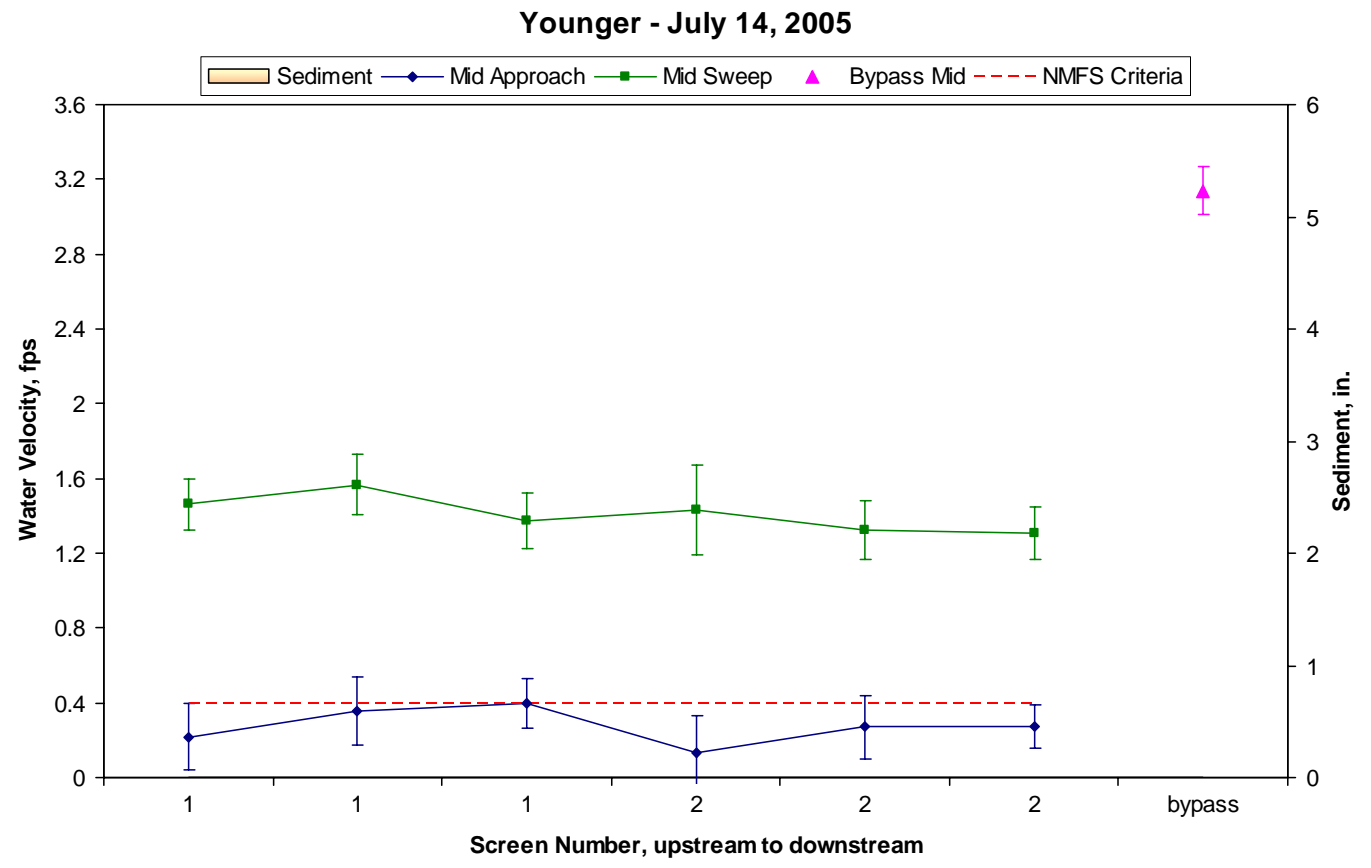

Figure 76. Younger water velocities and sediment accumulation, July 2005. Error bars represent turbulence. 


\subsection{Vertical Traveling Screen}

We evaluate only one Phase II site that has vertical traveling screens. This site is described in this section.

\section{Gleed}

The Gleed site was evaluated on May 25, June 30, and September 29, 2005. The metal plates used to protect the screens from debris were in place from the bottom of the forebay floor to the surface during our May and June inspections; their locations are shown on Figures 77 and 78. This typically causes wide variations in the strength and direction of both the sweep and approach velocities, and this year was no exception. Approach values exceeded the NMFS criterion in both May and June, with $25 \%$ and $50 \%$ of the approach values above $0.4 \mathrm{fps}$ and a maximum of $1.6 \mathrm{fps}$ in June at one point. There was also a strong back eddy in the downstream end of the site in June. We notified the WDFW of the high approach values in May and again in June. Also in June, we suggested the metal plates be raised above water, because debris is usually less of a problem later in the spring. When we reevaluated the site in July, overall flow was much more smooth, and overall approach velocities were much lower, although 38\% still exceeded the NMFS criterion (Figure 79). We would strongly suggest raising the metal plates out of the water as soon as the heaviest debris movement is over for the year. This would help reduce the extreme turbulence and approach velocity spikes that occur as water squirts between the plates straight at the screens, even though it may not reduce overall approach velocities enough to meet the criterion.

Average sweep was greater than average approach velocities in May and September (Figures 77 and 80). In June, the average of the sweep velocities showed upstream flow, while in July sweep and approach were nearly equal. Sweep generally did not increase toward the bypass except in September.

Screens 1 and 3 were starting to show gaps in vertical sections within each of the screens. These gaps may be up to $1 / 8$ in. wide, exceeding the NMFS criterion of 3/32 in. as the maximum opening. The panels comprising the screens may simply need to be tightened back together. Seals were generally in good condition. A stick apparently became wedged between the seal and mesh, separating the seal from the metal frame (Figure 81). We notified Ray Gilmour about this on October 3, and they were going to take care of it. We did not go back out to re-evaluate the site. The logbook indicated problems getting that screen to seat properly against the seal, and this may be the cause. 
Gleed - May 25, 2005

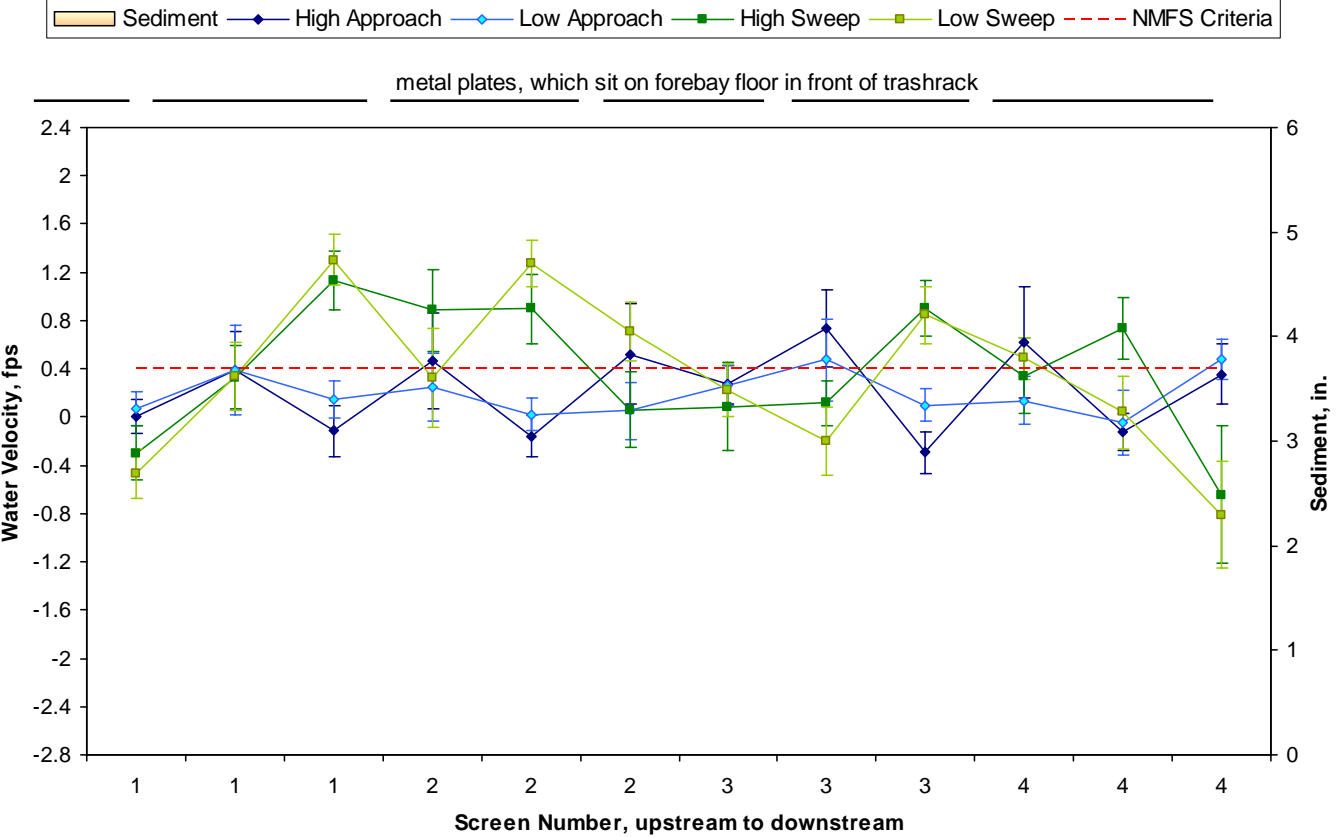

Figure 77. Gleed water velocities and sediment accumulation, May 2005. Error bars represent turbulence.

Gleed - June 30, 2005

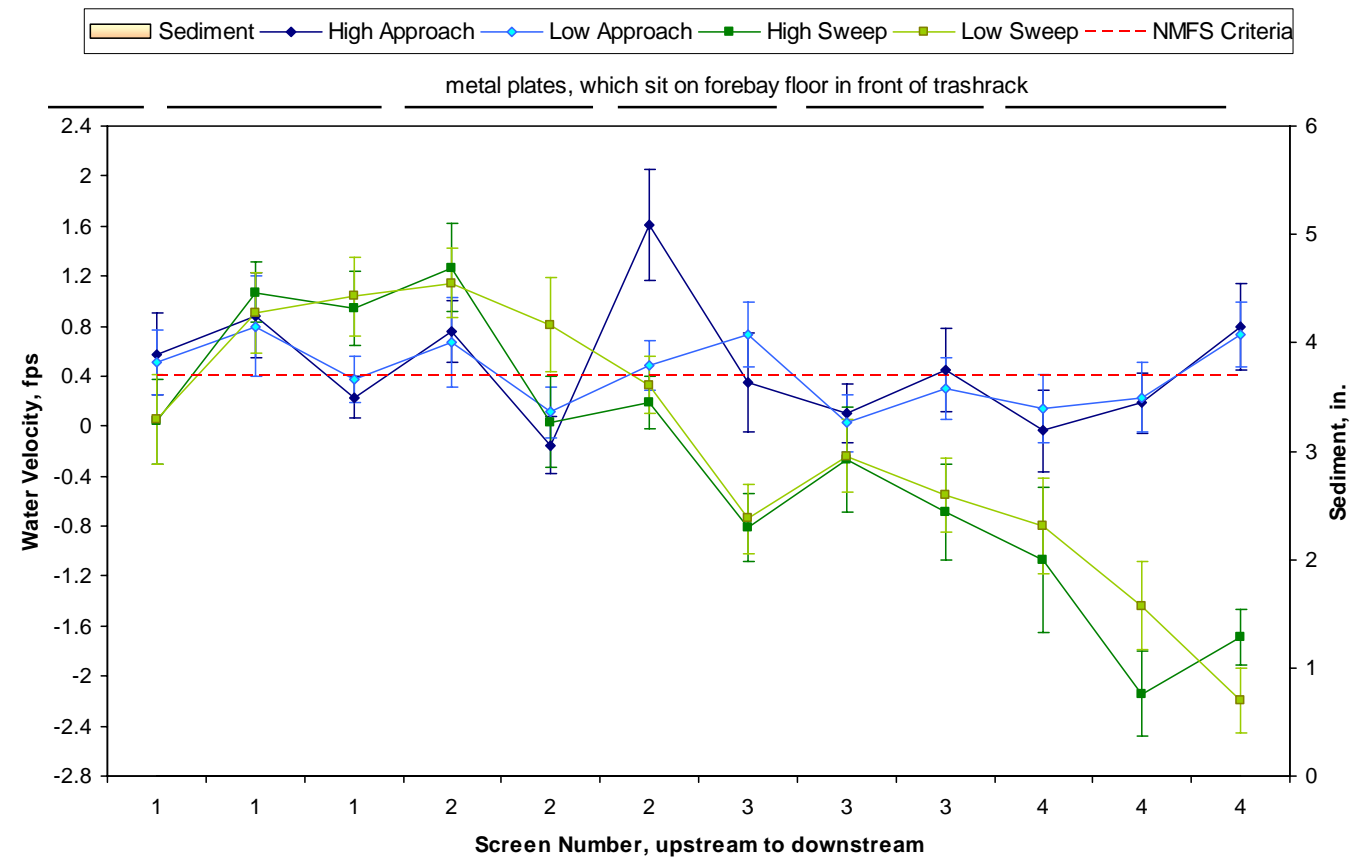

Figure 78. Gleed water velocities and sediment accumulation, June 2005. Error bars represent turbulence. 
Gleed - July 14, 2005

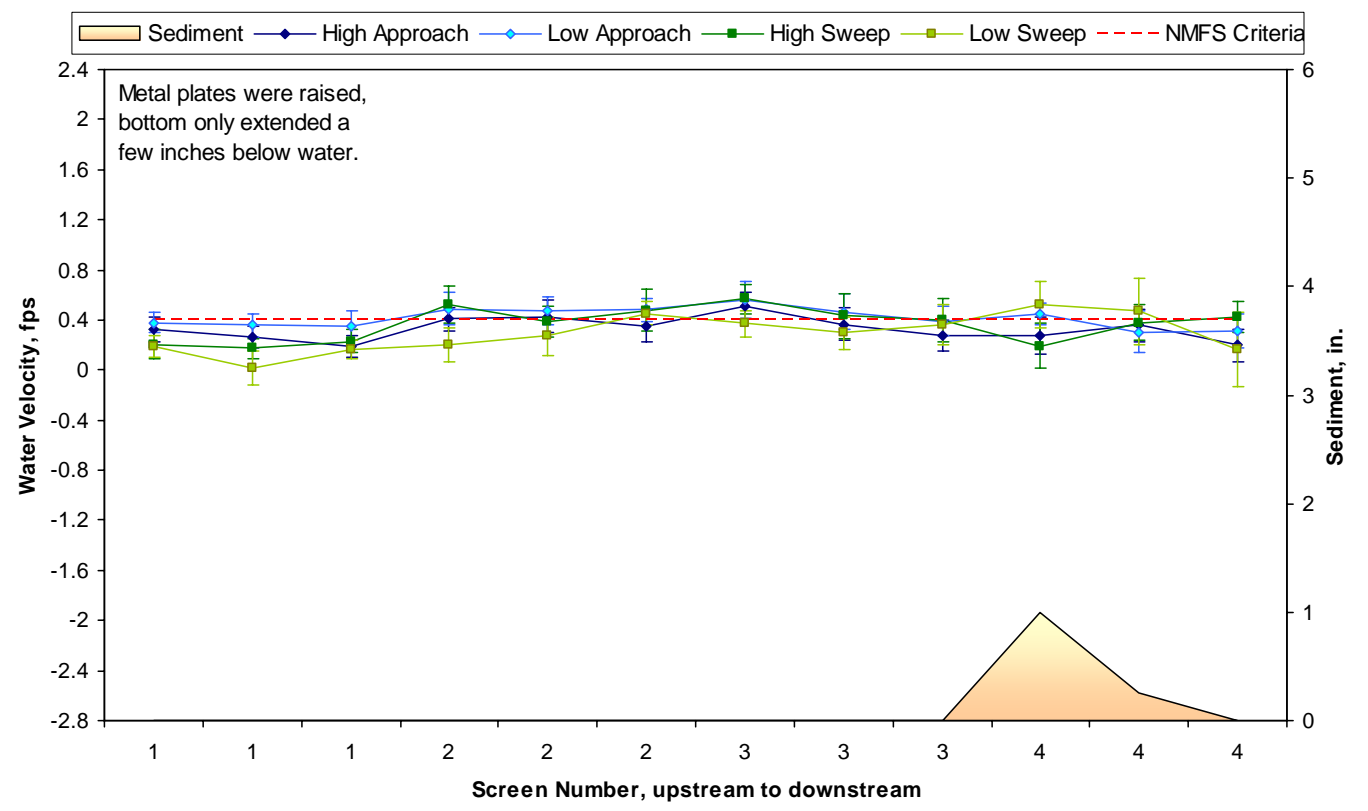

Figure 79. Gleed water velocities and sediment accumulation, July 2005. Error bars represent turbulence.

Gleed - September 29, 2005

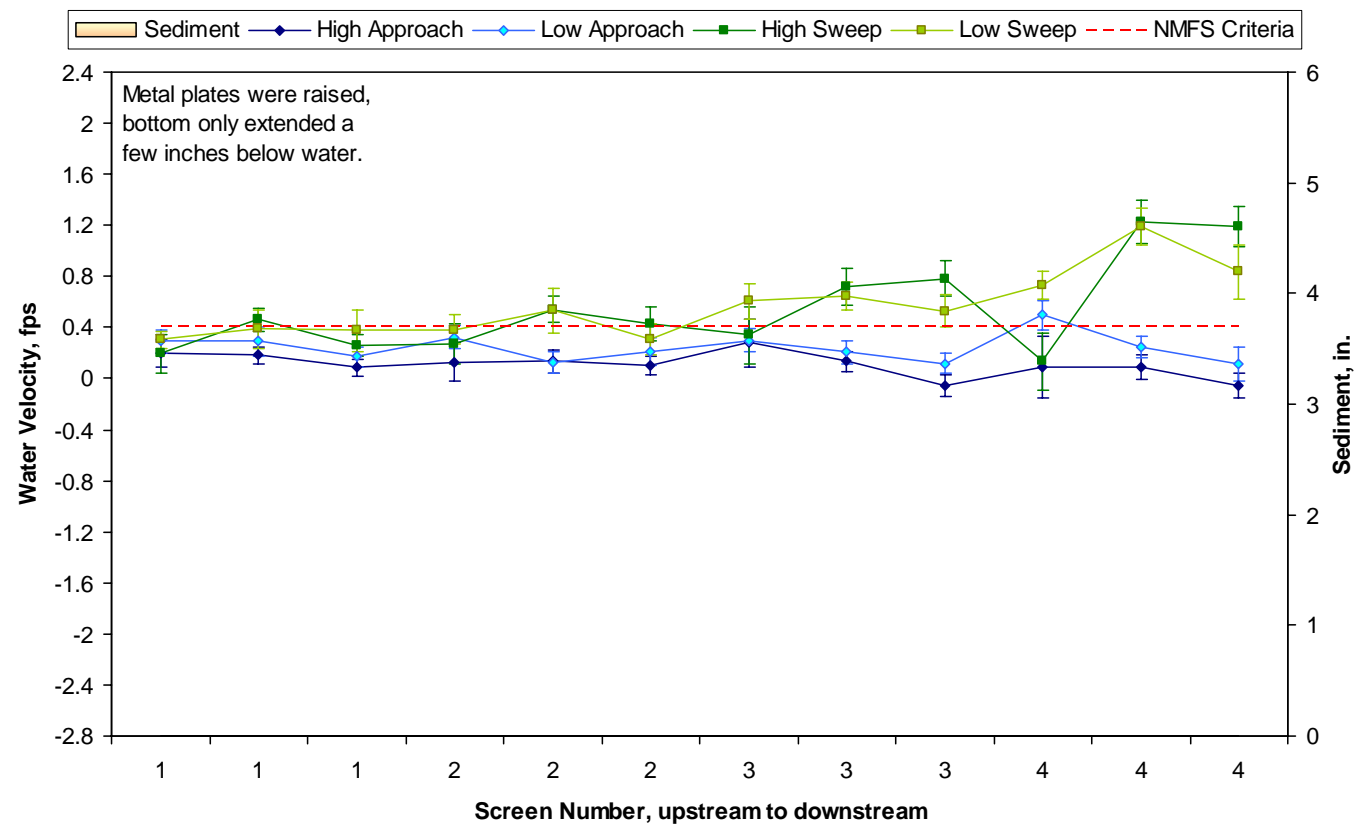

Figure 80. Gleed water velocities and sediment accumulation, September 2005. Error bars represent turbulence. 


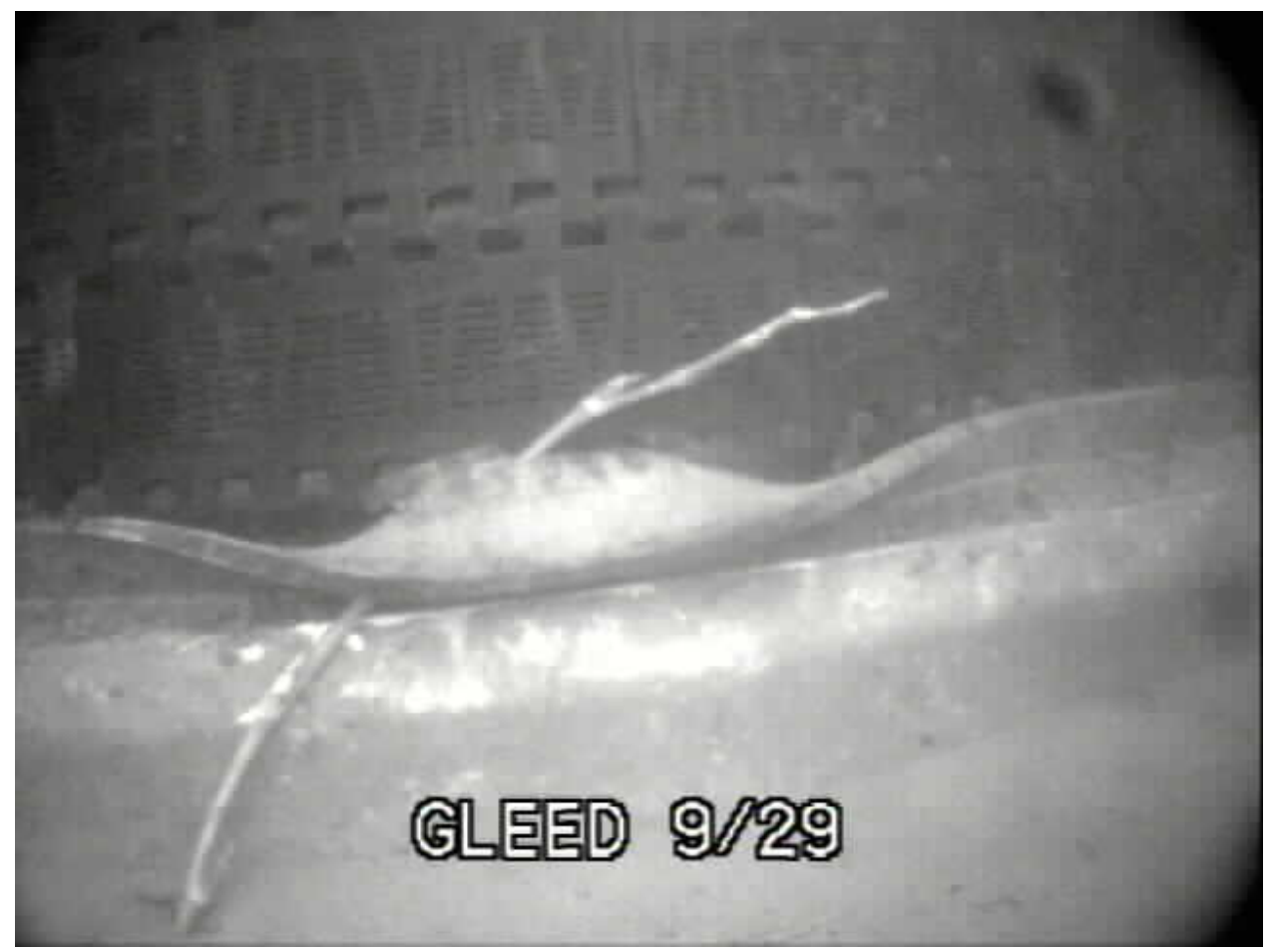

Figure 81. Stick twisted through a bottom seal at Gleed 


\subsection{Conclusions and Recommendations}

The 2005 evaluation of 25 Phase II fish screen facilities in the Yakima and Touchet River basins by PNNL indicates that the facilities are generally designed, constructed, operated, and maintained to provide fish a safe and efficient return to the river. In 2005, 75\% of all inspections showed sweep velocities less than bypass velocities, and in 95\% of the inspections, sweep was greater than approach velocities. Both of these conditions help move fish through the facility with minimal delays. Ten sites had $10 \%$ or more of their approach velocities greater than $0.4 \mathrm{fps}$ at least once during 2005, and more than half of these were flat-plate screen sites. The high approach velocities probably reflect the low water year and the irrigators' desire for a higher proportion of the water available. Flat-plate screen facilities are often placed at diversions with higher canal flows, which probably accounts for their higher proportion of exceedance. Anticipating low water availability, the Lower WIP site was not operated at all in 2005.

Low submergence was noted at five sites during 2005, up slightly from 2004 (Vucelick et al. 2005). Low submergence and little or no bypass flow at Fruitvale and Taylor were caused by shifts in the main river channel away from these sites. Alternatives to a fish screen facility should be considered for Taylor. It was not functioning within NMFS criteria during most of the year, although great effort was made to get enough water to the site.

Submergence problems could have been prevented at Huntsville Mill and Powell-LaFortune by more frequent debris removal at the trash racks. At the latter site, the irrigator is responsible for this but frequently allows up to $1 \mathrm{ft}$ of head loss across the trash rack, which decreases flow to the point that there is inadequate bypass flow. At Kelley-Lowry, the irrigator is responsible for removing sediment accumulating in the forebay. The mound had reached a height of several feet by the end of the season, impacting flow through the site and covering the bottom seals of the screens. Better ways need to be found to encourage irrigators to meet their commitments to maintain the sites to protect fish as well as provide irrigation water.

Screens and seals generally were well-maintained, preventing fish entrainment and injury. A couple of flat plate screens had missing caulking (i.e., Yakima-Tieton and Packwood), and a couple of the drum screens had developed slight bulges in the side seals (i.e., Lindsey, Upper WIP). These situations could entrain or injure salmonid fry if they continue into 2006. Drums turned smoothly at most sites, and brushes at flat plate screens were effective in removing large debris. Operations and maintenance personnel with the WDFW and USBR typically checked sites every 1 to 2 weeks, keeping equipment running smoothly and cleaning those facilities that are their respective responsibility. This schedule seems adequate for most sites, but sites with a history of problems should be visited more frequently. An example is Powell-LaFortune, where blockage of the upstream trash rack can result in rapid and dramatic fluctuations at the screening facility, and the ditch riders may not visit the site frequently.

The problem-tracking protocol has assisted in this process by documenting O\&M personnel accountability for proper operations and maintenance. Several sites have had consistent problems with high approach velocities. Pacific Northwest National Laboratory will take a more active part in 2006 by helping the WDFW and USBR identify possible causes for high approach velocities at several sites, including Congdon, Naches-Selah, Union Gap, and Yakima-Tieton, by reviewing the design flow criteria for each facility and its operating procedures. We will work with WDFW and USBR O\&M personnel to 
immediately monitor the effects of changing louvers at flat-plate screens and repositioning porosity boards at drum screen sites, and evaluate changes in weir settings until we can find the best settings and operating procedures to keep approach velocities at or below $0.4 \mathrm{fps}$. This process also will identify any circumstances that prevent the site from meeting NMFS criteria.

Gleed continues to have excessive approach velocities, although raising the protective metal plates helped moderate the extreme fluctuations in sweep and approach and may have helped reduce the large back eddy at the downstream end of the site. This site needs to be modified to bring it within NFMS criteria.

We recommend each site's logbox have a table showing the design bypass flow and the corresponding depths and settings to maintain good approach and sweep velocities while allowing adequate diversion to the canal. This is already available at some sites.

For the past 8 years, PNNL has evaluated Phase II sites and has provided feedback to the O\&M agencies and to BPA on the effectiveness of the O\&M activities at the screen facilities to provide safe passage to juvenile salmonids. There has been a progressive improvement in the maintenance and effectiveness of fish screen facilities in the Yakima and Touchet River basins during the past several years, partly as a result of the regular screen evaluations and the rapid feedback of information necessary to improve operations and design of these important fish protection devices. Continued periodic screen evaluations will increase the effectiveness of screen O\&M practices by confirming the effectiveness (or ineffectiveness) of screen operating procedures at individual sites. 


\subsection{References}

Abernethy C.S., D.A. Neitzel, and W.V. Mavros. 1996. Movement and Injury Rates for Three Life Stages of Spring Chinook Salmon Oncorhynchus tshawytscha: A Comparison of Submerged Orifices and an Overflow Weir for Fish Bypass in a Modular Rotary Drum Fish Screen. DOE/BP-62611-5, prepared by Pacific Northwest National Laboratory for the Division of Fish and Wildlife, Bonneville Power Administration, Portland, Oregon.

Abernethy C.S., D.A. Neitzel, and E.W. Lusty. 1990. Velocity Measurements at Three Fish Screen Facilities in the Yakima River Basin, Washington, Summer 1989. DOE/BP-01830-10, prepared by Pacific Northwest Laboratory for the Division of Fish and Wildlife, Bonneville Power Administration, Portland, Oregon.

Abernethy C.S., D.A. Neitzel, and E.W. Lusty. 1989. Velocity Measurements at Six Screening Facilities in the Yakima River Basin, Summer 1988. DOE/BP-01830-4, prepared by Pacific Northwest Laboratory for the Division of Fish and Wildlife, Bonneville Power Administration, Portland, Oregon.

Blanton S.L., G.A. McMichael, and D.A. Neitzel. 2000. Washington Phase II Fish Diversion Screen Evaluations in the Yakima River Basin, 1999. DOE/BP-00000652-4, prepared by Pacific Northwest National Laboratory for the Division of Fish and Wildlife, Bonneville Power Administration, Portland, Oregon.

Blanton S.L., G.A. McMichael, and D.A. Neitzel. 1999. Washington Phase II Fish Diversion Screen Evaluations in the Yakima River Basin, 1998. DOE/BP-62611-15, prepared by Pacific Northwest National Laboratory for the Division of Fish and Wildlife, Bonneville Power Administration, Portland, Oregon.

Blanton S.L., D.A. Neitzel, and C.S. Abernethy. 1998. Washington Phase II Fish Diversion Screen Evaluations in the Yakima River Basin, 1997. DOE/BP-00029-5, prepared by Pacific Northwest National Laboratory for the Division of Fish and Wildlife, Bonneville Power Administration, Portland, Oregon.

Carter J.A., G.A. McMichael, and M.A. Chamness. 2002. Yakima River Basin Phase II Fish Screen Evaluations, 2001. DOE/BP-00000652-8, prepared by Pacific Northwest National Laboratory for the Division of Fish and Wildlife, Bonneville Power Administration, Portland, Oregon.

Carter J.A., G.A. McMichael, and M.A. Chamness. 2003. Yakima River Basin Phase II Fish Screen Evaluations, 2001. DOE/BP-00000652-11, prepared by Pacific Northwest National Laboratory for the Division of Fish and Wildlife, Bonneville Power Administration, Portland, Oregon.

Chamness M.A., E.V. Arntzen, G.A. McMichael, and P.S. Titzler. 2001. Washington Phase II Fish Diversion Screen Evaluations in the Yakima River Basin, 2000. DOE/BP-00000652-3, prepared by Pacific Northwest National Laboratory for the Division of Fish and Wildlife, Bonneville Power Administration, Portland, Oregon. 
McMichael G.A., J.A. Vucelick, C.S. Abernethy, and D.A. Neitzel. 2004. "Comparing Fish Screen Performance to Physical Design Criteria.” Fisheries 29(7):10-16.

National Marine Fisheries Service (NMFS). 1995. Juvenile Fish Screen Criteria. National Marine Fisheries Service Environmental \& Technical Services Division, Portland, Oregon.

Neitzel D.A., S.L. Blanton, C.S. Abernethy, and D.S. Daly. 1997. Movement of Fall Chinook Salmon Fry Oncorhynchus tshawytscha: A Comparison of Approach Angles for Fish Bypass in a Modular Rotary Drum Fish Screen. DOE/BP-62611-10, prepared by the Pacific Northwest National Laboratory for the Environment, Fish and Wildlife Division, Bonneville Power Administration, Portland, Oregon.

Neitzel D.A., C.S. Abernethy, and E.W. Lusty. 1990a. A Fisheries Evaluation of the Wapato, Sunnyside, and Toppenish Creek Fish Screening Facilities, Spring 1988. DOE/BP-01830-6A, prepared by the Pacific Northwest Laboratory for the Division of Fish and Wildlife, Bonneville Power Administration, Portland, Oregon.

Neitzel D.A., C.S. Abernethy, and E.W. Lusty. 1990b. A Fisheries Evaluation of the Westside Ditch and Wapato Canal Fish Screening Facilities, Spring 1989. DOE/BP-01830-8, prepared by the Pacific Northwest Laboratory for the Division of Fish and Wildlife, Bonneville Power Administration, Portland, Oregon.

Neitzel D.A., C.S. Abernethy, E.W. Lusty, and S.J. Wampler. 1988. A Fisheries Evaluation of the Richland and Wapato Canal Fish Screening Facilities, Spring 1987. DOE/BP-01830-3, prepared by the Pacific Northwest Laboratory for the Division of Fish and Wildlife, Bonneville Power Administration, Portland, Oregon.

Neitzel D.A., C.S. Abernethy, and E.W. Lusty. 1986. A Fisheries Evaluation of the Richland and Toppenish/Satus Fish Screening Facilities, Spring 1986. DOE/BP-01830-2, prepared by the Pacific Northwest Laboratory for the Division of Fish and Wildlife, Bonneville Power Administration, Portland, Oregon.

Neitzel D.A., C.S. Abernethy, E.W. Lusty, and L.A. Prohammer. 1985. A Fisheries Evaluation of the Sunnyside Canal Fish Screening Facility, Spring 1985. DOE/BP-01830-1, prepared by the Pacific Northwest Laboratory for the Division of Fish and Wildlife, Bonneville Power Administration, Portland, Oregon.

Northwest Power Planning Council (NPPC). 1984. Fish and Wildlife Program: Measure 704(d). Northwest Power Planning Council, Portland, Oregon.

Northwest Power Planning Council (NPPC). 1987. Fish and Wildlife Program: 1403.4. Northwest Power Planning Council, Portland, Oregon.

Northwest Power Planning Council (NPPC). 1994. Fish and Wildlife Program: Measure 7.10. Northwest Power Planning Council, Portland, Oregon.

Northwest Power Planning Council (NPPC). 2000. Fish and Wildlife Program. Northwest Power Planning Council, Portland, Oregon. 
Vucelick J.A., G.A. McMichael, and M.A. Chamness. 2004. Yakima River Basin Phase II Fish Screen Evaluations, 2003. DOE/BP-00000652-16, prepared by the Pacific Northwest National Laboratory for the Division of Fish and Wildlife, Bonneville Power Administration, Portland, Oregon.

Vucelick J.A., G.A. McMichael, and M.A. Chamness. 2005. Yakima River Basin Phase II Fish Screen Evaluations, 2004. Prepared by the Pacific Northwest National Laboratory for the Division of Fish and Wildlife, Bonneville Power Administration, Portland, Oregon. 